\title{
Organophosphorus-Tellurium Chemistry: From Fundamentals to Applications
}

\author{
Andreas Nordheider, ${ }^{a}$ J. Derek Woollins ${ }^{a}$ and Tristram Chivers ${ }^{b} *$ \\ a. EaStCHEM School of Chemistry, University of St Andrews, St Andrews, Fife, KY16 9ST, \\ UK \\ b. Department of Chemistry, University of Calgary, Calgary, AB, Canada T2N 1N4
}

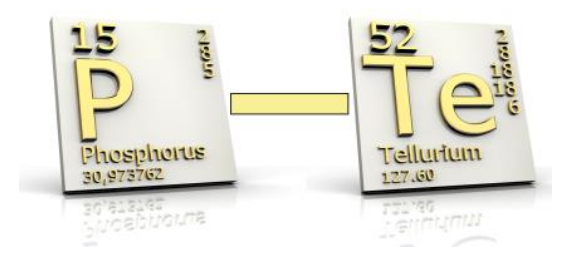

\section{CONTENTS}

1. Introduction

2. Fundamental Considerations

3. Binary Phosphorus-Tellurium Species

4. Phosphine Complexes of Tellurium Cations

5. Organophosphorus(III)-Tellurium Compounds

5.1 Acyclic Organophosphorus(III)-Tellurium Compounds

5.1.1 With P-Te-C Linkages

5.1.2 With P-Te-P Linkages

5.2 Organophosphorus(III)-Tellurium Heterocycles

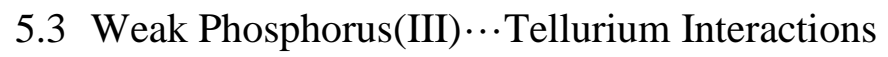

6. Organophosphorus(V) Tellurides

6.1 Synthesis and Spectroscopic Characterization

6.2 NMR Spectra and Phosphorus-Tellurium Exchange

6.3 X-Ray Structures

6.4 Bonding and Electronic Structure

6.5 Reaction with Electrophiles and Redox Behavior

6.6 Coordination Complexes

6.7 Applications as Tellurium-Transfer Reagents

$7 \quad$ Anionic Phosphorus-Tellurium Ligands

7.1 Tellurophosphates

7.2 Tellurophosphinites and Ditellurophosphinates

7.3 Telluroimidophosphinites, Tellurobisimidophosphinates. Mono- and Ditelluroimidodiphosphinates

7.3.1 Alkali-Metal Derivatives 


\subsubsection{Redox Chemistry}

7.3.3 p-Block, d-Block and f-Block Metal Complexes

7.4 PCP-Bridged Tellurium-Centered Anions

7.5 A Carbon-Bridged P-Te-Al Heterocycle

7.6 Tellurium-Centered Anions Supported by a $\mathrm{P}_{2} \mathrm{~N}_{2}$ Ring

7.6.1 Alkali-Metal Derivatives

7.6.2 Redox Chemistry

7.6.3 p-Block Metal Complexes

8 Single-Source Precursors for Metal Telluride Thin Films

9 Conclusions and Prospects

10 Acknowledgments

11 Addendum

Author Information

Corresponding Author

Notes

Biographies

Abbreviations

Dedication

References 


\section{INTRODUCTION}

Compounds incorporating phosphorus-chalcogen $(\mathrm{P}-\mathrm{E} ; \mathrm{E}=\mathrm{S}, \mathrm{Se})$ bonds are versatile reagents in both organic and inorganic synthesis. The best known example Lawesson's reagent [(4$\left.\left.\mathrm{MeOC}_{6} \mathrm{H}_{4}\right) \mathrm{P}=\mathrm{S}(\mu-\mathrm{S})\right]_{2}$ is widely used in organic chemistry, e.g. for the conversion of $\mathrm{C}=\mathrm{O}$ to $\mathrm{C}=\mathrm{S}$ groups. ${ }^{1-4}$ More recently a selenium analog $[\mathrm{PhP}=\mathrm{Se}(\mu-\mathrm{Se})]_{2}$, known as Woollins' reagent, has been shown to have wide applications in a variety of transformations. ${ }^{5,6}$ In addition, organophosphoruschalcogen compounds are used as pesticides or nerve agents, as precursors for metal chalcogenide thin films or nanoparticles, in metal extraction processes and as lubricant additives. The chemistry of phosphorus-chalcogen compounds has been covered comprehensively in a recent book chapter that deals primarily with sulfur and selenium-containing systems. ${ }^{8}$

The behavior of organophosphorus-tellurium compounds is markedly different from that of the lighter chalcogen analogs, primarily as a result of the relative weakness of the P-Te bond. However, this characteristic can be employed advantageously in a variety of important transformations (vide infra). The first organophosphorus-tellurium derivative was described in 1950 by Foss, who observed that the treatment of potassium diethylphosphite with finely divided tellurium in warm ethanol produced the corresponding tellurophosphate $\mathrm{K}\left[(\mathrm{EtO}){ }_{2} \mathrm{P}(\mathrm{Te}) \mathrm{O}\right]$ as colorless, hygroscopic crystals that darkened rapidly in moist air. ${ }^{9}$ This area of phosphoruschalcogen chemistry was stimulated by the discovery of the first tertiary phosphine telluride ${ }^{\mathrm{n}} \mathrm{Bu}_{3} \mathrm{PTe}$ in the early 1960 s by Zingaro (Section 6.1 ). ${ }^{10,11}$ Over the past 50 years this class of organophosphorus(V)-tellurium compound has attracted increasing attention, most notably as a source of reactive $\mathrm{Te}^{0}$ in the generation of semiconducting metal tellurides in the form of nanomaterials or quantum dots for applications as optoelectronic or thermoelectric materials and as infrared detectors or biomarkers (Section 6.7). Although neutral binary $\mathrm{P}-\mathrm{Te}$ compounds are unknown, the recent characterization of the anion $\mathrm{P}_{4} \mathrm{Te}_{2}{ }^{2-}$ in solution ${ }^{12}$ and, earlier, in a solid-state material $^{13}$ may presage an extensive series of $\mathrm{P}-\mathrm{Te}$ anions (Section 3 ). The challenge of 
characterizing organophosphorus(III)-tellurium heterocycles in the solid state has recently been surmounted by using bulky substituents on phosphorus thus providing the opportunity to compare the ligand properties of organophosphorus-tellurium rings with the established behavior of their acyclic and lighter chalcogen analogs (Section 5.2). ${ }^{14}$

The driving force for much of the current interest in $\mathrm{P}-\mathrm{Te}$ compounds is provided by the applications of a wide variety of metal tellurides as semi-conducting thin films or nanoparticles in solar cells, thermoelectric devices and IR detectors. Consequently, considerable attention is focused on the design of molecular precursors that will produce metal tellurides of high purity in the form of thin films or quantum dots. In this connection the weakness of the P-Te bond is an advantage and anionic ligands such as telluroimidophosphinates $\left[\mathrm{R}_{2} \mathrm{P}(\mathrm{Te}) \mathrm{NR}^{\prime}\right]^{-}$and ditelluroimidodiphosphinates $\left[\mathrm{N}\left(\mathrm{PR}_{2} \mathrm{Te}\right)_{2}\right]^{-}$have proved to be suitable for these applications (Sections 7.3 and 8$) .{ }^{15,16}$ Other areas of current interest include the stabilization of electrophilic tellurium cations, e.g. $\mathrm{Te}^{2+}$ and $\mathrm{ArTe}^{+}$, by

phosphine donors (Section 4$)^{17}$ and weak $\mathrm{P}^{\mathrm{III}} \ldots$ Te interactions (Section 5.3). ${ }^{18,19}$ The goal of this review is to provide a comprehensive account of organophosphorus-tellurium chemistry, including the historical development. It begins with a brief account of the strategies involved in investigations of phosphorus-tellurium chemistry. Subsequently, the discussion of each sub-topic will progress from a consideration of the rudiments for each class of phosphorus-tellurium compounds to a more advanced discourse culminating, where appropriate, in examples of applications, e.g. in organic chemistry and materials science. Comparisons will be made with the chemistry of the lighter chalcogen ( $\mathrm{S}$ and $\mathrm{Se}$ ) analogs, notably by using examples for which organophosphorus-tellurium compounds exhibit unique behavior. The literature is covered up to mid-2015.

\section{FUNDAMENTAL CONSIDERATIONS}

The synthesis of organophosphorus-tellurium compounds presents a number of challenges owing primarily to therelatively low thermal and photochemical stability of many derivatives. 
Consequently, the preparation of compounds incorporating P-Te bonds should usually be carried out at low temperatures and, in certain cases, with protection from light. According to DFT calculations for the phosphine chalcogenides $\mathrm{Me}_{3} \mathrm{PE}$, this lability can be attributed, in part, to the marked decrease in the phosphorus-chalcogen bond energies down the series $\mathrm{P}-\mathrm{S}(337)>\mathrm{P}-\mathrm{Se}$ (266) > P-Te (184) (in $\mathrm{kJ} \mathrm{mol}^{-1}$ ); however, multiple bonding becomes more important than the single bond for the heavier chalcogens. ${ }^{20} \mathrm{~A}$ similar trend in $\mathrm{P}-\mathrm{E}$ bond strengths for ${ }^{\mathrm{n}} \mathrm{Bu} 3 \mathrm{PE}$ has been estimated on the basis of experimentally determined enthalpies of the reactions of ${ }^{n} \mathrm{Bu}_{3} \mathrm{P}$ with chalcogens: P-S (401) > P-Se (314) > P-Te (218) $\left(\right.$ in $\left.\mathrm{kJ} \mathrm{mol}^{-1}\right){ }^{21}$ According to Hoff et al., these data suggest that simple dissociation of ${ }^{n} \mathrm{Bu}_{3} \mathrm{PTe}$ to ${ }^{\mathrm{n}} \mathrm{Bu}_{3} \mathrm{P}$ and a Te atom should occur at a negligible rate and that the reactivity of ${ }^{\mathrm{n}} \mathrm{Bu}_{3} \mathrm{PTe}$ may result from an associative (intermolecular) process. ${ }^{21}$ For further discussion of the P-Te exchange process, see Section 6.2.

NMR spectroscopy is a powerful technique for monitoring the reactions of organophosphorus-tellurium compounds in solution. ${ }^{31} \mathrm{P}$ NMR $\operatorname{spectra}{ }^{31} \mathrm{P}(I=1 / 2,100 \%)$ are readily acquired and especially informative, e.g. in distinguishing between $\mathrm{P}^{\mathrm{III}}$ and $\mathrm{P}^{\mathrm{V}}$ centers on the basis of chemical shifts. In addition, the presence of the spin-active nuclei ${ }^{125} \mathrm{Te}(I=1 / 2 ; 7.0 \%)$ and ${ }^{123} \mathrm{Te}(0.9 \%, I=1 / 2)$ gives rise to satellites as a result of ${ }^{31} \mathrm{P}-{ }^{125} \mathrm{Te}$ and ${ }^{31} \mathrm{P}-{ }^{123} \mathrm{Te}$ coupling. The large variation of the one-bond spin-spin coupling constant ${ }^{1} J\left({ }^{31} \mathrm{P},{ }^{125} \mathrm{Te}\right)$, which falls within the range of ca. $100 \mathrm{~Hz}$ to $>2,100 \mathrm{~Hz}$, is primarily determined by the formal oxidation state of the phosphorus center (vide infra). ${ }^{125} \mathrm{Te}$ NMR spectra are more difficult to acquire, especially for poorly soluble compounds, but may provide a decisive indication of the environment of the tellurium centers based on the simple multiplet patterns resulting from coupling to one (doublet) or two (triplet) phosphorus centers. ${ }^{125}$ Te NMR chemical shifts of organophosphorus-tellurium compounds embrace a very wide range of values in the range of ca. $-1,000$ to $+1,000$ (for a more detailed discussion, see Sections 5 and 6, Tables 1, 2 and 3). In some compounds that incorporate multiple phosphorus sites, 
structural inferences can be made based on an analysis of the spin system for the most abundant isotopomers (see, for examples, Sections 3 and 5.2)

In addition to multinuclear NMR spectroscopic studies, much of the recent progress in organophosphorus-tellurium chemistry can be attributed to the acquisition of X-ray structures of thermally labile compounds. The sum of the covalent radii of phosphorus and tellurium is ca. 2.47 $\AA$ for a single bond and ca. $2.30 \AA$ for a hypothetical double bond; ${ }^{22-24}$ the sum of the van der Waals radii is estimated to be $3.86 \AA{ }^{26} 4.12 \AA^{26}$ or $4.40 \AA{ }^{27}$ A close inspection of the available data indicates that the correlation between the values of $d(\mathrm{P}-\mathrm{Te})$ and ${ }^{1} J\left({ }^{31} \mathrm{P},{ }^{125} \mathrm{Te}\right)$, if it exists, is limited to a narrow range of constitutionally and structurally similar compounds. The Fermi Contact (FC) term is only one of the three nucleus-electron interactions that contribute to the magnitude of the coupling constant between heavy nuclei.and all three depend on the gyromagnetic ratios. Consequently, the use of the reduced coupling constant, $\mathrm{K}_{\mathrm{PTe}}$, might be more appropriate. ${ }^{28}$ The gyromagnetic ratio $\gamma$ has a negative value for ${ }^{125} \mathrm{Te}$, so ${ }^{31} \mathrm{P}_{-}{ }^{125} \mathrm{Te}$ couplings are negative. In practice, however, with a few exceptions (Section 3), the parameter ${ }^{1} \mathrm{~J}\left({ }^{31} \mathrm{P},{ }^{125} \mathrm{Te}\right)$ is reported as an absolute value (magnitude only, without sign) in the literature and we have adopted that practice in this review. It is noted, however, that the frequently invoked correlation of trends in ${ }^{1} J\left({ }^{31} \mathrm{P},{ }^{125} \mathrm{Te}\right)$ values with changes in the $\mathrm{s}$ (or $\mathrm{p}$ ) character of the $\mathrm{P}-\mathrm{Te}$ hybrid orbital must be regarded as an oversimplification, since the FC interaction is only one of the factors that determine the magnitude of ${ }^{1} J\left({ }^{31} \mathrm{P},{ }^{125} \mathrm{Te}\right)$ in covalent organophosphorus-tellurium compounds. The elucidation of the relative contributions of these factors awaits a modern theoretical treatment (Section 5.3).

The two major classes of phosphorus-tellurium compounds based on the most common formal oxidation states of +3 or +5 are (a) acyclic and cyclic organophosphorus(III) compounds that incorporate a $\mathrm{P}-\mathrm{Te}$ single bond and (b) organophosphorus(V) tellurides with terminal $\mathrm{P}=\mathrm{Te}$ bonds (i.e. a formal double bond). The chemistry of these two categories is discussed in detail in Sections 5 and 6, respectively, but a consideration of their characteristic features is appropriate here. 
Organophosphorus(V) tellurides typically exhibit P-Te bond lengths in the range 2.35-2.40 , which are affiliated with large ${ }^{1} J\left({ }^{31} \mathrm{P},{ }^{125} \mathrm{Te}\right)$ coupling constants of $1650-2290 \mathrm{~Hz}$. The highest values $(>2000 \mathrm{~Hz})$ are observed for the amino-substituted phosphorus $(\mathrm{V})$ tellurides $\left(\mathrm{R}_{2} \mathrm{~N}\right)_{3} \mathrm{PTe}(\mathrm{e} \cdot \mathrm{g} . \mathrm{R}=$ Me, Et; $\mathrm{R}_{2} \mathrm{~N}=$ morpholino). ${ }^{29}$ However, these large $J$ values are not associated with a significant disparity in $\mathrm{P}-\mathrm{Te}$ bond lengths compared to those found for the alkyl analogues $\mathrm{R}$ PTe $\left(\mathrm{R}={ }^{\mathrm{i}} \mathrm{Pr},{ }^{\mathrm{n}} \mathrm{Bu}\right.$, ${ }^{\mathrm{t}} \mathrm{Bu}$ ) (Sections 6.2 and 6.3, Table 3). On the other hand, the dimer $\left[\mathrm{TeP}^{\mathrm{i}} \mathrm{Pr}_{2} \mathrm{~N}^{\mathrm{i}} \mathrm{Pr}_{2} \mathrm{PTe}-\right]_{2}(\mathbf{1})$, which incorporates two types of $\mathrm{P}^{\mathrm{V}}-\mathrm{Te}$ bonds (terminal and bridging), exhibits $\mathrm{P}-\mathrm{Te}$ distances that differ by ca. $0.1 \AA$ and divergent ${ }^{1} J\left({ }^{31} \mathrm{P},{ }^{125} \mathrm{Te}\right)$ values of 1500 and $1026 \mathrm{~Hz} .{ }^{30}$

The bond lengths in acyclic or cyclic systems that incorporate a $\mathrm{P}^{\mathrm{III}}-\mathrm{Te}$ bond are in the range 2.46-2.58 $\AA$ and they are associated with much smaller ${ }^{1} J\left({ }^{31} \mathrm{P},{ }^{125} \mathrm{Te}\right)$ values typically in the range $200-575 \mathrm{~Hz}$; however, there is no correlation between ${ }^{1} J\left({ }^{31} \mathrm{P},{ }^{125} \mathrm{Te}\right)$ and $d(\mathrm{P}-\mathrm{Te})$ for organophosphorus(III) compounds (Section 5.2, Table 1). The tricyclic compounds $\mathrm{RP}^{\mathrm{III}}\left[\mathrm{TeP}^{\mathrm{V}}\left(\mathrm{N}^{\mathrm{t}} \mathrm{Bu}\right)\left(\mu-\mathrm{N}^{\mathrm{t}} \mathrm{Bu}\right)\right]_{2}\left(2, \mathrm{R}=\mathrm{Ad},{ }^{\mathrm{t}} \mathrm{Bu}\right)$ provide unique examples of the influence of the formal oxidation state of phosphorus in the same molecule on ${ }^{1} J\left({ }^{31} \mathrm{P},{ }^{125} \mathrm{Te}\right)$ coupling constants. The values are 420 and $1073 \mathrm{~Hz}$ for the $\mathrm{P}^{\mathrm{III}}-\mathrm{Te}$ and $\mathrm{P}^{\mathrm{V}}-\mathrm{Te}$ linkages, respectively, despite the equality of the P-Te bond lengths (Section 5.2). ${ }^{14}$ As is observed for organophosphorus(V)-tellurium compounds, higher values of ${ }^{1} J\left({ }^{31} \mathrm{P},{ }^{125} \mathrm{Te}\right)(560-575 \mathrm{~Hz})$ are found for acyclic $\mathrm{P}^{\mathrm{III}}-\mathrm{Te}$ systems in which two amino substituents are attached to the phosphorus atom; this number is reduced to 400$420 \mathrm{~Hz}$ for organophosphorus(III)-tellurium rings with organyl substituents on phosphorus.

Smaller values of ${ }^{1} J\left({ }^{31} \mathrm{P},{ }^{125} \mathrm{Te}\right)$ in the range $100-400 \mathrm{~Hz}$ are exhibited by three-membered $(\mathrm{RP})_{2} \mathrm{Te}$ rings (telluradiphosphiranes) in which the formal oxidation state of phosphorus is +2 (Section 5.2). ${ }^{14,31-35}$ Similarly, the intriguing cage system $\mathrm{P}_{6} \mathrm{C}_{4}{ }^{\mathrm{t}} \mathrm{Bu}_{4} \mathrm{Te}(\mathbf{3})$, in which the oxidation state of the phosphorus atoms in the $\mathrm{P}-\mathrm{Te}-\mathrm{P}$ unit is lowered by the presence of $\mathrm{P}-\mathrm{P}$ bonds, exhibits a low ${ }^{1} J\left({ }^{31} \mathrm{P},{ }^{125} \mathrm{Te}\right)$ coupling of $358 \mathrm{~Hz}$ (Section 5.1.2). ${ }^{36}$ The 1,2,4-tellurodiphosphole 4 is an especially anomalous example; the ${ }^{1} J\left({ }^{31} \mathrm{P},{ }^{125} \mathrm{Te}\right)$ value of $1025 \mathrm{~Hz}$ is $>400 \mathrm{~Hz}$ larger than typical 
values for acyclic $\mathrm{P}^{\mathrm{III}}-\mathrm{Te}=\mathrm{C}$ compounds (Section 5.1.1). ${ }^{24}$. This fascinating heterocycle is formally a $6 \pi$-electron system suggesting that higher s character in the the P-Te hybrid orbital (the Fermi contact term) may contribute to this abnormality. ${ }^{37}$

From an NMR perspective the most interesting class of organophosphorus(III)-tellurium compounds incorporate $\mathrm{R}_{2} \mathrm{P}$ and $\mathrm{TeR}$ substituents in peri positions on an acenaphthene scaffold, e.g. 5. ${ }^{18}$ Such derivatives exhibit weak "through space" phosphorus-tellurium interactions $[(d(\mathrm{P}-\mathrm{Te})$ $=3.090-3.205 \AA]$ that are associated with remarkably large ${ }^{1} J\left({ }^{31} \mathrm{P},{ }^{125} \mathrm{Te}\right)$ values of $1306-1357 \mathrm{~Hz}$ attributed to three-center four-electron bonding (Section 5.3).

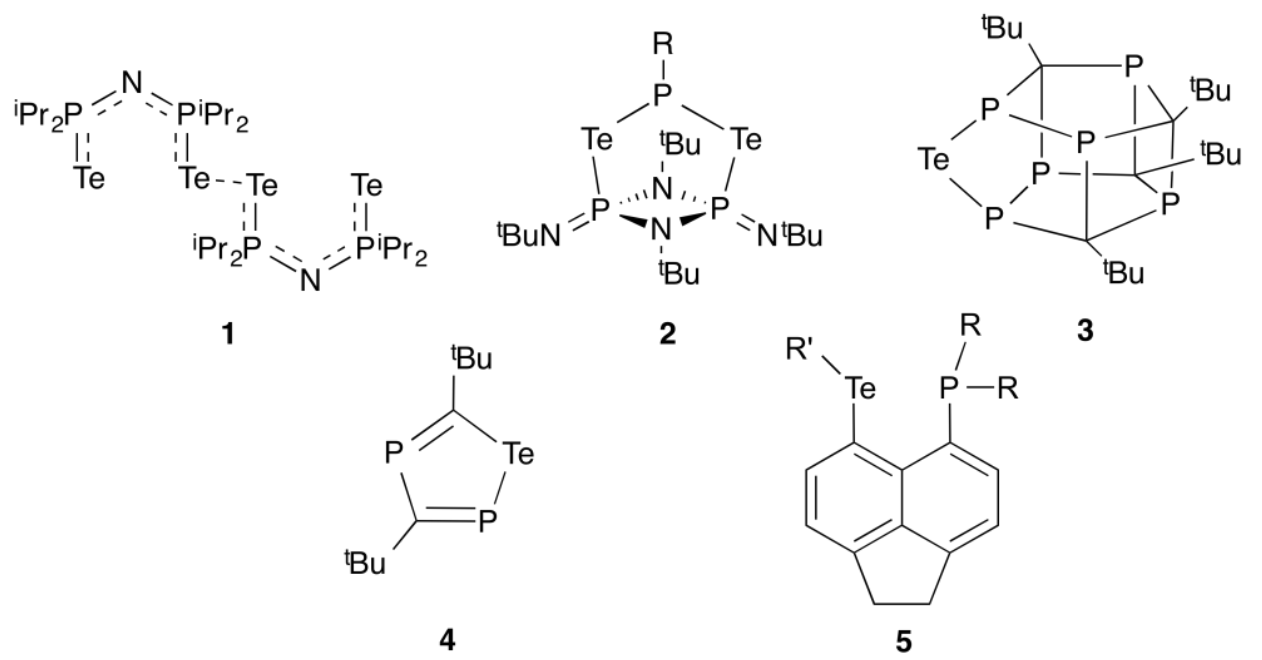

Figure 1. Selected organophosphorus-tellurium compounds.

Infrared spectroscopy has been used only to a limited extent for the characterization of organophosphorus-tellurium compounds. The infrared spectra of trialkylphosphine tellurides $\mathrm{R}_{3} \mathrm{PTe}$ ( $\mathrm{R}={ }^{\mathrm{n}} \mathrm{Pr},{ }^{\mathrm{n}} \mathrm{Bu}$, n-pentyl, $\mathrm{Cy}, \mathrm{n}$-octyl) have been investigated by Zingaro et al., who reported two absorption bands in the $400-470 \mathrm{~cm}^{-1}$ region; the lower frequency band at ca. $400 \mathrm{~cm}^{-1}$ does not vary with a change of the alkyl group. ${ }^{38}$ Subsequently, a detailed vibrational analysis of thermally unstable $\mathrm{Me}_{3} \mathrm{PTe}$ and its fully deuterated derivative led to the assignment of the $\mathrm{P}-\mathrm{Te}$ stretching vibration to a band at $376 \mathrm{~cm}^{-1} .39$ The value of the $\mathrm{P}-$ Te stretching force constant was found to be 
2.20 mdyn $\AA^{-1}$, cf. 3.73 and 2.84 mdyn $\AA^{-1}$ for $\mathrm{P}-\mathrm{S}$ and $\mathrm{P}-\mathrm{Se}$ force constants, respectively, ${ }^{39}$ in good agreement with the trend in calculated bond dissociation energies for $\mathrm{P}-\mathrm{E}$ bonds (vide infra). ${ }^{20}$ By contrast, Rømming et al. reported stretching frequencies of $490-526 \mathrm{~cm}^{-1}$ for tris(dialkylamino)phosphine tellurides, which are unexpectedly high compared to the values for the corresponding selenides ${ }^{40}$ in agreement with earlier work by Räuchle et al. ${ }^{41}$

In some cases mass spectrometry can provide confirmation of the molecular composition of organophosphorus-tellurium compounds, because naturally occurring tellurium is a mixture of seven isotopes: ${ }^{122} \mathrm{Te}(2.5 \%),{ }^{123} \mathrm{Te}(0.9 \%),{ }^{124} \mathrm{Te}(4.6 \%),{ }^{125} \mathrm{Te}(7.0 \%),{ }^{126} \mathrm{Te}(18.7 \%),{ }^{128} \mathrm{Te}$ $(31.8 \%)$ and ${ }^{130} \mathrm{Te}(34.5 \%)$ that give rise to characteristic patterns in the mass spectra. The observation of molecular ion peaks in electron impact or field ionization mass spectra has been especially useful for the identification of organophosphorus(III)-tellurium rings that cannot be crystallized for X-ray analysis. $^{14,32}$

\section{Binary Phosphorus-Tellurium Species}

A characteristic feature of phosphorus-chalcogen chemistry is the existence of an extensive series of cage molecules of the type $\mathrm{P}_{4} \mathrm{E}_{n}\left(\mathrm{E}=\mathrm{S}\right.$, Se) that are based on a $\mathrm{P}_{4}$ tetrahedron with various numbers of bridging and/or terminal chalcogen atoms. ${ }^{42}$ In the case of sulfur $(E=S)$ the entire series $(n=3-10)$ is known and the first member $\mathrm{P}_{4} \mathrm{~S}_{3}$ is used in "strike-anywhere" matches. Tellurium analogs of these binary phosphorus-chalcogen systems have not been reported, presumably reflecting the weakness of $\mathrm{P}-\mathrm{Te}$ bonds. However, the reactions of the elements phosphorus, sulfur and tellurium in the molten state $(700 \mathrm{~K})$ followed by extraction with $\mathrm{CS}_{2}$ gave a mixture of $\mathrm{P}_{4} \mathrm{~S}_{3}, \mathrm{P}_{4} \mathrm{~S}_{2} \mathrm{Te}$, and $\mathrm{P}_{4} \mathrm{STe}_{2}$ in the approximate ratio of $160: 4: 1{ }^{43}$ On the basis of ${ }^{31} \mathrm{P}$ NMR spectra it was concluded that tellurium replaces one or two of the bridging sulfur atoms, respectively, in $\mathrm{P}_{4} \mathrm{~S}_{3}$ in the very small amounts of ternary species that are formed. 
Binary $\mathrm{P}-\mathrm{Te}$ species can, however, be stabilized in solid-state materials as manifested by the ternary telluride $\mathrm{BaP}_{4} \mathrm{Te}_{2}$, which is prepared by heating a stoichiometric mixture of the three elements at $475{ }^{\circ} \mathrm{C} .{ }^{13}$ As illustrated in Figure 2, the crystal structure of $\mathrm{BaP}_{4} \mathrm{Te}_{2}$ incorporates chains of $\left[\mathrm{P}_{4} \mathrm{Te}_{2}\right]^{2-}$ dianions comprised of condensed $\mathrm{P}_{6}$ rings in the chair form, with the tellurium atoms in the 1,4 positions, and two covalent $\mathrm{P}-\mathrm{Te}$ bonds $(2.47$ and $2.54 \AA$ ).

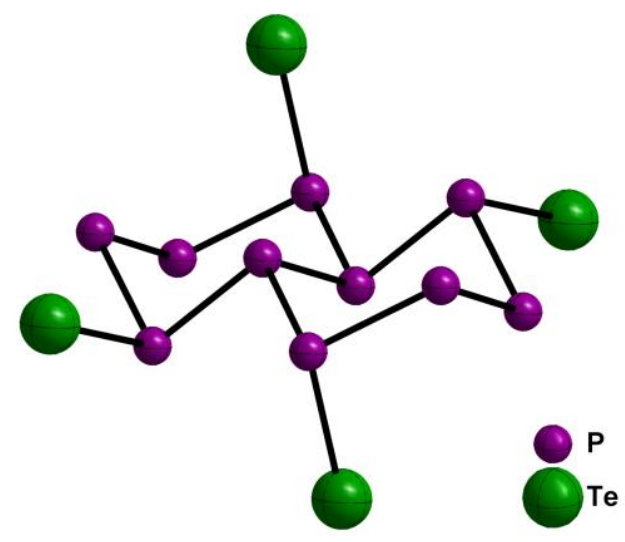

Figure 2. Section of the ${ }^{1}\left[\mathrm{P}_{4} \mathrm{Te}_{2}\right]^{2-}$ chain of $\mathrm{BaP}_{4} \mathrm{Te}_{2}$

Karaghiosoff et al. have shown that the disodium salt of the $\left[\mathrm{P}_{4} \mathrm{Te}_{2}\right]^{2-}$ dianion (6) is generated in solution in $98 \%$ yield by the reaction of white phosphorus with $\mathrm{Na}_{2} \mathrm{Te}_{2}$ in $N$ methylimidazole at ambient temperature (Scheme 1). ${ }^{12}$ The ${ }^{31} \mathrm{P}$ and ${ }^{125} \mathrm{Te}$ NMR spectra of 6 revealed a bicyclo[1.1.0]tetraphosphane (butterfly) structure with exo chalcogen atoms resulting from cleavage of one $\mathrm{P}-\mathrm{P}$ bond of the $\mathrm{P}_{4}$ tetrahedron via oxidative addition of $[\mathrm{Te}-\mathrm{Te}]^{2-}$. The ${ }^{1} J\left({ }^{31} \mathrm{P},{ }^{125} \mathrm{Te}\right)$ value for 6 is $-457 \mathrm{~Hz}$ and an unexpectedly large three-bond coupling $\left[{ }^{3} J\left({ }^{31} \mathrm{P},{ }^{125} \mathrm{Te}\right)=\right.$ $-138 \mathrm{~Hz}]$ is also observed for this discrete $\mathrm{P}-\mathrm{Te}$ anion.

\section{Scheme 1. Synthesis of the $\left[\mathrm{P}_{4} \mathrm{Te}_{2}\right]^{2-}$ dianion 6}

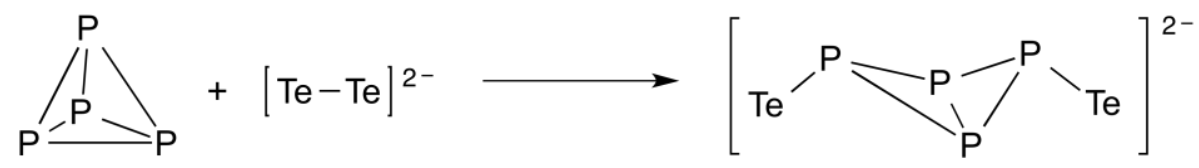




\section{Phosphine Complexes of Tellurium Cations}

The cations $\mathrm{RTe}^{+}$and $\mathrm{Te}^{2+}$ are potentially useful reagents in organic and inorganic tellurium chemistry, respectively, and some success has been achieved in stabilizing these highly electrophilic species (six valence electrons) by coordination to phosphine donors. In 1965 Petragnani and Moura Campos reported the first compound of the type $\mathrm{R}_{3} \mathrm{PTe}(\mathrm{Ar}) \mathrm{X}(\mathrm{Ar}=2$ naphthyl, $\mathrm{X}=\mathrm{I}) .{ }^{44}$ Thirty-five years later Godfrey et al. prepared the adduct $\mathrm{Ph}_{3} \mathrm{PTe}(\mathrm{Ph}) \mathrm{I}(7)$ by treatment of the tetramer $\mathrm{Ph}_{4} \mathrm{Te}_{4} \mathrm{I}_{4}$ with a stoichiometric amount of $\mathrm{PPh}_{3}$ in diethyl ether; the phosphorus-tellurium bond length in the linear P-Te-I unit of 7 is $2.568(2) \AA$ (Figure 3$){ }^{45}$

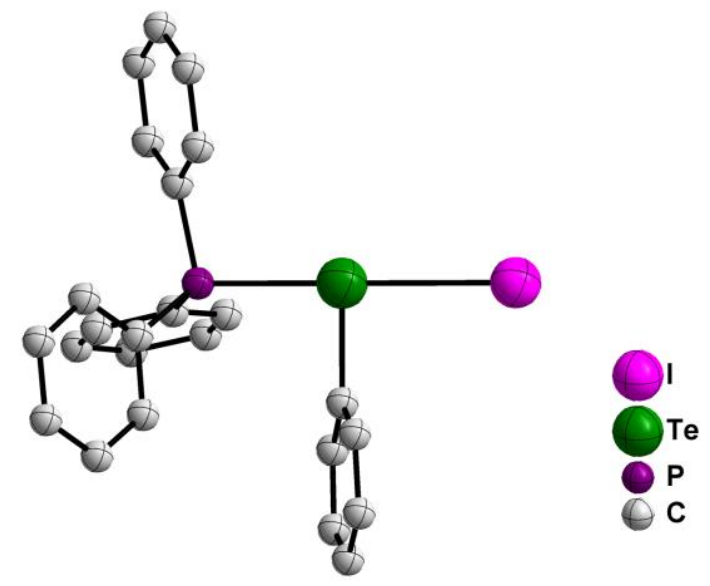

Figure 3. Molecular structure of $\mathrm{Ph}_{3} \mathrm{PTe}(\mathrm{Ph}) \mathrm{I}(7)$

In 1986 Kuhn and Schumann described the reaction of tellurophosphoranes $R_{3} P=T e(R=$ $\left.\mathrm{Me},{ }^{\mathrm{i}} \mathrm{Pr},{ }^{\mathrm{n}} \mathrm{Bu},{ }^{\mathrm{t}} \mathrm{Bu}, \mathrm{NMe}_{2}\right)$ with methyl iodide to give $\left[\mathrm{MeTe}\left(\mathrm{PR}_{3}\right)\right]^{+} \mathrm{I}^{-}$; these phosphine-stabilized $\mathrm{MeTe}^{+}$cations, which were characterized by elemental analyses and ${ }^{1} \mathrm{H} /{ }^{31} \mathrm{P} \mathrm{NMR}$ spectra, undergo nucleophilic attack by MeLi to give $\mathrm{Me}_{2} \mathrm{Te}$ and free $\mathrm{PR}_{3} \cdot{ }^{46}$ Subsequently, Sladky and Köllemann obtained the salts $\left[\mathrm{RTe}\left(\mathrm{P}^{\mathrm{n}} \mathrm{Bu}_{3}\right)\right]^{+} \mathrm{X}^{-}\left(\mathbf{8 a}, \mathrm{R}=4-\mathrm{FC}_{6} \mathrm{H}_{4}, \mathrm{X}=\mathrm{ClO}_{4} ; \mathbf{8 b}, \mathrm{R}=\mathrm{Me}, \mathrm{X}=\mathrm{BF}_{4}\right)$ as oils upon oxidation of the corresponding ditelluride RTeTeR with a nitrosyl salt followed by treatment of the product with ${ }^{\mathrm{n}} \mathrm{Bu}_{3} \mathrm{P}$; the ${ }^{1} J\left({ }^{31} \mathrm{P},{ }^{125} \mathrm{Te}\right)$ values for $\mathbf{8 a}$ and $\mathbf{8 b}$ are 1071 and $1046 \mathrm{~Hz}$, respectively. ${ }^{47}$

Very recently, two groups have structurally characterized phosphine complexes of aryltellurenyl cations by using different synthetic approaches. ${ }^{48,49}$ Tokitoh et al. employed the 
reaction of two equivalents of a trimethylsilyl reagent with a mixed-valent $\mathrm{Te}^{\mathrm{II}}-\mathrm{Te}^{\mathrm{IV}}$ difluoride in the presence of $\mathrm{PPh}_{3}$ to generate phosphine complexes of an aryltellurenyl cation (9) via the thermodynamically favorable elimination of trimethylsilyl fluoride (Scheme 2a); the complexes 9 were also obtained by treatment of an aryltellurenyl halide with $\mathrm{AgBF}_{4}$ in the presence of $\mathrm{PPh}_{3}{ }^{48}$ Beckmann and co-workers utilized the direct reaction of $\mathrm{PPh}_{3}$ with the cation $\left[\mathrm{MesTe}(\mathrm{TeMes})_{2}\right]^{+}$to produce $\left[\mathrm{MesTe}\left(\mathrm{PPh}_{3}\right)\right]^{+}$as the triflate salt $\mathbf{1 0}$ (Scheme 2b), which may also be prepared by treatment of $\mathrm{Mes}_{2} \mathrm{Te}$ with triflic acid in the presence of $\mathrm{PPh}_{3} .{ }^{49}$ The $\mathrm{P}-\mathrm{Te}$ bond distance in $\mathbf{1 0}$ is $2.467 \AA$ and ${ }^{1} J\left({ }^{31} \mathrm{P},{ }^{125} \mathrm{Te}\right)=1148 \mathrm{~Hz},{ }^{49}$ in reasonable agreement with the $J$ values reported earlier by Sladky (vide supra). ${ }^{47}$ The ${ }^{1} J\left({ }^{31} \mathrm{P},{ }^{125} \mathrm{Te}\right.$ ) coupling of $1387 \mathrm{~Hz}$ reported for $9 \mathrm{a}^{48}$ is significantly higher than those for other aryltellurenyl cations.

Scheme 2. Syntheses of Phosphine Adducts of Aryltellurenyl Cations

a)

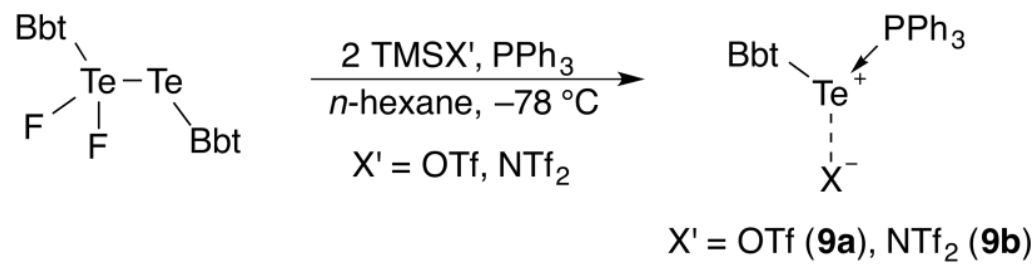

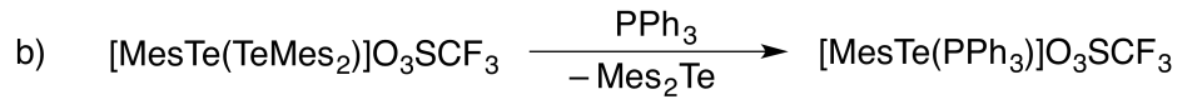

10

Aryltellurenyl cations may also be stabilized via interaction with a peri-phosphino substituent on an acenaphthene scaffold. ${ }^{19}$ Typical syntheses of such compounds are shown in Scheme 3 and a representative structure is illustrated in Figure 4. The P-Te distances are around $2.5 \AA$ being slightly enlarged as a result of the peri arrangement and the delocalization to form a three centre-four electron P-Te $\cdots$ I system. 
Scheme 3. Synthesis of Intramolecularly-Stabilized Aryltellurenyl Cations

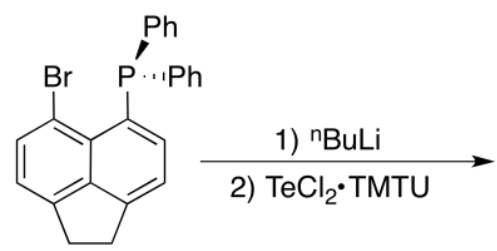<smiles>ClC[C@H]1Cc2ccc3c4c(ccc1c24)P(c1ccccc1)[Te]3([Te]Cl)c1ccccc1</smiles>
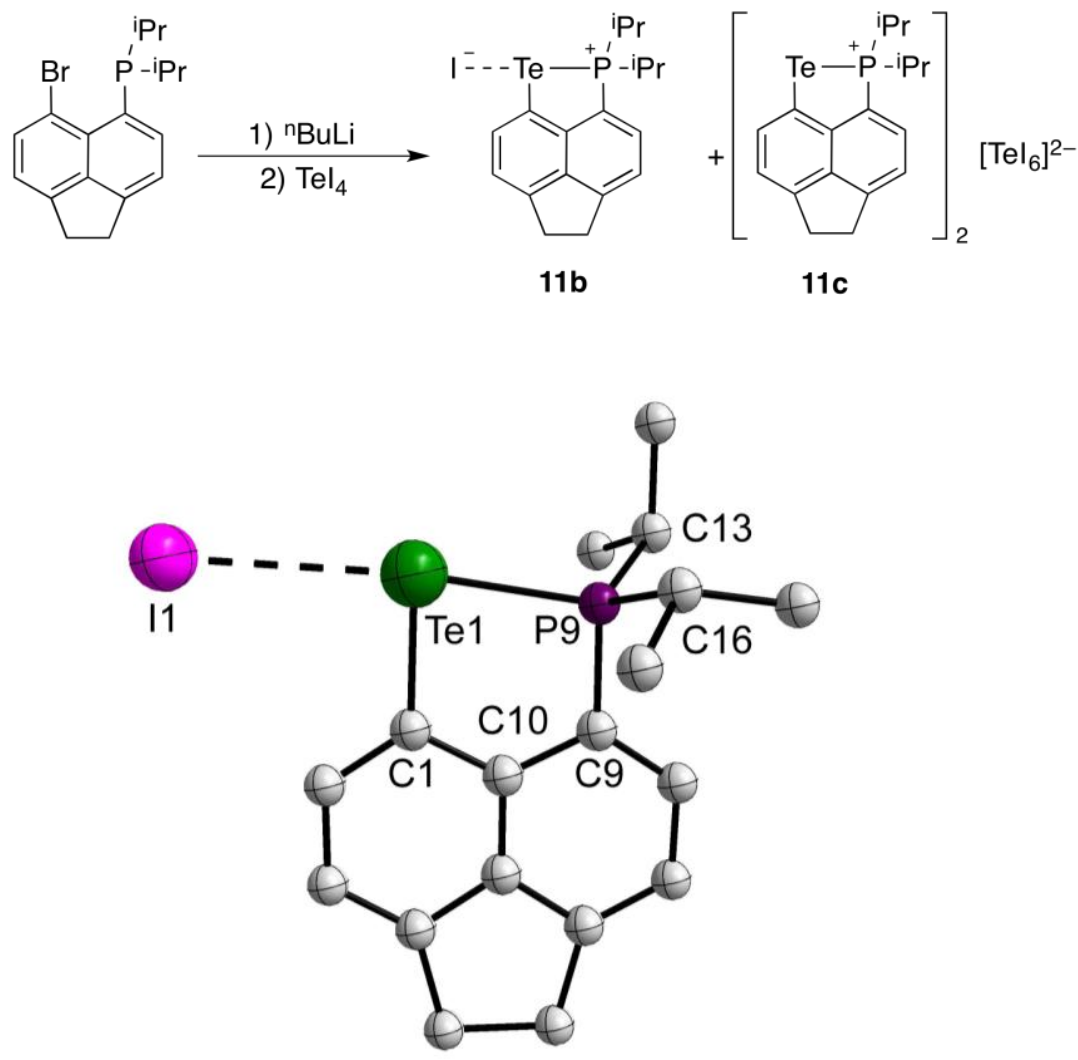

Figure 4. Molecular structure of the intramolecularly stabilized aryltellurenyl cation $\mathbf{1 1 b}$. Hydrogen atoms omitted for clarity. Selected bond lengths $(\AA)$ and angles $\left(^{\circ}\right)$ : Te1-P9 2.5107(16),

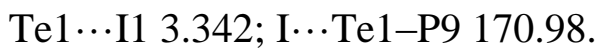

The $\mathrm{Te}^{2+}$ cation has been sequestered as the DPPE-chelated complex 12 by Ragogna and coworkers, who used a ligand-exchange protocol (Scheme 4). ${ }^{17}$ The mean P-Te distance of $2.48 \AA$ and the ${ }^{1} J\left({ }^{31} \mathrm{P},{ }^{125} \mathrm{Te}\right)$ value of $1020 \mathrm{~Hz}$ in $\mathbf{1 2}$ are similar to the corresponding parameters for phosphine complexes of $\mathrm{ArTe}^{+}$cations (vide supra). The frontier Kohn-Sham orbitals and electron localization function for $\mathbf{1 2}$ reveal two lone pairs on the two-coordinate tellurium center. According 
to natural population analysis, the atomic charges are located primarily on the donating phosphorus atoms (Scheme 4). ${ }^{17}$ A substantially longer P-Te bond length of 2.604(1) $\AA$ associated with a modest ${ }^{1} J\left({ }^{31} \mathrm{P},{ }^{125} \mathrm{Te}\right)$ coupling of $780 \mathrm{~Hz}$ was found for the $\mathrm{PCy}_{3}$ complex of a 1,2,5telluradiazolium cation 13 (Scheme 5). ${ }^{50}$

\section{Scheme 4. Synthesis of $[\mathrm{Te}(\mathrm{DPPE})]^{2+}$ Dication (12)}

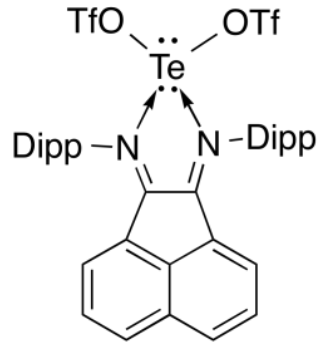<smiles>C1C[Te]P2CCP(C1)[Te+]2</smiles>

12

\section{Scheme 5. Charge Distribution in Phosphine Complexes of Tellurium Cations}

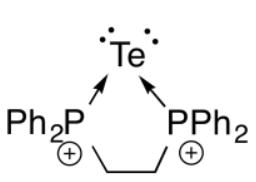

12<smiles>C[13C]n1ccn[14c]1[Te]</smiles>

13

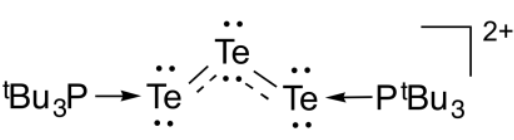

14

An intriguing example of a phosphine-stabilized tellurium cation was reported in 1987 by Kuhn and co-workers, who showed that the oxidation of ${ }^{\mathrm{t}} \mathrm{Bu}_{3} \mathrm{PTe}$ with a ferrocenium salt gives the dication $\left[{ }^{t} \mathrm{Bu}_{3} \mathrm{P}-\mathrm{Te}-\mathrm{Te}-\mathrm{Te}-\mathrm{P}^{t} \mathrm{Bu}_{3}\right]^{2+}(\mathbf{1 4}){ }^{51}$ The crystal structure of the $\mathrm{SbF}_{6}{ }^{-}$salt of $\mathbf{1 4}$ revealed a mean P-Te distance of ca. $2.50 \AA$, cf. $2.368 \AA$ for ${ }^{t} \mathrm{Bu}_{3} \mathrm{PTe} ;{ }^{52}$ the mean Te-Te bond length of $2.71 \AA$ is in the typical range for single bonds in organic ditellurides RTe-TeR. On the basis of these structural parameters, the authors suggested that $\mathbf{1 4}$ should be considered as a $\mathrm{Te}_{3}{ }^{2+}$ dication coordinated to two phosphine ligands rather than a tellurophosphorane complex of $\mathrm{Te}^{2+} .51$ Calculations of the electronic structure of $\mathbf{1 4}$ are warranted in order to elucidate this dichotomy. 


\section{Organophosphorus(III)-Tellurium Compounds}

The lability of the P-Te bond is strikingly illustrated by the interesting history of organophosphorus(III)-tellurium compounds containing either $\mathrm{P}^{\mathrm{III}}-\mathrm{Te}-\mathrm{C}$ or $\mathrm{P}^{\mathrm{III}}-\mathrm{Te}-\mathrm{P}^{\mathrm{III}}$ linkages. Since the initial success in the characterization of these fickle systems was achieved with acyclic derivatives, a discussion of those compounds precedes an account of the synthesis and structures of cyclic analogs in this section. Table 1 summarizes pertinent structural and NMR data for selected organophosphorus(III)-tellurium compounds, which provide a benchmark for subsequent discussions.

Table 1. Bond Lengths and NMR Data for Organophosphorus(III)-Tellurium Compounds

\begin{tabular}{|c|c|c|c|c|}
\hline P-Te Compound & $d(\mathrm{P}-\mathrm{Te})(\AA)$ & ${ }^{1} J\left({ }^{31} \mathrm{P},{ }^{125} \mathrm{Te}\right)(\mathrm{Hz}){ }^{a}$ & $\delta^{125} \mathrm{Te}(\mathrm{ppm})^{b}$ & Ref. \\
\hline \multicolumn{5}{|l|}{ Acyclic P-Te-C Systems } \\
\hline${ }^{\mathrm{t}} \mathrm{Bu} \mathrm{u}_{2} \mathrm{PTe}$ - $p$-tolyl & $c$ & 532 & $-190.8(d)$ & 55 \\
\hline${ }^{1} \mathrm{Pr}_{2} \mathrm{PTe}-p$-tolyl & $c$ & 495 & $-234.8(\mathrm{~d})$ & 55 \\
\hline${ }^{\mathrm{t}} \mathrm{Bu}_{2} \mathrm{PTeSiMe}_{3}$ & $c$ & 384 & $-772(d)$ & 56 \\
\hline$\left[\left(\mathrm{Me}_{3} \mathrm{Si}\right)_{2} \mathrm{C}=\mathrm{P}\right]_{2} \mathrm{Te}$ & $c$ & 573.3 & $+1022(\mathrm{t})$ & 58 \\
\hline$\left[\left({ }^{\mathrm{i}} \mathrm{PrMe} \mathrm{Si}_{2} \mathrm{Si}\right)_{2} \mathrm{C}=\mathrm{P}\right]_{2} \mathrm{Te}$ & $c$ & 578.5 & $+823(\mathrm{t})$ & 58 \\
\hline$\left(\mathrm{Me}_{3} \mathrm{Si}\right)_{2} \mathrm{C}=\mathrm{PTeMes}$ & $c$ & 638 & $+646.0(\mathrm{~d})$ & 58 \\
\hline$\left(\mathrm{Me}_{3} \mathrm{Si}\right)_{2} \mathrm{C}=\mathrm{PTeTIP}$ & $c$ & 652.8 & $+600.1(\mathrm{~d})$ & 58 \\
\hline$\left(\mathrm{Me}_{3} \mathrm{Si}\right)_{2} \mathrm{C}=\mathrm{PTeMes} *$ & $c$ & 701.5 & $+859.2(\mathrm{~d})$ & 58 \\
\hline \multicolumn{5}{|l|}{ Acyclic P-Te-P Systems } \\
\hline${ }^{\mathrm{t}} \mathrm{Bu}_{2} \mathrm{PTeP}^{\mathrm{t}} \mathrm{Bu}_{2}$ & $c$ & 451 & $-574(\mathrm{t})$ & 59,67 \\
\hline${ }^{\mathrm{i}} \mathrm{Pr}_{2} \mathrm{PTeP}^{\mathrm{i}} \mathrm{Pr}_{2}$ & $c$ & 420 & $-276(t)$ & 61 \\
\hline$\left.\left[\left\{\left(\mathrm{Me}_{3} \mathrm{Si}\right)_{2} \mathrm{CH}\right]\right\} \mathrm{P}\right]_{2} \mathrm{Te}$ & $\begin{array}{l}2.505(2) \\
2.552(2)\end{array}$ & 377 & $c$ & 62 \\
\hline$\left({ }^{1} \mathrm{Pr}_{2} \mathrm{~N}\right)_{2} \mathrm{PTeP}\left(\mathrm{N}^{1} \mathrm{Pr}_{2}\right)_{2}$ & $\begin{array}{l}2.559(1) \\
2.576(2)\end{array}$ & 562 & $c$ & 63 \\
\hline$\left[\left(\mathrm{H}_{2} \mathrm{C}\right)_{2}(\mathrm{DippN})_{2} \mathrm{P}\right]_{2} \mathrm{Te}$ & $\begin{array}{l}2.584(7) \\
2.587(8)\end{array}$ & 556 & $c$ & 64 \\
\hline $\begin{array}{l}\frac{\text { Metal Complexes }}{(\mathrm{CO})_{4} \mathrm{Cr}\left({ }^{\mathrm{t}} \mathrm{Bu}_{2} \mathrm{PTeP}^{\mathrm{t}} \mathrm{Bu}_{2}\right)} \\
(\mathrm{CO})_{4} \mathrm{Cr}\left({ }^{\mathrm{i}} \mathrm{Pr}_{2} \mathrm{PTeP}^{\mathrm{i}} \mathrm{Pr}_{2}\right)\end{array}$ & $\begin{array}{c}2.481(1) \\
2.491(1) \\
c\end{array}$ & $\begin{array}{l}324 \\
243\end{array}$ & $\begin{array}{l}+142(\mathrm{t}) \\
+1233(\mathrm{t})\end{array}$ & $\begin{array}{l}65,66 \\
61\end{array}$ \\
\hline
\end{tabular}




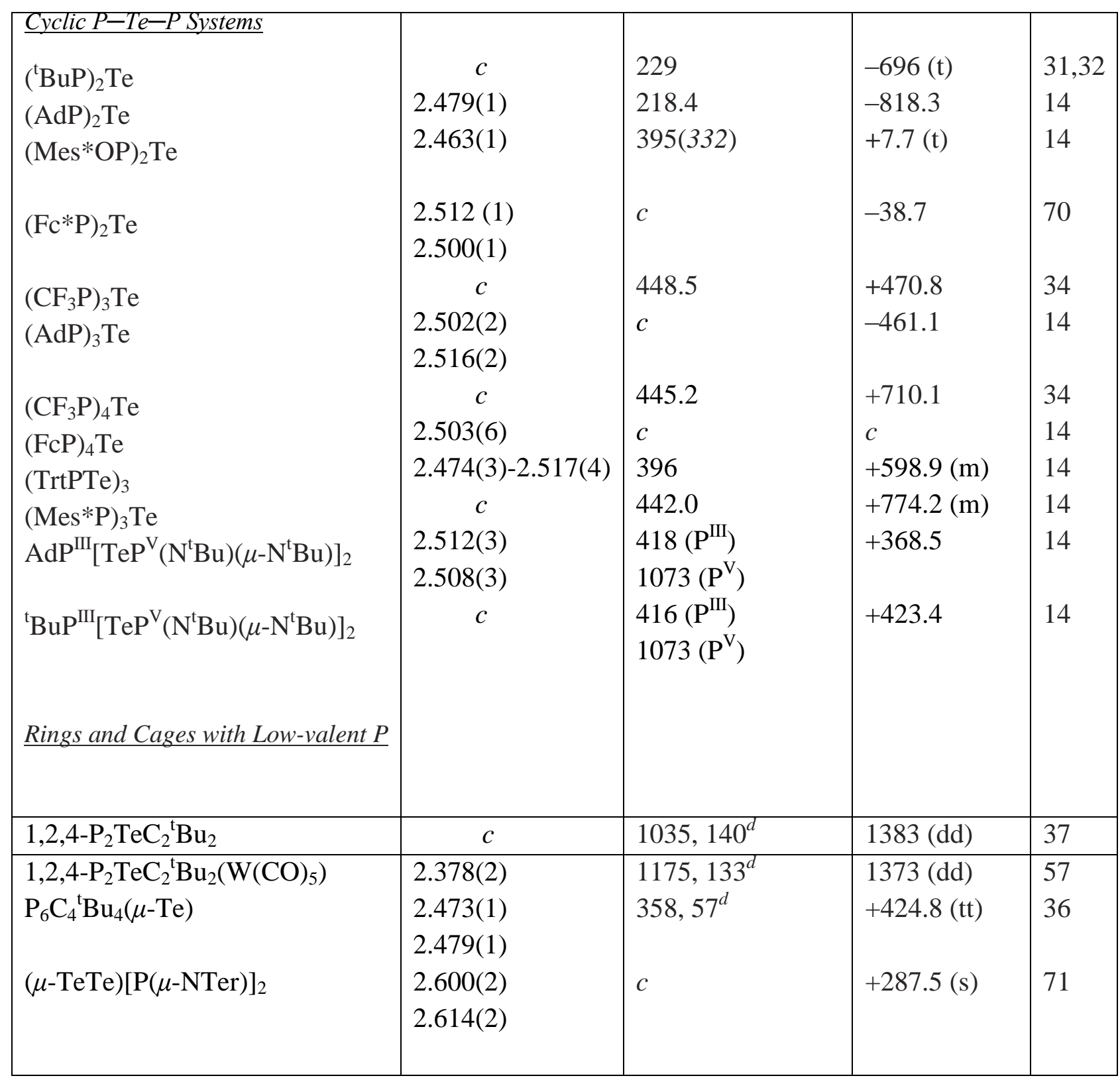

${ }^{a}$ Absolute values (magnitude only) taken from ${ }^{125}$ Te NMR spectra where available; ${ }^{1} J\left({ }^{31} \mathrm{P},{ }^{123} \mathrm{Te}\right)$ data from ${ }^{31} \mathrm{P}$ NMR spectra are given in italics

${ }^{b}$ Ref. $\mathrm{Me}_{2} \mathrm{Te}$ (external); $\mathrm{d}=$ doublet; $\mathrm{t}=$ triplet; $\mathrm{dd}=$ doublet of doublets; $\mathrm{m}=$ multiplet

${ }^{c}$ Not reported

${ }^{d}{ }^{2} J\left({ }^{31} \mathrm{P},{ }^{125} \mathrm{Te}\right)$

\subsection{Acyclic Organophosphorus(III)-Tellurium Compounds}

\subsubsection{With P-Te-C Linkages}

The first organophosphorus(III)-tellurium compound of the type $\mathrm{R}_{2} \mathrm{PTeR}^{\prime}$ (tellurophosphinites) was reported in 1979 by Grobe et al. ${ }^{53}$ The derivative $\left(\mathrm{CF}_{3}\right)_{2} \mathrm{PTeMe}(\mathbf{1 5 a})$ was 
obtained as an orange oil from the slow redistribution of $\left(\mathrm{CF}_{3}\right)_{2} \mathrm{PP}\left(\mathrm{CF}_{3}\right)_{2}$ and $\mathrm{MeTeTeMe}(\mathrm{eq} 1)$ and characterized by ${ }^{1} \mathrm{H},{ }^{19} \mathrm{~F}$ and ${ }^{31} \mathrm{P}$ NMR spectra and the formation of the chromium complex $\mathrm{Cr}(\mathrm{CO})_{5}\left(\mathrm{CF}_{3}\right)_{2} \mathrm{PTeMe}$ upon photolysis in a THF solution of $\mathrm{Cr}(\mathrm{CO})_{6} \cdot{ }^{54}$ Subsequently, du Mont and co-workers prepared aryl tellurophosphinites $\mathrm{R}_{2} \mathrm{PTe}-p$-tolyl $\left(\mathbf{1 5 b}, \mathrm{R}={ }^{\mathrm{i}} \mathrm{Pr} ; \mathbf{1 5 c},{ }^{\mathrm{t}} \mathrm{Bu}\right)$ in a similar manner; these yellow liquids exhibit a doublet in the ${ }^{125} \mathrm{Te}$ NMR spectra with ${ }^{1} J\left({ }^{31} \mathrm{P},{ }^{125} \mathrm{Te}\right)$ values of $495 \mathrm{~Hz}$ and $532 \mathrm{~Hz}$, respectively (Table 1). ${ }^{55,56}$ Examples of metal complexes of the isomeric anions $[\mathrm{RPTeAr}]^{-}$and $\left[\mathrm{R}_{2} \mathrm{PTe}\right]^{-}$are discussed in Section 7.2.

$$
\begin{aligned}
& \mathrm{R}_{2} \mathrm{P}_{-} \mathrm{PR}_{2}+\mathrm{R}^{\prime} \mathrm{Te}-\mathrm{TeR} \longrightarrow 2 \mathrm{R}_{2} \mathrm{P}^{\prime} \mathrm{Te} \mathrm{R}^{\prime} \\
& \mathbf{1 5 a}, \mathrm{R}=\mathrm{CF}_{3} ; \mathrm{R}^{\prime}=\mathrm{Me} \\
& \mathbf{1 5 b}, \mathrm{R}=\mathrm{i}_{\mathrm{Pr}} ; \mathrm{R}^{\prime}=p \text {-tolyl } \\
& \mathbf{1 5 c}, \mathrm{R}={ }^{\mathrm{B} u} ; \mathrm{R}^{\prime}=p \text {-tolyl }
\end{aligned}
$$

The 1,2,4-tellurodiphosphole $\mathbf{4}$ also incorporates a C-P-Te functionality. This fascinating heterocycle, which is formally a six $\pi$-electron system, is obtained as a yellow oil by reaction of $\left[\mathrm{Li}(\mathrm{TMEDA})_{2}\right]\left[\mathrm{SbP}_{2} \mathrm{C}_{2}{ }^{\mathrm{t}} \mathrm{Bu}_{2}\right]$ with $\mathrm{Te}\left(\mathrm{S}_{2} \mathrm{CNEt}_{2}\right)_{2}$ in DME. ${ }^{37}$ The heterocycle 4 readily forms the $P$ bonded $\eta^{1}-\mathrm{W}(\mathrm{CO})_{5}$ complex 16 as illustrated in Scheme $6 .{ }^{57}$ Although the free ligand $\mathbf{4}$ has not been structurally characterized, the five-membered ring in $\mathbf{1 6}$ is planar and exhibits a short phosphorustellurium bond $[d(\mathrm{P}-\mathrm{Te})=2.378(2) \AA]$. The ${ }^{1} J\left({ }^{31} \mathrm{P},{ }^{125} \mathrm{Te}\right)$ coupling of $1175 \mathrm{~Hz}$ in 16 is ca. $140 \mathrm{~Hz}$ larger than that in 4 (Table 1). ${ }^{37}$ The latter value is $>400 \mathrm{~Hz}$ higher than typical values for acyclic $\mathrm{P}^{\mathrm{III}}-\mathrm{Te}=\mathrm{C}$ systems (vide infra); higher $s$ character in the $\mathrm{P}-\mathrm{Te}$ hybrid orbital may contribute to this discrepancy for the cyclic system.

\section{Scheme 6. Synthesis of a Tungsten Complex of a 1,2,4-Tellurodiphosphole}
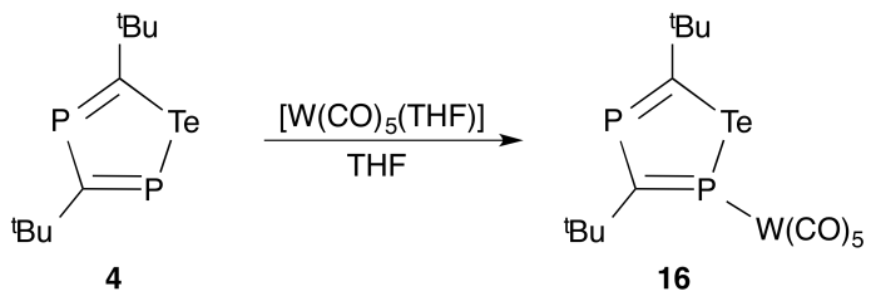
The du Mont group has also prepared acyclic compounds incorporating the unsaturated $\mathrm{C}=\mathrm{P}-\mathrm{Te}$ functionality. ${ }^{58}$ Tellurobis(phosphaalkenes) $\mathrm{Te}\left(\mathrm{P}=\mathrm{CR}_{2}\right)_{2}(\mathbf{1 7} \mathbf{a}$ and $\mathbf{1 7 b})$ are generated by the reaction of a $P$-chlorophosphaalkene with a disilyltelluride (eq 2 ). $P$-aryltellurophosphaalkenes $\left({ }^{\mathrm{i}} \mathrm{PrMe}_{2} \mathrm{Si}\right)_{2} \mathrm{C}=\mathrm{P}-\mathrm{TeAr}\left(\mathrm{Ar}=\mathrm{Ph}, \mathrm{Mes}, \mathrm{TIP}, \mathrm{Mes}^{*}\right)\left(\mathrm{TIP}=2,4,6-{ }^{\mathrm{i}} \mathrm{Pr}_{3} \mathrm{C}_{6} \mathrm{H}_{2}\right)$ were also prepared via metathesis of the bulky $P$-chlorophosphaalkene $\left(\mathrm{R}={ }^{\mathrm{i}} \mathrm{Pr}\right)$ with lithium aryltellurolates. ${ }^{58}$ The ${ }^{1} J\left({ }^{31} \mathrm{P}\right.$, ${ }^{125} \mathrm{Te}$ ) couplings for the $\mathrm{C}=\mathrm{P}^{\mathrm{III}}-\mathrm{Te}$ unit are in the range $570-700 \mathrm{~Hz}$ (Table 1$)$.

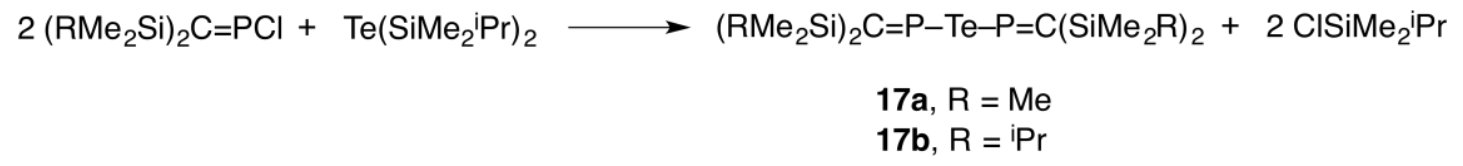

\subsubsection{With P-Te-P Linkages}

The first acyclic organophosphorus(III)-tellurium compound with a $\mathrm{P}-\mathrm{Te}-\mathrm{P}$ grouping, ${ }^{t} \mathrm{Bu}{ }_{2} \mathrm{P}-\mathrm{Te}-\mathrm{P}^{t} \mathrm{Bu}_{2}$ was reported by du Mont in $1980 .{ }^{59}$ The initial synthesis involved the insertion of tellurium (in the form of either the element or the reagent $\mathrm{TeP}^{\mathrm{n}} \mathrm{Bu}_{3}$ ) into the $\mathrm{P}-\mathrm{E}$ bond of ${ }^{t} \mathrm{Bu}_{2} \mathrm{P}-$ $\mathrm{EMe}_{3}(\mathrm{E}=\mathrm{Si}, \mathrm{Ge}, \mathrm{Sn})$. The short-lived insertion products ${ }^{\mathrm{t}} \mathrm{Bu}_{2} \mathrm{P}-\mathrm{Te}-\mathrm{EMe}_{3}$ were characterized in situ by multinuclear NMR spectroscopy, ${ }^{1} J\left({ }^{31} \mathrm{P},{ }^{125} \mathrm{Te}\right)=348-384 \mathrm{~Hz}$, but they undergo a rapid redistribution to give ${ }^{t} \mathrm{Bu}_{2} \mathrm{P}-\mathrm{Te}-\mathrm{P}^{t} \mathrm{Bu}_{2} \mathbf{1 8 a}$ and $\mathrm{Te}\left(\mathrm{EMe}_{3}\right)_{2}$ (Scheme 7a). ${ }^{59}$ The telluride 18a is preferably prepared in $80 \%$ yield as pale yellow needles via metathesis (Scheme $7 \mathrm{~b}) .{ }^{59}$ The tertbutyl derivative 18a and the isopropyl analog ${ }^{\mathrm{i}} \mathrm{Pr}_{2} \mathrm{P}-\mathrm{Te}-\mathrm{P}^{\mathrm{i}} \mathrm{Pr}_{2}$ (18b) may also be prepared via tellurium insertion; ${ }^{60,61}$ the telluride $\mathbf{1 8 b}$ is also obtained via metathesis (Scheme $\left.7 \mathrm{~b}\right) .{ }^{59}$ In contrast to $\mathbf{1 8 b}$, the isopropyl derivative exists in solution in equilibrium with the diphosphine ${ }^{\mathrm{i}} \operatorname{Pr}_{2} \mathrm{P}-\mathrm{P}^{\mathrm{i}} \mathrm{Pr}_{2}$ and elemental tellurium. ${ }^{61}$ Recently, Cowley and co-workers have shown that the congener $\mathrm{R}_{2} \mathrm{P}-$ Te- $\mathrm{PR}_{2}\left(\mathbf{1 8 c}, \mathrm{R}=\mathrm{CH}\left(\mathrm{SiMe}_{3}\right)_{2}\right)$ is obtained in $31 \%$ yield from reaction of the persistent phosphinyl radical $\cdot \mathrm{P}\left[\mathrm{CH}\left(\mathrm{SiMe}_{3}\right)_{2}\right]_{2}$ with tellurium in toluene at ambient temperature; the $\mathrm{P}-\mathrm{Te}-\mathrm{P}$ bond angle is $94.87(8)^{\circ}$ (Figure 5a). ${ }^{62}$

Scheme 7. Synthesis of ${ }^{\mathrm{t}} \mathrm{B} \mathrm{u}_{2} \mathrm{P}-\mathrm{Te}-\mathrm{P}^{\mathrm{t}} \mathrm{Bu} \mathbf{u}_{2}$ (18a) 

a) $2 \mathrm{BBu}_{2} \mathrm{P}-\mathrm{Te}-\mathrm{EMe}_{3}-\frac{}{-\left(\mathrm{Me}_{3} \mathrm{E}\right)_{2} \mathrm{Te}}$
b) $\mathrm{Na}_{2} \mathrm{Te}+2 \mathrm{Bu}_{2} \mathrm{PCl}$

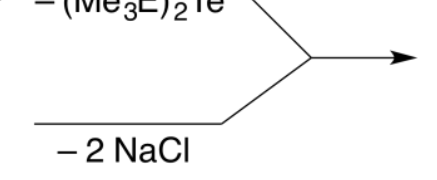
${ }^{\mathrm{t}} \mathrm{Bu}_{2} \mathrm{P}-\mathrm{Te}-\mathrm{P}^{\mathrm{t} B \mathrm{Bu}_{2}}$
$18 \mathrm{a}$

In an alternative approach, Niecke et al. obtained the acyclic derivative $\left(\mathrm{R}_{2}{ }_{2} \mathrm{~N}\right)_{2} \mathrm{P}-\mathrm{Te}-$ $\mathrm{P}\left(\mathrm{NR}_{2}^{\prime}\right)_{2}\left(\mathbf{1 9 a}, \mathrm{R}^{\prime}={ }^{\mathrm{i}} \mathrm{Pr}\right)$ in $44 \%$ yield via slow insertion of elemental tellurium (6 days) into the $\mathrm{P}-\mathrm{P}$ bond of $\left({ }^{\mathrm{i}} \mathrm{Pr}_{2} \mathrm{~N}\right)_{2} \mathrm{P}-\mathrm{P}\left(\mathrm{N}^{\mathrm{i}} \mathrm{Pr}_{2}\right)_{2}$ in toluene. ${ }^{63}$ Very recently, a bulky analog $\left(\mathrm{RR}{ }^{\prime} \mathrm{N}\right)_{2} \mathrm{P}-\mathrm{Te}-\mathrm{P}(\mathrm{NRR})_{2}$ (19b, $\mathrm{R}=$ Dipp, $\mathrm{R}^{\prime}=-\mathrm{CH}_{2}-$ ) was isolated as colorless crystals in $82 \%$ yield from a similar, but more rapid (16 h in THF), tellurium-insertion process. ${ }^{64,65}$ Crystal structure determinations of 19a (Figure 5b) and 19b confirmed the acyclic arrangement with long P-Te bonds of $2.56 \AA(\mathbf{1 9 a})^{63}$ and $2.59 \AA(\mathbf{1 9 b})^{64}$ and narrow P-Te-P bond angles of $94.5^{\circ}$ for $19 \mathbf{a}$, cf. $100^{\circ}$ for the sulfur analog, ${ }^{63}$ and $83.0(2)^{\circ}$ for $\mathbf{1 9 b}$. The ${ }^{1} J\left({ }^{31} \mathrm{P},{ }^{125} \mathrm{Te}\right)$ values for acyclic $\mathrm{P}^{\mathrm{III}}-\mathrm{Te}-\mathrm{P}^{\mathrm{III}}$ compounds are in the range 375-560 Hz (Table 1), significantly smaller than those of $\mathrm{C}=\mathrm{P}^{\mathrm{III}}-\mathrm{Te}$ systems (vide supra).

(a)

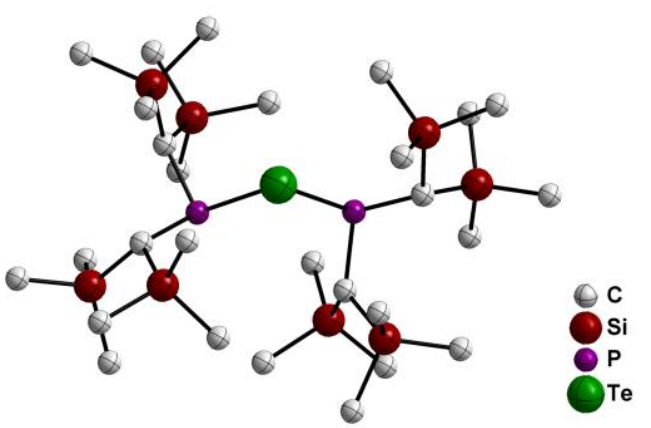

(b)

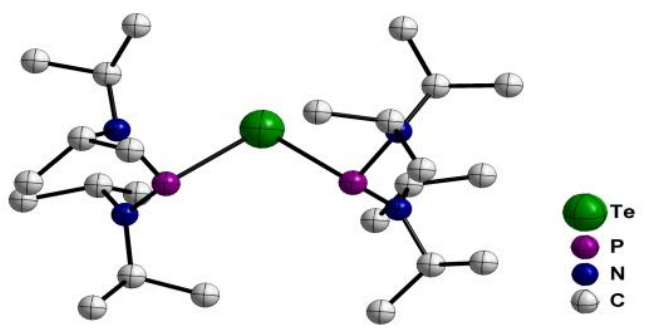

Figure 5. Molecular structures of (a) $\left[\left(\mathrm{Me}_{3} \mathrm{Si}\right)_{2} \mathrm{CH}\right]_{2} \mathrm{PTeP}\left[\mathrm{CH}\left(\mathrm{SiMe}_{3}\right)_{2}\right]_{2}$ (18c) and (b) $\left({ }^{\mathrm{i}} \operatorname{Pr}_{2} \mathrm{~N}\right)_{2} \mathrm{PTeP}\left(\mathrm{N}^{\mathrm{i}} \operatorname{Pr}_{2}\right)_{2}(\mathbf{1 9 a})$.

An intriguing example of tellurium insertion into a $\mathrm{P}-\mathrm{P}$ bond is provided by the reaction of the element with the hexaphosphaprismane $\mathrm{P}_{6} \mathrm{C}_{4}{ }^{\mathrm{t}} \mathrm{Bu}_{4}$ in toluene at $60{ }^{\circ} \mathrm{C}$ to give the polycyclic compound $3\left[d(\mathrm{P}-\mathrm{Te})=2.479(1) \AA{ }^{1} J\left({ }^{31} \mathrm{P},{ }^{125} \mathrm{Te}\right)=358 \mathrm{~Hz}\right]$, which is remarkably stable towards air and moisture and thermally robust (Scheme 8). ${ }^{36}$

\section{Scheme 8. Insertion of Tellurium into a P-P Bond}



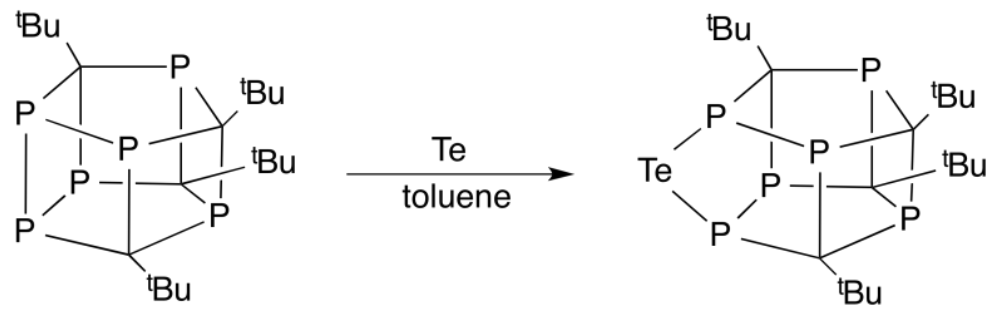

3

There have been only limited investigations of the coordination behavior of $\mathrm{R}_{2} \mathrm{P}-\mathrm{Te}-\mathrm{PR}_{2}$ ligands and in all cases $P, P$-chelated complexes are formed. For example, $\mathbf{1 8 a}$ or $\mathbf{1 8 b}$ react with $\left(\eta^{4}-\right.$ $\left.\mathrm{C}_{7} \mathrm{H}_{8}\right) \mathrm{M}(\mathrm{CO})_{4}(\mathrm{M}=\mathrm{Cr}, \mathrm{Mo})$ or $\mathrm{W}(\mathrm{CO})_{4}(\mathrm{MeCN})_{2}$ to give the complexes $\left[(\mathrm{CO})_{4} \mathrm{M}\left\{\left(\mathrm{PR}_{2}\right)_{2} \mathrm{Te}\right\}\right](\mathbf{2 0 a}$, $\mathrm{R}={ }^{\mathrm{t}} \mathrm{Bu}, \mathrm{M}=\mathrm{Cr}, \mathrm{Mo} \mathrm{W} ; \mathbf{2 0 b}, \mathrm{R}={ }^{\mathrm{i}} \mathrm{Pr}, \mathrm{M}=\mathrm{Cr}$ ) in good yields. ${ }^{66-68}$ The $\mathrm{P}-\mathrm{Te}-\mathrm{P}$ bond angle in the four-membered $\mathrm{CrPTeP}$ ring of $\mathbf{2 0 a}(\mathrm{M}=\mathrm{Cr})$ is constrained to $81.4^{\circ}$ as a result of $P, P$-chelation (Figure 6). ${ }^{66}$ The ${ }^{1} J\left({ }^{31} \mathrm{P},{ }^{125} \mathrm{Te}\right.$ ) values for $\mathbf{1 8 a}$ and $\mathbf{1 8 c}$ are reduced substantially (by 127 and $177 \mathrm{~Hz}$, respectively) upon complexation to chromium (Table 1). Reactions of 18a with either $(\mathrm{PhCN})_{2} \mathrm{PtCl}_{2}$ in $\mathrm{CH}_{2} \mathrm{Cl}_{2}$ or $\mathrm{PtCl}_{2}$ in toluene produce $\left[\mathrm{Cl}_{2} \mathrm{Pt}\left\{\left(\mathrm{P}^{t} \mathrm{Bu}_{2}\right)_{2} \mathrm{Te}\right\}\right]$; the ${ }^{31} \mathrm{P} \mathrm{NMR}$ spectrum of this platinum(II) complex exhibits coupling constants of $J\left({ }^{195} \mathrm{Pt},{ }^{31} \mathrm{P}\right)=3282 \mathrm{~Hz}$ and $J\left({ }^{125} \mathrm{Te},{ }^{31} \mathrm{P}\right)=$ $325 \mathrm{~Hz}$, consistent with $P, P$-chelation of the ligand to platinum. ${ }^{69}$

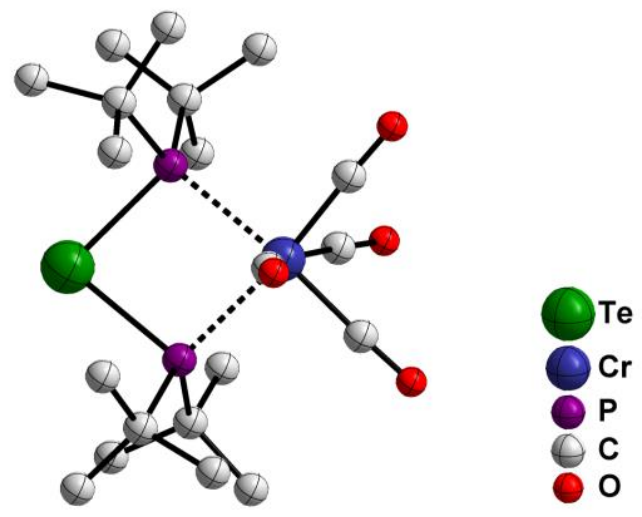

Figure 6. Molecular structure of $\left[(\mathrm{CO})_{4} \mathrm{Cr}\left\{\left(\mathrm{P}^{t} \mathrm{Bu}_{2}\right)_{2} \mathrm{Te}\right\}\right](\mathbf{2 0 a})$.

\subsection{Organophosphorus(III)-Tellurium Heterocycles}


Pioneering studies by the groups of du Mont and Kariaghiosoff disclosed several methods for the synthesis of organophosphorus(III)-tellurium heterocycles of the type $(\mathrm{RP})_{\mathrm{x}} \mathrm{Te}_{\mathrm{y}}$ and provided important information about the influence of the $\mathrm{R}$ substituent on the thermal stability of these labile pnictogen-chalcogen ring systems. The approaches employed by these investigators are summarized below:

(a) Cyclocondensation of ${ }^{\mathrm{t}} \mathrm{Bu}(\mathrm{Cl}) \mathrm{P}-\mathrm{P}(\mathrm{Cl})^{\mathrm{t}} \mathrm{Bu}$ with $\mathrm{Na}_{2} \mathrm{Te}^{31}$

(b) Insertion of tellurium into a $\mathrm{P}-\mathrm{Si}$ bond of ${ }^{\mathrm{t}} \mathrm{BuP}\left(\mathrm{SiMe}_{3}\right)_{2}{ }^{31,32}$

(c) Salt or $\mathrm{Me}_{3} \mathrm{SiCl}$ elimination from treatment of $\mathrm{RPCl}_{2}\left[\mathrm{R}={ }^{\mathrm{t}} \mathrm{Bu}, \mathrm{CF}_{3}, \mathrm{R}_{2}{ }_{2} \mathrm{~N}\left(\mathrm{R}^{\prime}={ }^{\mathrm{i}} \mathrm{Pr}, \mathrm{Cy}, \mathrm{Ph}\right)\right]$ with $\mathrm{Na}_{2} \mathrm{Te}, \mathrm{Li}_{2} \mathrm{Te}_{2}$ or $\mathrm{Te}\left(\mathrm{SiMe}_{3}\right)_{2}{ }^{31-34}$

The products were invariably obtained as mixtures of organophosphorus(III)-tellurium ring systems. However, in many cases, the components of these mixtures could be tentatively identified by solution-state NMR spectroscopy because the spin system for a particular ring size and/or composition, e.g. $(\mathrm{RP})_{\mathrm{x}} \mathrm{Te}(\mathrm{x}=2,3,4)$ and $(\mathrm{RP})_{\mathrm{x}} \mathrm{Te}_{2}(\mathrm{x}=3,4)$, gives rise to characteristic ${ }^{31} \mathrm{P}$ and ${ }^{125}$ Te NMR spectra, which can be simulated to afford spin-spin coupling constants. Derivatives in which the electronegative $\mathrm{CF}_{3}$ group is attached to phosphorus exhibit higher stability with respect to loss of tellurium in solution compared to analogs where $\mathrm{R}=$ alkyl, aryl or $\mathrm{NR}_{2}$. In one study the three-membered ring $\left({ }^{\mathrm{t}} \mathrm{BuP}\right)_{2} \mathrm{Te}$ (a tellurodiphosphirane) was isolated as a yellow oil after trap-totrap distillation under vacuum. ${ }^{31}$

In summary, detailed spectroscopic studies by the groups of du Mont and Karaghiosoff led to the identification of two classes of organophosphorus(III)-tellurium heterocycles: (a) three-, fourand five-membered rings containing one tellurium atom $(\mathrm{RP})_{\mathrm{x}} \mathrm{Te}(\mathrm{x}=2,3,4)$ and (b) five- and sixmembered rings containing two tellurium atoms $(\mathrm{RP})_{\mathrm{x}} \mathrm{Te}_{2}(\mathrm{x}=3,4)$ (Figure 7). ${ }^{31-34}$ In contrast to the known organophosphorus-sulfur and selenium ring systems, ${ }^{1-6}$ no evidence was found for 
heterocycles containing either a $\mathrm{Te}-\mathrm{Te}$ bond or a $\mathrm{P}=\mathrm{Te}$ functionality, i.e. a terminal (exo) tellurium atom.

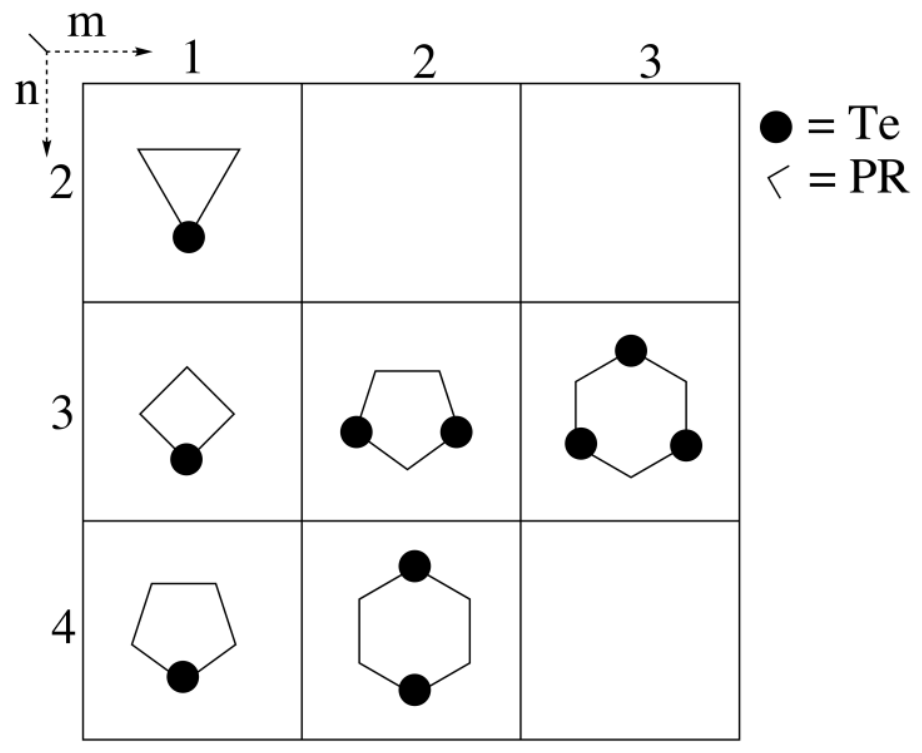

Figure 7. Organophosphorus(III)-tellurium heterocycles $\mathrm{Te}_{\mathrm{m}}(\mathrm{PR})_{\mathrm{n}}$ Adapted from ref. 14. Copyright 2014 Wiley-VCH Verlag GmbH \& Co. KGaA

Very recently, Nordheider et al. obtained solid-state structural confirmation of examples of 3-, 4-, and 5-membered rings $(\mathrm{RP})_{\mathrm{x}} \mathrm{Te}(\mathrm{x}=2,3,4)$ by employing very bulky substituents in the cyclocondensation reactions of $\mathrm{RPCl}_{2}$, e.g. $\mathrm{R}=\mathrm{Fc}$, Ad, Mes*O, Mes* and $\mathrm{CPh}_{3}$, with sodium ditelluride $\mathrm{Na}_{2} \mathrm{Te}_{2}$, which was found to be the most effective source of tellurium in these reactions. ${ }^{14}$ X-ray crystal structures were obtained for the telluradiphosphirane $(\mathrm{RP})_{2} \mathrm{Te}(\mathbf{2 1 a}, \mathrm{R}=$ OMes*), the telluratriphosphetane $(\mathrm{AdP})_{3} \mathrm{Te}(\mathbf{2 2})$, and the telluratetraphospholane $(\mathrm{FcP})_{4} \mathrm{Te}(\mathbf{2 3})$ (Figure 8a-c). In addition, the first example of a tritelluratriphosphorinane $(\operatorname{TrtP})_{3} \mathrm{Te}_{3}(\mathbf{2 4})$ was prepared and structurally characterized (Figure 8d). ${ }^{14}$ The dramatic increase in the P-Te-P bond angle with ring size for the heterocycles containing one tellurium atom, although expected, is particularly noteworthy: $54.1^{\circ}\left(\mathrm{Mes}^{*} \mathrm{OP}\right)_{2} \mathrm{Te}(\mathbf{2 1 a}) \ll 80.4^{\circ}(\mathrm{AdP})_{3} \mathrm{Te}(\mathbf{2 2}) \ll 104.9^{\circ}(\mathrm{FcP})_{4} \mathrm{Te}(\mathbf{2 3})$. The six-membered $\mathrm{P}_{3} \mathrm{Te}_{3}$ ring in $\mathbf{2 4}$ crystallizes in a chair conformation with $\mathrm{P}-\mathrm{Te}-\mathrm{P}$ bond angles in the range $80.9-82.5^{\circ}$ and Te-P-Te bond angles of $102.1-105.7^{\circ}$; by contrast, no examples of the 
$\mathrm{P}_{3} \mathrm{Se}_{3}$ ring have been reported. The $\mathrm{P}-\mathrm{Te}$ bond lengths and pertinent NMR data for 21-24 and related organophosphorus(III)-tellurium heterocycles are summarized in Table 1.

Three-membered $\mathrm{P}_{2}$ Te rings may also be generated by oxidation of a diphosphene $\mathrm{RP}=\mathrm{PR}$. Thus, Tokitoh et al. obtained the unsymmetrical telluradiphosphirane $(\mathrm{TbtP})(\mathrm{FcP}) \mathrm{Te}$ as an orange solid in $66 \%$ yield from reaction of $\mathrm{TeP}^{\mathrm{n}} \mathrm{Bu}_{3}$ with the corresponding diphosphene in hot benzene. Interestingly, this telluradiphosphirane exhibited markedly different $J\left({ }^{125} \mathrm{Te},{ }^{31} \mathrm{P}\right)$ values of 260 and $100 \mathrm{~Hz}$, indicative of a significant influence of the phosphorus substituent on this parameter, but the crystal structure was not reported. ${ }^{35}$ More recently, however, the same group prepared orange crystals of the symmetrical derivative $\left(\mathrm{Fc}^{*} \mathrm{P}\right)_{2} \mathrm{Te} \quad\left(\mathbf{2 1 b}, \quad \mathrm{Fc}^{*}=2,5\right.$-bis $(3,5$-di- $t$ butylphenyl)ferocenyl) by very slow oxidation of $\mathrm{Fc}^{*} \mathrm{P}=\mathrm{PFc}^{*}$ with elemental tellurium in benzene at $70{ }^{\circ} \mathrm{C}$ and determined the X-ray structure. ${ }^{70}$ The acute $\mathrm{P}-\mathrm{Te}-\mathrm{P}$ bond angle of $52.21(3)^{\circ}$ is similar to the value of $54.1^{\circ}$ found for $\mathbf{2 1 a} ;|d(\mathrm{P}-\mathrm{Te})|=2.506(1) \AA$ for $\mathbf{2 1 b}$, cf. $2.467 \AA$ in $21 \mathbf{a} .{ }^{14}$ The value of $J\left({ }^{125} \mathrm{Te},{ }^{31} \mathrm{P}\right)$ for $\mathbf{2 1 b}$ could not be determined owing to the very broad ${ }^{125} \mathrm{Te}$ NMR resonance.

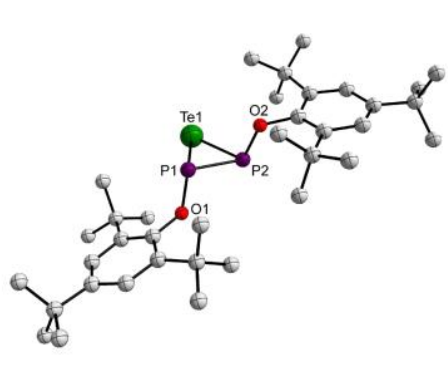

a) $21 a$

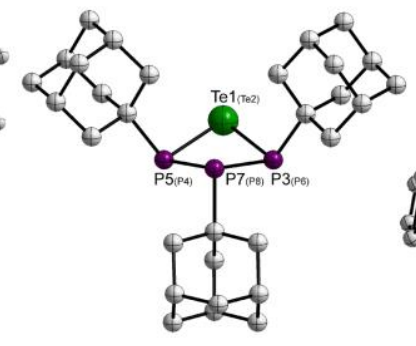

b) 22

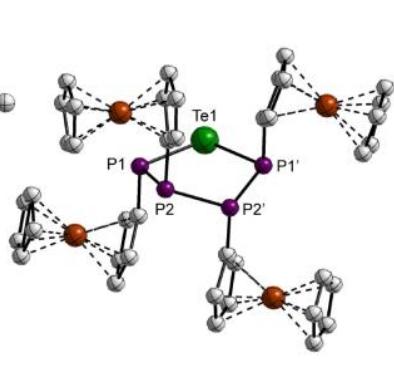

c) 23

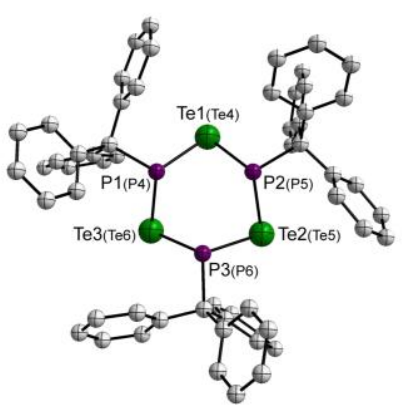

d) 24

Figure 8. Molecular structures of organophosphorus(III)-tellurium heterocycles (a) (Mes*OP) $)_{2} \mathrm{Te}$ (21a) (b) $(\mathrm{AdP})_{3} \mathrm{Te}(\mathbf{2 2})(\mathrm{c})(\mathrm{FcP})_{4} \mathrm{Te}(\mathbf{2 3})(\mathrm{d})(\mathrm{TrtP})_{3} \mathrm{Te}_{3}(\mathbf{2 4})$. Adapted from ref. 14. Copyright 2014 Wiley-VCH Verlag GmbH \& Co. KGaA 
Schulz and co-workers have recently described the slow reaction (14 days) of the intriguing biradicaloid $[\mathrm{P}(\mu \text {-NTer })]_{2}$ (Ter $=2,6$-bis(2,4,6-trimethylphenyl)phenyl) with elemental tellurium at $60{ }^{\circ} \mathrm{C}$ in THF to give dark green crystals of the tricyclic compound 25 in which a ditellurido (-TeTe-) unit bridges the $\mathrm{P}^{\mathrm{III}}{ }_{2} \mathrm{~N}_{2}$ ring (Scheme 9a). ${ }^{71}$ The steric strain in the five-membered $\mathrm{NP}_{2} \mathrm{Te}_{2}$ rings of 25 is evident from the long P-Te bonds (2.60-2.61 $\AA$, Table 1$)$. The tricyclic compounds 2 (Section 2) with a-Te-P $\mathrm{P}^{\mathrm{III}}(\mathrm{R})-\mathrm{Te}-$ linkage $\left(\mathrm{R}=\mathrm{Ad},{ }^{\mathrm{t}} \mathrm{Bu}\right)$ between the phosphorus atoms of a $\mathrm{P}_{2}^{\mathrm{V}} \mathrm{N}_{2}$ ring are obtained from metathesis between $\mathrm{RPCl}_{2}$ and the dianion $\left[{ }^{\mathrm{t}} \mathrm{BuN}(\mathrm{Te}) \mathrm{P}\left(\mu-\mathrm{N}^{\mathrm{t}} \mathrm{Bu}\right)\right]^{2-}(\mathrm{Scheme}$ $9 b$ ); they provide unique examples of the influence of the formal oxidation state of phosphorus on $J\left({ }^{125} \mathrm{Te},{ }^{31} \mathrm{P}\right)$ values in the same molecule (Section 2, Table 1). ${ }^{14}$

\section{Scheme 9. Synthesis of Tricyclic Phosphorus(III)-Tellurium compounds}

a)<smiles>[Al]n1p2n([Al-])p12</smiles>

b)

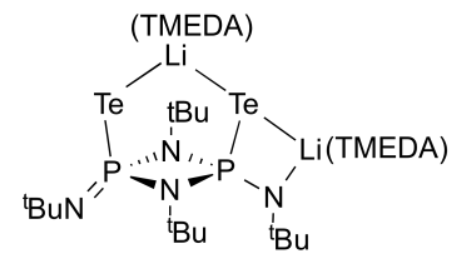

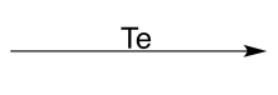

$\underset{-78{ }^{\circ} \mathrm{C}, \text { toluene }}{\stackrel{\mathrm{RPCl}}{2},-2 \mathrm{LiCl}}$

$\mathrm{R}=\mathrm{Ad}, \mathrm{tBu}^{\mathrm{B}}$

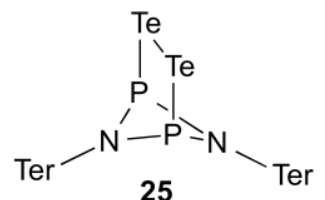

25

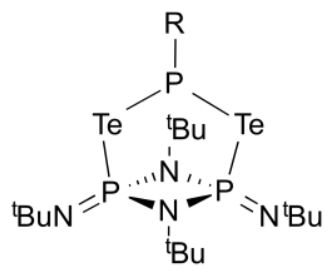

2

\subsection{Weak Phosphorus(III) $\cdots$ Tellurium Interactions}

A series of peri-substituted phosphorus-tellurium systems $\mathrm{R}^{\prime} \mathrm{Te}-\mathrm{Acenap}-\mathrm{PR}_{2}\left(\mathrm{R}^{\prime}=\mathrm{Ph}, p\right.$ An, Nap, Mes, Tip; $\mathrm{R}={ }^{\mathrm{i}} \mathrm{Pr}, \mathrm{Ph}$ ) exhibiting large "through space" spin-spin coupling constants $\left(J\left({ }^{31} \mathrm{P},{ }^{125} \mathrm{Te}\right)=1210-1360 \mathrm{~Hz}\right)$ have recently been described. ${ }^{18}$ These peri-substituted phosphorustellurium systems were prepared by the addition of organotellurium monohalides to lithiated $\mathrm{R}_{2} \mathrm{P}-$ Acenap-Li systems (Scheme 10). These compounds have P...Te separations in the range 3.094$3.205 \AA$ (Figure 9, Table 2), cf. sum of the van der Waals radii of the phosphorus and tellurium atoms is $3.86 \AA \AA^{25} 4.12 \AA^{26}$ or $4.40 \AA{ }^{27}$ The magnitudes of the $J\left({ }^{31} \mathrm{P},{ }^{125} \mathrm{Te}\right)$ and $J\left({ }^{31} \mathrm{P},{ }^{123} \mathrm{Te}\right)$ cannot 
be explained by through bond spin-spin coupling constants since couplings through five and six bonds are not expected to give such high values. The observed "through-space" spin-spin coupling was rationalized by an overlap of lone pair orbitals and not a $\operatorname{lp}(\mathrm{X}) \rightarrow \sigma^{*}(\mathrm{Y}-\mathrm{Z})$ donor-acceptor interaction. The species can be described as demonstrating the "onset" of three-centre four-electron type interactions. Oxidation of the phosphorus atoms by sulfur and selenium resulted in a disappearance of the strong $\mathrm{P}-\mathrm{Te}$ coupling as lone pair orbitals are no longer available for the interaction with those of the tellurium atom.

Scheme 10. Syntheses of Peri-substituted Phosphorus(III)-Tellurium Compounds

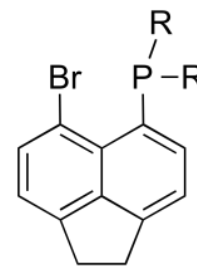

$\underset{\text { 1) }{ }^{\mathrm{n} B u L i}, \mathrm{THF},-78^{\circ} \mathrm{C}}{\stackrel{\text { 2) } \mathrm{R}^{\prime} \mathrm{Tel}, \mathrm{THF},-78^{\circ} \mathrm{C}}{\longrightarrow}}$

$\mathrm{R}={ }^{\mathrm{i}} \mathrm{Pr} ; \mathrm{R}$ ' = Ph (26a), $p$-An

$\mathrm{R}=\mathrm{Ph} ; \mathrm{R}^{\prime}=\operatorname{Mes}(\mathbf{2 7})$

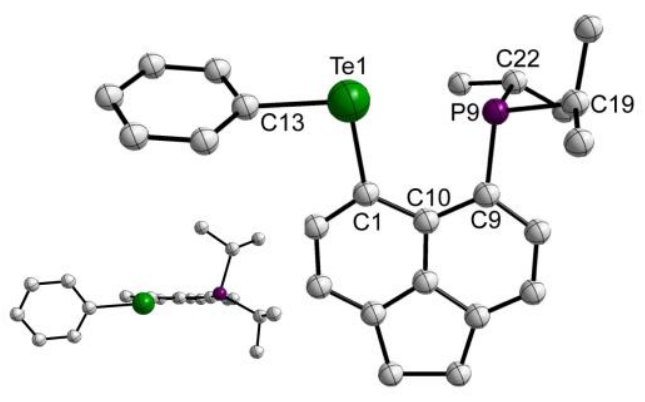

26a

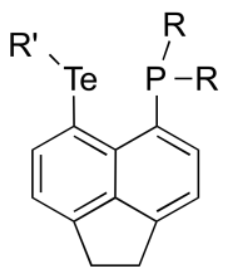

(26b), Nap (26c), Mes (26d), Tip (26e)

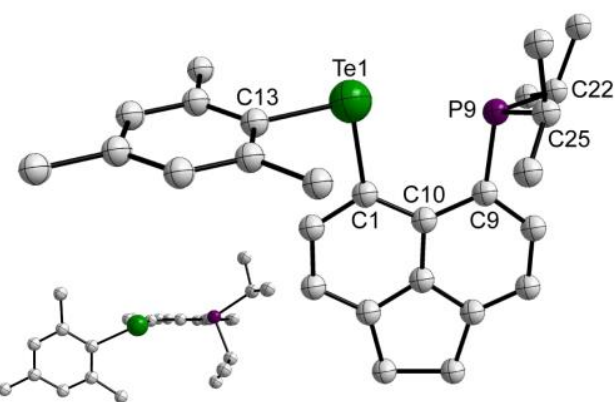

$26 e$

Figure 9. Molecular structures of typical peri-substituted phosphorus(III)-tellurium compounds 26a and 26e. Adapted from ref. 18. Copyright 2015 American Chemical Society.

Table 2. Bond Lengths and NMR Data for peri-Substituted Phosphorus-Tellurium Compounds. ${ }^{18}$

\begin{tabular}{llll}
\hline Compound & $d(\mathrm{P} \cdots \mathrm{Te})[\AA]$ & $\delta^{125} \mathrm{Te}[\mathrm{ppm}]$ & $J\left({ }^{31} \mathrm{P},{ }^{125 / 123} \mathrm{Te}\right)[\mathrm{Hz}]^{a}$ \\
\hline
\end{tabular}




\begin{tabular}{cccc}
\hline $\mathbf{2 6 a}$ & 3.131 & 597.4 & $1306 / 1084$ \\
$\mathbf{2 6 b}$ & 3.090 & 580.9 & $1323 / 1096$ \\
& & & \\
$\mathbf{2 6 c}$ & 3.108 & 483.9 & $1349 / 1119$ \\
$\mathbf{2 6 d}$ & 3.205 & 372.2 & $1332 / 1105$ \\
$\mathbf{2 6 e}$ & 3.181 & 410.8 & $1213 / 1006$ \\
$\mathbf{2 7}$ & 3.094 & 320.9 & $1357 / 1127$
\end{tabular}

${ }^{a}$ Experimental coupling constants are given as absolute values (magnitude only), but calculated values are negative

\section{ORGANOPHOSPHORUS(V) TELLURIDES}

Triorganophosphine $(\mathrm{V})$ tellurides (tellurophosphoranes) $\mathrm{R}_{3} \mathrm{PTe}$ are quintessential $\mathrm{P}-\mathrm{Te}$ compounds in view of their (a) prominent position in the historical development of phosphorustellurium chemistry, (b) wide use as tellurium-transfer reagents in a variety of applications, and (c) role as models for understanding the nature of the $\mathrm{P}^{\mathrm{V}}=\mathrm{Te}$ bond. This section will begin with a discussion of the synthesis, spectroscopic properties, and the molecular and electronic structures of $\mathrm{R}_{3} \mathrm{PTe}$ derivatives as well as related compounds with terminal $\mathrm{P}=\mathrm{Te}$ functionalities. There follows a description of their redox behavior, coordination complexes and applications as a reactive source of tellurium. A comprehensive account of early work (up to 1996) on the chemistry of phosphine tellurides has been published. ${ }^{72}$

\subsection{Synthesis and Spectroscopic Characterization}

Zingaro pioneered the field of organophosphorus(V)-tellurium chemistry more than 50 years ago with the synthesis of ${ }^{n} \mathrm{Bu}_{3} \mathrm{PTe}$ by oxidation of ${ }^{\mathrm{n}} \mathrm{Bu}_{3} \mathrm{P}$ with elemental tellurium in boiling toluene. ${ }^{10}$ Shortly thereafter, a wide variety of derivatives $\mathrm{RR}_{2}^{\prime} \mathrm{PTe}\left(\mathrm{R}=\mathrm{R}^{\prime}=\mathrm{Et},{ }^{\mathrm{n}} \mathrm{Pr}, \mathrm{Cy} ; \mathrm{R}=\mathrm{Ph}, \mathrm{R}^{\prime}\right.$ 
$\left.={ }^{\mathrm{n}} \mathrm{Pr},{ }^{\mathrm{n}} \mathrm{Bu}\right),{ }^{11}$ as well as $\mathrm{Me}_{3} \mathrm{PTe},{ }^{73}$ were prepared in a similar manner. These phosphine tellurides were isolated as air, light and thermally sensitive pale yellow solids, which readily deposit grey elemental Te in solution. The derivatives $\mathrm{R}_{3} \mathrm{PTe}\left(\mathrm{R}=\mathrm{Cy},{ }^{74}{ }^{\mathrm{t}} \mathrm{Bu}^{75}\right)$, which are obtained in essentially quantitative yields by oxidation of $\mathrm{R}_{3} \mathrm{P}$ with grey tellurium at room temperature, are thermally stable both in the solid state and in solutions. ${ }^{75}$

The oxidation of the $\mathrm{P}^{\mathrm{III}}$ center in $\mathrm{R}_{3} \mathrm{P}$ becomes more difficult with the introduction of $\mathrm{Ph}$ substituents and, consequently, yields are low for $\mathrm{PhR}_{2}^{\prime} \mathrm{PTe}\left(\mathrm{R}^{\prime}={ }^{\mathrm{n}} \mathrm{Pr},{ }^{\mathrm{n}} \mathrm{Bu}\right) .{ }^{11} \mathrm{~A}$ recent manifestation of this influence is provided by the synthesis of the bis(phosphine tellurides) $\mathrm{Ph}_{2} \mathrm{P}(\mathrm{Te})\left(\mathrm{CH}_{2}\right)_{\mathrm{n}} \mathrm{P}(\mathrm{Te}) \mathrm{Ph}_{2}(\mathrm{n}=2,6)$ and the monotelluride $\mathrm{Ph}_{2} \mathrm{P}(\mathrm{Te})\left(\mathrm{CH}_{2}\right)_{4} \mathrm{PPh}_{2}$ in isolated yields of only $6 \% ;^{76}$ similarly, the yield of $\mathrm{Ph}_{2} \mathrm{MePTe}$ from the reaction of $\mathrm{Ph}_{2} \mathrm{MeP}$ and $\mathrm{Te}_{\infty}$ in $\mathrm{THF}$ is estimated to be ca. $6 \%$ according to ${ }^{31} \mathrm{P}$ NMR spectra. ${ }^{77}$ By contrast, the alkyl-substituted analogue $\mathrm{Me}_{2} \mathrm{P}(\mathrm{Te})\left(\mathrm{CH}_{2}\right)_{2} \mathrm{P}(\mathrm{Te}) \mathrm{Me}_{2}$ was obtained in $51 \%$ yield ${ }^{78}$ and the monotelluride ${ }^{\mathrm{i}} \mathrm{Pr}_{2} \mathrm{PCH}_{2} \mathrm{P}(\mathrm{Te}){ }^{\mathrm{i}} \mathrm{Pr}_{2}$ is isolated in $98 \%$ yield from the direct oxidation of the appropriate $\mathrm{P}^{\mathrm{III}} / \mathrm{P}^{\mathrm{III}}$ precursor with elemental tellurium. ${ }^{79}$ Elemental tellurium does not oxidize $\mathrm{Ph}_{3} \mathrm{P}$, but the use of a more reactive source of Te in the form of the tellurocyanate $\left[\mathrm{Ph}_{4} \mathrm{As}\right][\mathrm{TeCN}]$ generates a 1:1 adduct of $\mathrm{Ph}_{3} \mathrm{PTe}$ with $\mathrm{Ph}_{3} \mathrm{P}$ (Section 6.3). ${ }^{80}$

The introduction of an imino substituent increases the nucleophilicity of the phosphorus center, as first demonstrated by Nöth and Mardersteig in the high-yield synthesis of $\mathrm{Ph}_{3} \mathrm{P}=\mathrm{NP}(\mathrm{Te}) \mathrm{Ph}_{2} .{ }^{81}$ Secondary amino substituents, especially those derived from cyclic secondary amines, have an even more dramatic effect on the rate of the reaction of phosphines with elemental tellurium. Thus, reaction times are reduced to a few hours at ca. $50{ }^{\circ} \mathrm{C}$ in benzene or cyclohexane for the synthesis of $\left(\mathrm{R}_{2} \mathrm{~N}\right)_{3} \mathrm{PTe}\left(\mathrm{R}=\mathrm{Me},{ }^{41,82,83} \mathrm{Et},{ }^{84} \mathrm{R}_{2} \mathrm{~N}=\right.$ morpholino, piperidino, pyrrolidino $\left.{ }^{40,85}\right)$. The latter are readily crystallized (Section 6.2) and exhibit enhanced thermal and air stability compared to their trialkyl analogs. The mixed alkyl/dialkylamino derivative $\operatorname{Me}\left(\mathrm{Et}_{2} \mathrm{~N}\right)_{2} \mathrm{PTe}$ and the related bifunctional compound $\left(\mathrm{Et}_{2} \mathrm{~N}\right)_{2} \mathrm{P}(\mathrm{Te})\left(\mathrm{CH}_{2}\right)_{4} \mathrm{P}(\mathrm{Te})\left(\mathrm{NEt}_{2}\right)_{2}$ have also been prepared. ${ }^{86}$ 
Another compelling example of the influence of phenyl substituents on the reactivity of $\mathrm{P}^{\mathrm{III}}$ centers towards tellurium is provided by imidobis(phosphines) $\mathrm{HN}\left(\mathrm{PR}_{2}\right)_{2}$. Although the $\mathrm{R}=\mathrm{Ph}$ derivative is unreactive towards $\mathrm{Te}_{\infty}$, treatment of $\mathrm{HN}\left(\mathrm{P}^{\mathrm{i}} \mathrm{Pr}_{2}\right)_{2}$ with tellurium in n-hexane at $23{ }^{\circ} \mathrm{C}$ produces the monotelluride $\mathrm{HP}^{\mathrm{i}} \mathrm{Pr}_{2} \mathrm{~N}^{\mathrm{i}} \mathrm{Pr}_{2} \mathrm{PTe}(\mathbf{2 8})$ in $87 \%$ yield. ${ }^{30}$ An X-ray structural determination revealed that $\mathbf{2 8}$ exists as the $\mathrm{P}-\mathrm{H}$ tautomer in the solid state (Figure 10a); that isomer is also preferred in solution, as demonstrated by the observation of a doublet characteristic of a $\mathrm{P}-\mathrm{H}$ functionality $\left({ }^{1} J\left({ }^{31} \mathrm{P},{ }^{1} \mathrm{H}\right)=400 \mathrm{~Hz}\right)$ in the ${ }^{31} \mathrm{P}$ NMR spectrum. The air oxidation of a pale yellow solution of 28 produces small amounts of the unusual ditelluride $\left[\mathrm{TeP}^{\mathrm{i}} \mathrm{Pr}_{2} \mathrm{~N}^{\mathrm{i}} \mathrm{Pr}_{2} \mathrm{PTe}-\right]_{2}$ (1) (Figure 10b), which incorporates two types of $\mathrm{P}(\mathrm{V})-\mathrm{Te}$ bonds (terminal and bridging) with distances that differ by $0.1 \AA$ and ${ }^{1} J\left({ }^{31} \mathrm{P},{ }^{125} \mathrm{Te}\right)$ values of 1500 and $1026 \mathrm{~Hz} ;{ }^{30}$ the dimer $\mathbf{1}$ is preferably prepared (in $87 \%$ yield) by one-electron oxidation of the corresponding anion with iodine (Section 7.3.2). ${ }^{30}$

a)

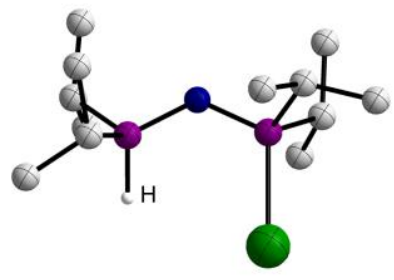

28 b)

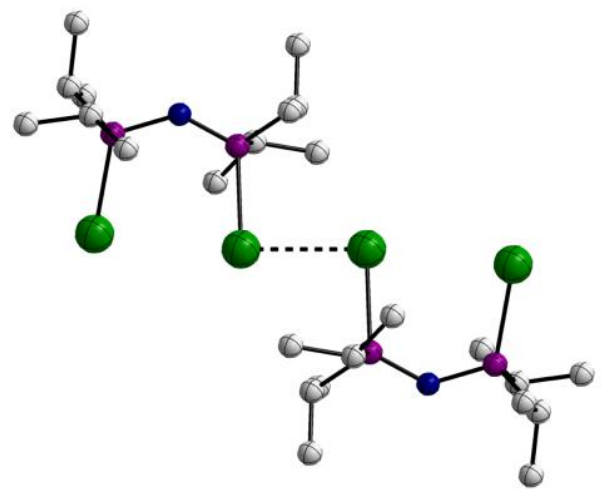

1

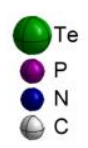

Figure 10. Molecular structures of (a) $\mathrm{HP}^{\mathrm{i}} \operatorname{Pr}_{2} \mathrm{~N}^{\mathrm{i}} \operatorname{Pr}_{2} \mathrm{PTe}(\mathbf{2 8})$ and (b) $\left[\mathrm{TeP}^{\mathrm{i}} \operatorname{Pr}_{2} \mathrm{~N}^{\mathrm{i}} \operatorname{Pr}_{2} \mathrm{PTe}-\right]_{2}$ (1)

The influence of nitrogen substituents on the ease of formation and stability of the terminal $\mathrm{P}=$ Te functionality is also manifested in derivatives based on a cyclodiphosphazane, i.e. a saturated four-membered $\mathrm{P}_{2} \mathrm{~N}_{2}$ ring. Scherer and Schnabl showed that $\left[\mathrm{MeP}^{\mathrm{III}}\left(\mu-\mathrm{N}^{\mathrm{t} B u}\right)\right]_{2}$ is oxidized by elemental tellurium in benzene at room temperature $(48 \mathrm{~h})$ to give the ditelluride $c i s-\left[\mathrm{MeP}^{\mathrm{V}}(\mathrm{Te})(\mu\right.$ $\mathrm{N}^{\mathrm{t}} \mathrm{Bu}$ )] in $8 \%$ yield; under similar conditions only the monotelluride was obtained from the unsymmetrical $\mathrm{P}^{\mathrm{III}} / \mathrm{P}^{\mathrm{III}}$ derivative $\left[\mathrm{MeP}^{\mathrm{III}}\left(\mu-\mathrm{N}^{\mathrm{t}} \mathrm{Bu}\right)_{2} \mathrm{P}^{\mathrm{III}} \mathrm{Cl}\right]$ and tellurium. ${ }^{87}$ Keat and Thompson 
prepared the monotelluride $\left[\mathrm{Me}_{2} \mathrm{NP}^{\mathrm{III}}\left(\mu-\mathrm{N}^{\mathrm{t}} \mathrm{Bu}\right)_{2} \mathrm{P}^{\mathrm{V}}(\mathrm{Te}) \mathrm{NMe}_{2}\right]$ in a similar manner. ${ }^{88}$ The tellurides based on a cyclo- $\mathrm{P}_{2} \mathrm{~N}_{2}$ framework are stable both in the solid state and in solutions.

The Mössbauer spectra of $\mathrm{R}_{3} \mathrm{PTe}$ compounds have been interpreted to indicate significant $s$ character in the $\mathrm{P}-\mathrm{Te}$ bond. $^{29}$ The yellow color of tris(dialkylamino)phosphine tellurides is attributed to a UV absorption band with a maximum at $280-290 \mathrm{~cm}^{-1}$ and a tail in the visible region. ${ }^{40}$ The IR spectra of $\mathrm{R}_{3} \mathrm{PTe}$ compounds are discussed in Section 2.

\subsection{NMR Spectra and Phosphorus-Tellurium Exchange}

The ${ }^{31} \mathrm{P}$ NMR spectra of organophosphorus(V) tellurides exhibit singlets accompanied by ${ }^{125} \mathrm{Te}$ (and ${ }^{123} \mathrm{Te}$ ) satellites (Section 2) and the ${ }^{125} \mathrm{Te}$ NMR spectra display doublets as a result of ${ }^{31} \mathrm{P}-{ }^{125} \mathrm{Te}$ coupling. Pertinent NMR data and phosphorus-tellurium bond distances for phosphine tellurides and related compounds with terminal $\mathrm{P}=\mathrm{Te}$ functionalities are summarized in Table 3; these data provide a yardstick for subsequent discussion of organophosphorus(V)-tellurium compounds. The ${ }^{125}$ Te NMR spectra exhibit substantial negative shifts ( -492 to $-837 \mathrm{ppm}$ ) with reference to $\mathrm{Me}_{2} \mathrm{Te}$ indicating considerable shielding at the Te nucleus. ${ }^{29}$ The ${ }^{1} J\left({ }^{31} \mathrm{P},{ }^{125} \mathrm{Te}\right)$ coupling constants fall within the range $1500-2290 \mathrm{~Hz}$; higher values are associated with derivatives in which imino or amino substituents are attached to phosphorus. The highest reported value of $2290 \mathrm{~Hz}$ is found for the unsymmetrical derivative $\mathrm{TeP}(\mathrm{OEt})\left(\mathrm{NEt}_{2}\right)_{2}$, cf. $1964 \mathrm{~Hz}$ for $\mathrm{TeP}(\mathrm{OEt}) \mathrm{Et}_{2} .{ }^{84}$

From the entries in Table 3 it is evident that this coupling is not observed in some cases owing to rapid phosphorus-tellurium exchange, which may involve $\mathrm{P}^{\mathrm{III}}$ centers of unreacted phosphine. Indeed, the addition of an excess of the appropriate phosphine $\mathrm{R}_{3} \mathrm{P}$ to a solution of $\mathrm{R}_{3} \mathrm{PTe}$ results in the collapse of the well-resolved doublet. ${ }^{29,75} \mathrm{~A}$ manifestation of this process is the acceleration of the UV photolysis of ditellurides RTeTeR (to give $\mathrm{R}_{2} \mathrm{Te}$ and $\mathrm{Te}$ ) by tertiary phosphines, e.g. $\mathrm{Ph}_{2} \mathrm{MeP}$, which occurs via an $\mathrm{Ph}_{2} \mathrm{MePTe}$ intermediate. ${ }^{89}$ In early studies, du Mont 
and Kroth proposed that this exchange involves linear intermediates of the type $\mathrm{R}_{3} \mathrm{P} \cdots \mathrm{Te} \cdots \mathrm{PR}_{3},{ }^{90}$ similar to that observed in the solid state for the adduct $\mathrm{Ph}_{3} \mathrm{P}=\mathrm{Te} \cdots \mathrm{PPh}_{3}\left(\right.$ Section 6.3). ${ }^{80}$

Table 3. Bond Lengths and NMR Data for Compounds with Terminal P=Te Linkages

\begin{tabular}{|c|c|c|c|c|}
\hline P-Te Compound & $d(\mathrm{P}-\mathrm{Te})(\AA)$ & ${ }^{1} J\left({ }^{31} \mathrm{P},{ }^{125} \mathrm{Te}\right)(\mathrm{Hz})^{a}$ & $\delta^{125} \mathrm{Te}(\mathrm{ppm})^{b}$ & Ref. \\
\hline Organophosphorus $(V)$ Tellurides & & & & \\
\hline${ }^{\mathrm{B}} \mathrm{Bu}_{3} \mathrm{PTe}$ & $2.368(4)$ & 1663 & $-836.5(\mathrm{~d})$ & 29 \\
\hline${ }^{n} \mathrm{Bu}_{3} \mathrm{PTe}$ & $2.368(1)$ & 1730,1732 & $-807(\mathrm{~d}),-803(\mathrm{~d})$ & 29,52 \\
\hline${ }^{\mathrm{i}} \mathrm{Pr}_{3} \mathrm{PTe}$ & $2.363(1)$ & 1735 & $-1000(d)$ & 52 \\
\hline $\mathrm{Et}_{3} \mathrm{PTe}$ & $c$ & 1743 & $-875(\mathrm{~d})$ & 52 \\
\hline $\mathrm{Cy}_{3} \mathrm{PTe}$ & $2.3632(7)$ & $c$ & $c$ & 74 \\
\hline $\mathrm{Ph}_{3} \mathrm{P}=\mathrm{Te} \cdots \mathrm{PPh}_{3}$ & $\begin{array}{l}2.270-2.424 \\
3.376-3.948\end{array}$ & $d$ & -491.8 & 29,80 \\
\hline${ }^{\mathrm{t}} \mathrm{Bu}_{2} \mathrm{P}(\mathrm{Te}) \mathrm{NHCy}$ & $2.371(1)$ & $c$ & $c$ & 95 \\
\hline $\mathrm{Me}_{2} \mathrm{P}(\mathrm{Te})\left(\mathrm{CH}_{2}\right)_{2} \mathrm{P}(\mathrm{Te}) \mathrm{Me}_{2}$ & $2.357(2)$ & $d$ & $d$ & 78 \\
\hline $\mathrm{Ph}_{2} \mathrm{P}(\mathrm{Te})\left(\mathrm{CH}_{2}\right)_{2} \mathrm{P}(\mathrm{Te}) \mathrm{Ph}_{2}$ & $2.363(1)$ & $d$ & $-653(\mathrm{~s})$ & 76 \\
\hline $\mathrm{Ph}_{2} \mathrm{P}(\mathrm{Te})\left(\mathrm{CH}_{2}\right)_{4} \mathrm{PPh}_{2}$ & $\begin{array}{l}2.349(1) \\
2.242(1)\end{array}$ & $d$ & $-636.5(\mathrm{~s})$ & 76 \\
\hline $\mathrm{Ph}_{2} \mathrm{P}(\mathrm{Te})\left(\mathrm{CH}_{2}\right)_{6} \mathrm{P}(\mathrm{Te}) \mathrm{Ph}_{2}$ & $\begin{array}{l}2.365(1) \\
2.377(1)\end{array}$ & $d$ & $-641.4(\mathrm{~s})$ & 76 \\
\hline${ }^{\mathrm{i}} \mathrm{Pr}_{2} \mathrm{PCH}_{2} \mathrm{P}(\mathrm{Te}){ }^{\mathrm{i}} \mathrm{Pr}_{2}$ & $2.360(1)$ & 1735 & $-940.3(d)$ & 79 \\
\hline $\mathrm{TeP}^{\mathrm{i}} \mathrm{Pr}_{2} \mathrm{NP}(\mathrm{H}){ }^{\mathrm{i}} \mathrm{Pr}_{2}$ & $2.380(1)$ & 1642 & $-846(\mathrm{dd})$ & 30 \\
\hline $\mathrm{TeP}^{\mathrm{i}} \mathrm{Pr}_{2} \mathrm{NP}(\mathrm{I}){ }^{\mathrm{i}} \mathrm{Pr}_{2}$ & $2.378(1)$ & 1758 & $-723(d)$ & 106 \\
\hline $\mathrm{TeP}^{t} \mathrm{Bu} \mathrm{u}_{2} \mathrm{NP}(\mathrm{I})^{t} \mathrm{Bu}_{2}$ & $2.401(1)$ & 1750 & $-596(d)$ & 106 \\
\hline$\left[\mathrm{TeP}^{\mathrm{i}} \mathrm{Pr}_{2} \mathrm{~N}^{\mathrm{i}} \mathrm{Pr}_{2} \mathrm{PTe}-\right]_{2}$ & $2.394(2)$ & 1500 & $d$ & 30 \\
\hline
\end{tabular}




\begin{tabular}{|c|c|c|c|c|}
\hline & $2.489(2)$ & 1026 & & \\
\hline \multirow[t]{2}{*}{$\left(\mathrm{Me}_{2} \mathrm{~N}\right)_{3} \mathrm{PTe}$} & $c$ & 2095,2105 & $-822(\mathrm{~d}),-826(\mathrm{~d})$ & 29,52 \\
\hline & & 2045(1709) & $d$ & 82 \\
\hline$\left[\mathrm{O}\left(\mathrm{CH}_{2} \mathrm{CH}_{2}\right)_{2} \mathrm{~N}\right]_{3} \mathrm{PTe}$ & $2.357(1)$ & 2153 & $-813(\mathrm{~d})$ & 29,52 \\
\hline$\left[\left(\mathrm{CH}_{2} \mathrm{CH}_{2}\right)_{2} \mathrm{~N}\right]_{3} \mathrm{PTe}$ & $2.355(3)$ & $c$ & $d$ & 85 \\
\hline$\left({ }^{t} \mathrm{Bu}_{2} \mathrm{Im}=\mathrm{N}\right) \mathrm{Ph}_{2} \mathrm{PTe}^{e}$ & 2.372(2) & 2245 & $c$ & 98 \\
\hline \multicolumn{5}{|l|}{ Cyclo- $P_{2} \underline{N}_{2}$ Derivatives } \\
\hline$\left.{ }_{[}^{\mathrm{t}} \mathrm{Bu}(\mathrm{H}) \mathrm{N}(\mathrm{Te}) \mathrm{P}^{\mathrm{V}}\left(\mu-\mathrm{N}^{\mathrm{t}} \mathrm{Bu}\right)_{2} \mathrm{P}^{\mathrm{III}} \mathrm{N}(\mathrm{H})^{\mathrm{t}} \mathrm{Bu}\right]$ & $2.370(1)$ & 2010 & $-188(\mathrm{~d})$ & 105 \\
\hline $\operatorname{Mg}\left[{ }^{t} \mathrm{BuN}(\mathrm{Te}) \mathrm{P}^{\mathrm{V}}\left(\mu-\mathrm{N}^{t} \mathrm{Bu}\right)_{2} \mathrm{P}^{\mathrm{III}} \mathrm{N}^{t} \mathrm{Bu}\right]$ & $2.385(3)$ & 1851 & $-137(\mathrm{~d})$ & 105 \\
\hline${ }^{\mathrm{t}} \mathrm{BuP} \mathrm{P}^{\mathrm{III}}(\mu-\mathrm{NMe})_{2} \mathrm{P}^{\mathrm{V}}(\mathrm{Te})^{\mathrm{t}} \mathrm{Bu}$ & $2.354(7)$ & $d$ & $d$ & 107 \\
\hline Cis- $\left[{ }^{[} \mathrm{BuP}(\mathrm{Te})(\mu-\mathrm{NMe})\right]_{2}$ & $2.288(5)$ & $c$ & $c$ & 96 \\
\hline & $2.322(5)$ & & & \\
\hline Trans $-\left[{ }^{\mathrm{t}} \mathrm{BuP}(\mathrm{Te})(\mu-\mathrm{NMe})\right]_{2}$ & $2.327(2)$ & $c$ & $c$ & 96 \\
\hline \multicolumn{5}{|l|}{ Metal Complexes } \\
\hline $\mathrm{W}(\mathrm{CO})_{5}\left(\mathrm{TeP}^{\mathrm{t}} \mathrm{Bu}_{3}\right)$ & $2.439(2)$ & 1600 & $-770(\mathrm{~d})$ & 99 \\
\hline $\mathrm{Cr}(\mathrm{CO})_{5}\left(\mathrm{TeP}^{\mathrm{t}} \mathrm{Bu}_{3}\right)$ & $c$ & 1502 & $-635(\mathrm{~d})$ & 99 \\
\hline $\mathrm{Mo}(\mathrm{CO})_{5}\left(\mathrm{TeP}^{t} \mathrm{Bu}_{3}\right)$ & $c$ & 1602 & $-749(\mathrm{~d})$ & 99 \\
\hline$\left[\mathrm{FeCp}(\mathrm{CO})_{2}\left(\mathrm{TePMe}_{3}\right)\right] \mathrm{BF}_{4}$ & $c$ & 1333 & $-462.6(d)$ & 100 \\
\hline$\left[\mathrm{FeCp}(\mathrm{CO})_{2}\left(\mathrm{TeP}^{\mathrm{i}} \mathrm{Pr}_{3}\right)\right] \mathrm{BF}_{4}$ & $c$ & 1410 & $-781.8(\mathrm{~d})$ & 100 \\
\hline$\left[\mathrm{FeCp}(\mathrm{CO})_{2}\left(\mathrm{TeP}^{\mathrm{t}} \mathrm{Bu}_{3}\right)\right] \mathrm{BF}_{4}$ & $c$ & 1480 & $-531.9(\mathrm{~d})$ & 100 \\
\hline$\left[\mathrm{FeCp}(\mathrm{CO})_{2}\left\{\mathrm{TeP}\left(\mathrm{NMe}_{2}\right)_{3}\right\}\right] \mathrm{BF}_{4}$ & $c$ & 2086 & -825.8 & 100 \\
\hline$\left[\mathrm{Ag}_{2}\left(\mathrm{NMs}_{2}\right)_{2}\left({ }^{i} \mathrm{Pr}_{3} \mathrm{PTe}\right)_{2}\right]$ & $2.40-2.43$ & $1419(1176)$ & $c$ & 103 \\
\hline$\left[\mathrm{Ag}_{2}\left(\mathrm{NMs}_{2}\right)\left({ }^{(} \mathrm{Pr}_{3} \mathrm{PTe}\right)_{4}\right]\left[\mathrm{NMs}_{2}\right] \cdot \mathrm{MeCN}$ & $2.40-2.43$ & $1452(1204)$ & $c$ & 103 \\
\hline
\end{tabular}




\begin{tabular}{|c|c|c|c|c|}
\hline$\left[\mathrm{Ag}_{2}\left({ }^{\mathrm{i}} \mathrm{Pr}_{3} \mathrm{PTe}\right)_{2}\right]\left[\mathrm{SbF}_{6}\right]$ & $2.40-2.43$ & 1435 & $c$ & 103 \\
\hline $\mathrm{Cd}\left[{ }^{\mathrm{n}} \mathrm{Bu}_{3} \mathrm{PTe}\right]_{4}\left(\mathrm{ClO}_{4}\right)_{2}$ & $c$ & 1317 & $-715(d)$ & 102 \\
\hline $\mathrm{Cd}\left[\left(\mathrm{Me}_{2} \mathrm{~N}\right)_{3} \mathrm{PTe}\right]_{4}\left(\mathrm{ClO}_{4}\right)_{2}$ & $c$ & 1674 & $-630(d)$ & 102 \\
\hline $\mathrm{Cd}\left[\mathrm{Pip}_{3} \mathrm{PTe}\right]_{4}\left(\mathrm{ClO}_{4}\right)_{2}^{f}$ & $c$ & 1710 & $-550(d)$ & 102 \\
\hline $\mathrm{Cd}\left[\mathrm{Pyrr}_{3} \mathrm{PTe}\right]_{4}\left(\mathrm{ClO}_{4}\right)_{2}{ }^{f}$ & $c$ & 1632 & $-594(d)$ & 102 \\
\hline $\mathrm{CdCl}_{2}\left[{ }^{\mathrm{n}} \mathrm{Bu}_{3} \mathrm{PTe}\right]_{2}$ & $c$ & 1287 & $-720(d)$ & 102 \\
\hline $\mathrm{CdCl}_{2}\left[\left(\mathrm{Me}_{2} \mathrm{~N}\right)_{3} \mathrm{PTe}\right]_{2}$ & $c$ & 1617 & $-728(d)$ & 102 \\
\hline $\mathrm{CdCl}_{2}\left[\mathrm{Pip}_{3} \mathrm{PTe}\right]_{2}^{f}$ & $c$ & 1587 & $-782(d)$ & 102 \\
\hline $\mathrm{CdCl}_{2}\left[\mathrm{Pyrr}_{3} \mathrm{PTe}\right]_{2}^{f}$ & $c$ & 1580 & $-665(d)$ & 102 \\
\hline \multicolumn{5}{|l|}{$\underline{\text { Dihalides }}$} \\
\hline $\mathrm{Et}_{3} \mathrm{PTeCl}_{2}$ & $2.466(1)$ & $1390(1152)$ & $+766(d)$ & 97 \\
\hline $\mathrm{Et}_{3} \mathrm{PTeBr}_{2}$ & $2.473(1)$ & $1315(1091)$ & $+627(d)$ & 97 \\
\hline $\mathrm{Et}_{3} \mathrm{PTeI}_{2}$ & $2.490(1)$ & $1251(1038)$ & $+331(\mathrm{~d})$ & 97 \\
\hline
\end{tabular}

${ }^{a}$ Coupling constants are taken from ${ }^{125}$ Te NMR spectra where available and reported as absolute values (magnitude only). ${ }^{1} J\left({ }^{31} \mathrm{P},{ }^{123} \mathrm{Te}\right.$ ) values given in parentheses are taken from ${ }^{31} \mathrm{P}$ NMR spectra; $\mathrm{s}=$ singlet, $\mathrm{d}=$ doublet, $\mathrm{dd}=$ doublet of doublets

${ }^{b}$ Chemical shifts are reported relative to $\mathrm{Me}_{2} \mathrm{Te}$ as external reference

${ }^{c}$ Not reported

${ }^{d}$ Not available owing to insolubility and/or rapid exchange processes

${ }^{e}{ }^{t} \mathrm{Bu}_{2} \operatorname{Im}=1,3$-di-tert-butyl-imidazolin-2-ylidine

${ }^{f}$ Pip $=$ piperidino $;$ Pyrr $=$ pyrrolidino 
Cyclodiphosphazane tellurides that incorporate both $\mathrm{P}^{\mathrm{V}}$ and $\mathrm{P}^{\mathrm{III}}$ sites provide an opportunity to determine whether the phosphorus-tellurium exchange process is inter- or intra-molecular. ${ }^{87,88}$ In an early example, Scherer and Schnabl demonstrated that the monotelluride $\left[{ }^{t} \mathrm{BuP} \mathrm{P}^{\mathrm{III}}(\mu\right.$ $\mathrm{NMe})_{2} \mathrm{P}^{\mathrm{V}}(\mathrm{Te})^{\mathrm{t}} \mathrm{Bu}$ ( 29) (Figure 11) undergoes fast site exchange, but they were unable to distinguish between an intermolecular or intramolecular process on the basis of the concentration-dependence of the coalescence temperature. ${ }^{91}$ Very recently, Elder et al. carried out a detailed variabletemperature and variable-concentration multinuclear NMR spectroscopic study of the acyclic $\mathrm{P}^{\mathrm{III}} / \mathrm{P}^{\mathrm{V}}$ monotelluride ${ }^{i} \operatorname{Pr}_{2} \mathrm{PCH}_{2} \mathrm{P}(\mathrm{Te}){ }^{\mathrm{i}} \mathrm{Pr}_{2}$ (30) (Figure 11), which showed that the exchange process is intermolecular (Figure 12) and occurs with an activation energy of $21.9 \pm 3.2 \mathrm{~kJ} \mathrm{~mol}^{-1}$; the experimental value was corroborated by DFT calculations which gave a value of $20.4 \mathrm{~kJ} \mathrm{~mol}{ }^{-1} .^{79}$ In a recent book chapter on dynamic NMR, Bain has described this process "as an excellent example of intermolecular exchange", since it provides a very clear demonstration that the rates depend linearly on concentration. ${ }^{92}$<smiles>CCCCN1B(CC(C)C)N(C)[PH]1=[Te]</smiles>

29

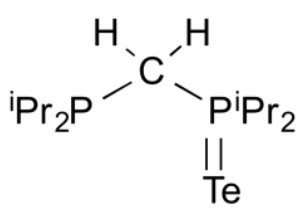

30

Figure 11. Phosphine tellurides with both $\mathrm{P}^{\mathrm{III}}$ and $\mathrm{P}^{\mathrm{V}}$ centers
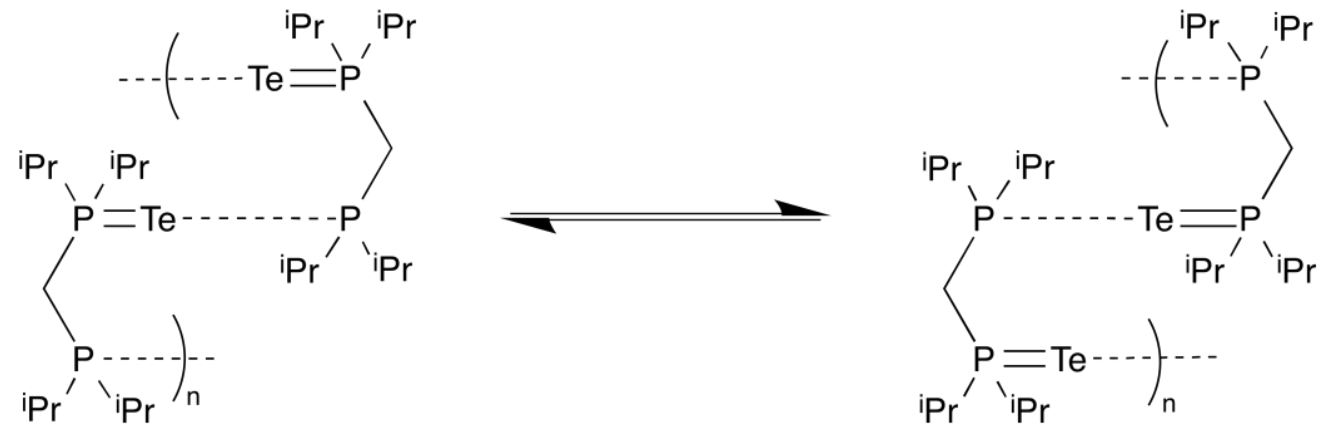

Figure 12. Intermolecular exchange of tellurium between $\mathrm{P}^{\mathrm{III}}$ and $\mathrm{P}^{\mathrm{V}}$ sites in $\mathbf{3 0}$ 


\subsection{X-ray Structures}

A listing of compounds with terminal $\mathrm{P}=\mathrm{Te}$ functionalities that have been structurally characterized is included in Table 3. Typically, monotellurides of the type $\mathrm{R}_{3} \mathrm{PTe}$ adopt distorted tetrahedral structures with $\mathrm{P}-\mathrm{Te}$ bond lengths in the range $2.35-2.40 \AA \AA^{53,79,93-95} \mathrm{~A}$ few bis(phosphine tellurides) have also been structurally characterized (e.g. 31a,b and 32 in Figure $13)^{76,78,96}$

a)

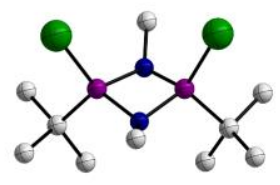

31a

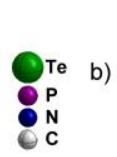

西

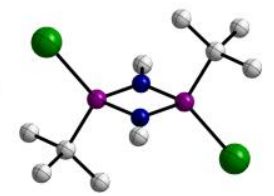

$31 \mathrm{~b}$

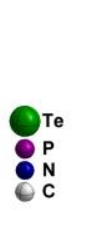

c)

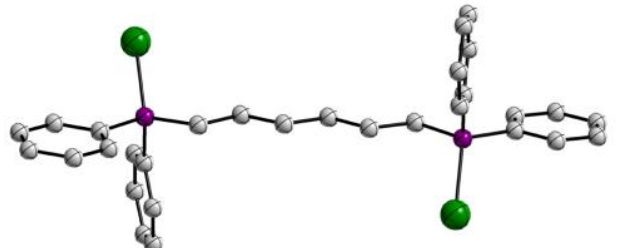

32

Figure 13. Molecular structures of (a) cis- $\left[{ }^{\mathrm{t}} \mathrm{BuP}(\mathrm{Te})(\mu-\mathrm{NMe})\right]_{2}$ (31a) (b) trans- $\left[{ }^{\mathrm{t}} \mathrm{BuP}(\mathrm{Te})(\mu-\right.$ $\mathrm{NMe})]_{2}$ (31b) and (c) $\mathrm{Ph}_{2} \mathrm{P}(\mathrm{Te})\left(\mathrm{CH}_{2}\right)_{6} \mathrm{P}(\mathrm{Te}) \mathrm{Ph}_{2}(32)$.

The most intriguing structure involves the bright yellow 1:1 adduct of triphenylphosphine telluride and triphenylphosphine $\mathrm{Ph}_{3} \mathrm{P}=\mathrm{Te} \cdot \mathrm{PPh}_{3}$ (33), which exhibits a linear, but markedly asymmetric, P-Te-P configuration with bond lengths in the ranges 2.270-2.424 and 3.376$3.948 \AA^{80}$ (sum of the van der Waals radii for Te $=3.86 \AA{ }^{25} 4.12 \AA^{26}$ or $4.40 \AA^{27}$ ). Intermolecular phosphorus-tellurium interactions between $\mathrm{P}^{\mathrm{III}}$ and $\mathrm{P}^{\mathrm{V}}$ sites are not observed in the solid state for 30, but the linear arrangement in this adduct is reminiscent of the proposed intermediate in the phosphorus-tellurium exchange process (Figure 12).

\subsection{Bonding and Electronic Structure}

The nature of bonding of the phosphorus-tellurium bond in triorganophosphine tellurides $\mathrm{R}_{3} \mathrm{PTe}$ has been a matter of debate. In early studies a bond order of ca. 1.5 was suggested by Kuhn et al. on the basis of P-Te bond lengths. ${ }^{94}$ On the other hand, solution and solid-state ${ }^{125}$ Te NMR and Mössbauer 
spectroscopic data have been interpreted by Jones and Sharma to indicate the absence of multiple bonding. ${ }^{29}$ The DFT calculations of Ziegler et al. for the model compounds $\mathrm{Me}_{3} \mathrm{PE}(\mathrm{E}=\mathrm{O}, \mathrm{S}, \mathrm{Se}$, Te) provide some insights into the nature of the formal $\mathrm{P}=\mathrm{Te}$ double bond as well as a rationale for the thermodynamic lability of the tellurium derivative. ${ }^{20}$ The phosphorus-chalcogen bond in these chalcogenides is comprised of a $\sigma$ and two $\pi$ components that can be represented by resonance structures $\mathbf{A}$ and $\mathbf{B}$, respectively (Figure 14). The two $\pi$ contributions result from hyperconjugative back-donation from the chalcogen $\mathrm{p}$ orbitals to $\sigma^{*}$ orbitals on the $\mathrm{R}_{3} \mathrm{P}$ fragment. The $\sigma$-bond component decreases dramatically down the series $\mathrm{O}>\mathrm{S}>\mathrm{Se}>\mathrm{Te}$, whereas the $\pi$-bond orders are only attenuated slightly. The combination of these bonding effects results in calculated $\mathrm{P}-\mathrm{E}$ bond energies of approximately $-544,-337,-266$ and $-184 \mathrm{~kJ} \mathrm{~mol}^{-1}$, thus accounting for the thermal and photochemical instability of compounds with terminal P-Te bonds. The relative contributions of the resonance structures $\mathbf{A}$ and $\mathbf{B}$ will be strongly influenced by the nature of the $\mathrm{R}$ substituents attached to phosphorus, as indicated by the range of values of ${ }^{1} J\left({ }^{31} \mathrm{P},{ }^{125} \mathrm{Te}\right)$ given in Table 3 .

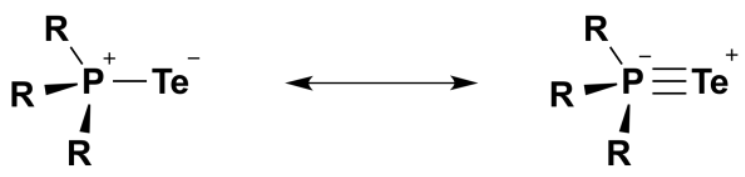

A

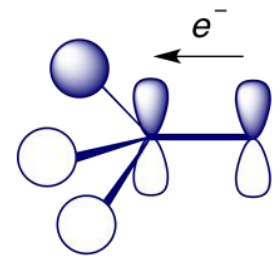

B

Figure 14. Resonance structures and one of the $\pi$-back bonds for $\mathrm{R}_{3} \mathrm{PTe}$. Adapted from ref.162. Copyright 2015 The Royal Society of Chemistry.

\subsection{Reaction with Electrophiles and Redox Behavior}

Kuhn and Schumann demonstrated that triorganophosphine tellurides $\mathrm{R}_{3} \mathrm{PTe}\left(\mathrm{R}=\mathrm{Me},{ }^{\mathrm{i}} \mathrm{Pr}\right.$, ${ }^{\mathrm{n}} \mathrm{Bu},{ }^{\mathrm{t}} \mathrm{Bu}, \mathrm{NMe}_{2}$ ) react with methyl iodide in benzene to produce the tellurophosphonium cations $\left[\mathrm{R}_{3} \mathrm{P}-\mathrm{TeMe}\right] \mathrm{I}$ in high yields. ${ }^{46}$ The structure of the tritelluro dication $\left[{ }^{\mathrm{t}} \mathrm{Bu} \mathrm{u}_{3} \mathrm{P}-\mathrm{Te}-\mathrm{Te}-\mathrm{Te}-\mathrm{P}^{\mathrm{t}} \mathrm{Bu}_{3}\right]^{2+}$ 
(14) $\left(<\mathrm{Te}-\mathrm{Te}-\mathrm{Te} 109.0(1)^{\circ}\right.$, Figure $\left.15 \mathrm{a}\right)$ produced by oxidation of ${ }^{\mathrm{t}} \mathrm{Bu}_{3} \mathrm{PTe}$ with a ferrocenium salt (eq 3$)^{51}$ has been discussed in connection with phosphine-stabilized tellurium cations in Section 4. By contrast, Chivers and Konu have shown that the oxidation of $\mathrm{Et}_{3} \mathrm{PTe}$ with $\mathrm{SO}_{2} \mathrm{Cl}_{2}$ or $\mathrm{I}_{2}$ produce the dihalides $\mathrm{Et}_{3} \mathrm{PTeX}_{2}(\mathbf{3 4 a}, \mathrm{X}=\mathrm{Cl} ; \mathbf{3 4 c}, \mathrm{X}=\mathrm{I})$ (eq 4 and 5); the corresponding dibromide $34 \mathbf{b}(\mathrm{X}$ $=\mathrm{Br}$ ) is prepared by halogen exchange between $\mathbf{3 4 a}$ and $\mathrm{Me}_{3} \mathrm{SiBr}$ (eq 6). ${ }^{97}$ The $\mathrm{TeX}_{2}$ moiety in the weakly associated dimers $\left(\mathrm{Et}_{3} \mathrm{PTeX}_{2}\right)_{2}$ is almost linear $\left(<\mathrm{X}-\mathrm{Te}-\mathrm{X}=171.0^{\circ}, \mathrm{X}=\mathrm{Cl} ; 173.2^{\circ}, \mathrm{X}=\mathrm{Br}\right.$; $176.8^{\circ}, \mathrm{X}=\mathrm{I}$ ); the structure of $\mathbf{3 4 c}$ is shown as a representative example in Figure $15 \mathrm{~b} .{ }^{97}$ The $\mathrm{P}-\mathrm{Te}$ distances in 14 and 34a-c are similar at 2.50 and 2.47-2.49 $\AA$, respectively; however, the values of ${ }^{1} J\left({ }^{31} \mathrm{P},{ }^{125} \mathrm{Te}\right)$ become significantly smaller as the electronegativity of the halogen $\mathrm{X}$ decreases: 1390, 1315 and $1251 \mathrm{~Hz}$ for 34a, 34b and 34c, respectively (Table 3$).{ }^{97}$ Unfortunately, ${ }^{1} J\left({ }^{31} \mathrm{P},{ }^{125} \mathrm{Te}\right)$ has not been reported for the dication 14 .

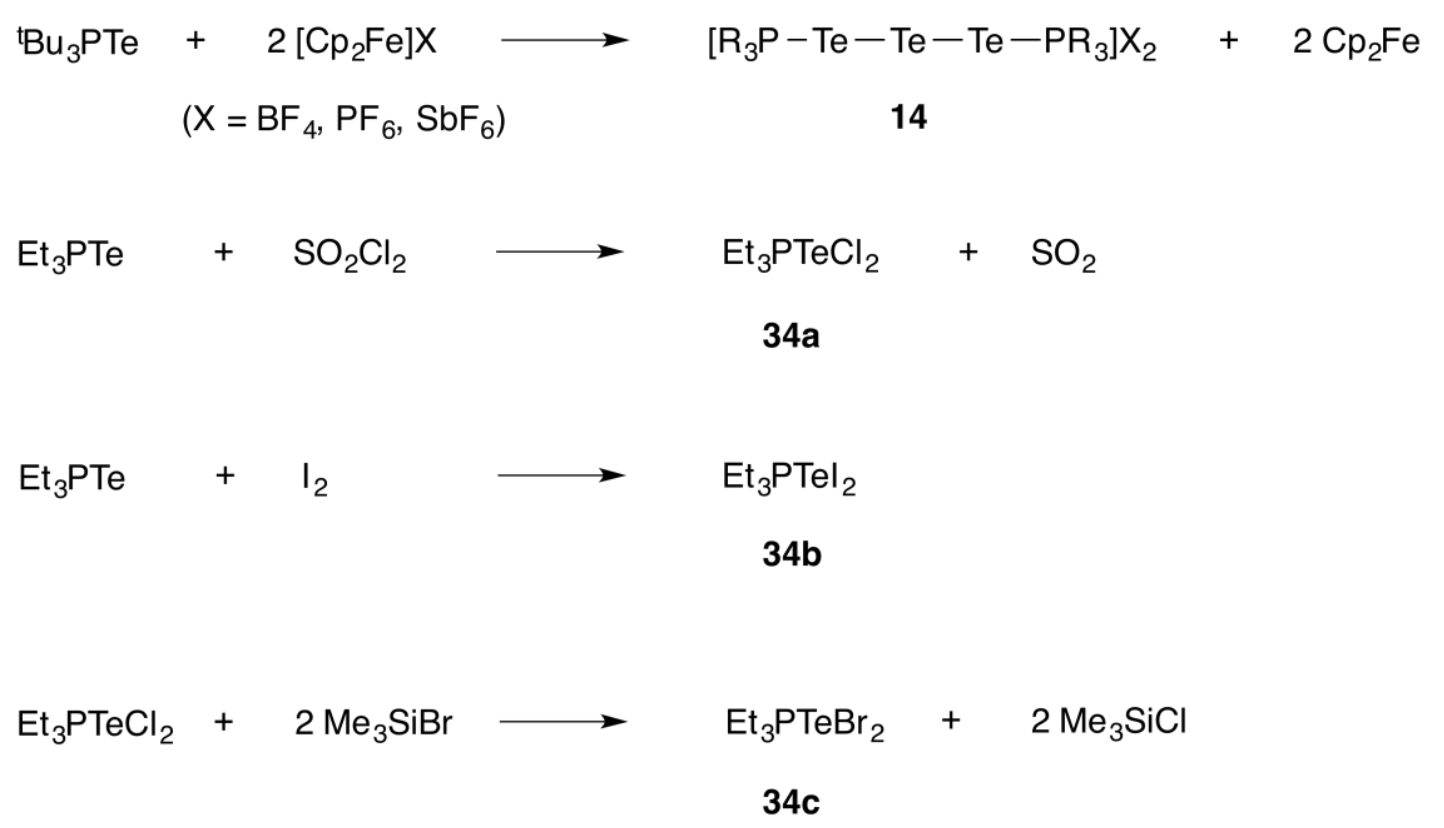


a)

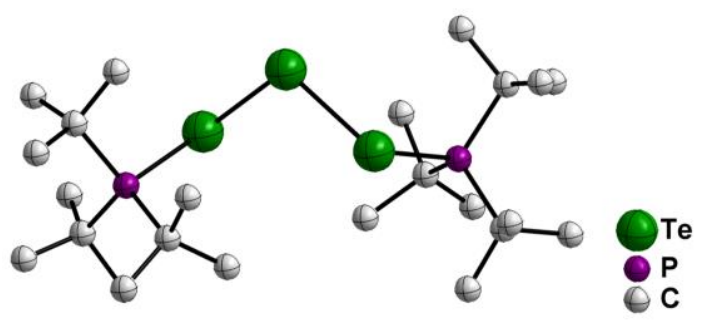

14

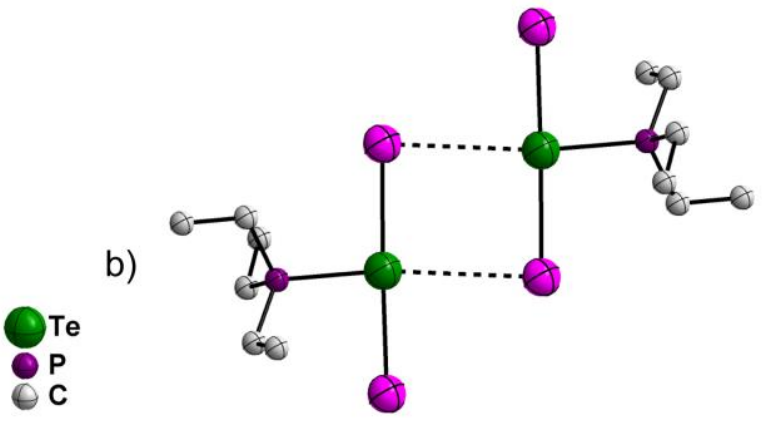

$34 c$

Figure 15. Molecular structures of (a) $\left[{ }^{t} \mathrm{Bu}_{3} \mathrm{P}-\mathrm{Te}-\mathrm{Te}-\mathrm{Te}-\mathrm{P}^{\mathrm{t}} \mathrm{Bu}_{3}\right]^{2+}\left(\mathbf{1 4}, \mathrm{SbF}_{6}^{-}\right.$salt) and (b) $\left(\mathrm{Et}_{3} \mathrm{PTeI}_{2}\right)_{2}(\mathbf{3 4 c})$.

\subsection{Coordination Complexes}

Although the lability of the phosphorus-tellurium bond has restricted the development of coordination chemistry, it has been shown that $\mathrm{R}_{3} \mathrm{PTe}$ ligands may fulfill either a terminal or a bridging role in metal complexes. The first examples of the former coordination mode were reported in 1985 by Kuhn et al., who generated $\mathrm{M}(\mathrm{CO})_{5}\left(\mathrm{TeP}^{\mathrm{t}} \mathrm{Bu}_{3}\right)(\mathrm{m}=\mathrm{Cr}, \mathrm{Mo}, \mathrm{W})$ by photolysis of $\mathrm{M}(\mathrm{CO})_{6}$ in the presence of ${ }^{\mathrm{t}} \mathrm{Bu}_{3} \mathrm{PTe}$ in THF and determined the X-ray structure of the tungsten derivative 35 (Figure 16a). ${ }^{99}$ Upon coordination the P-Te bond length increases by ca. $0.07 \AA$ and, concomitantly, the ${ }^{1} J\left({ }^{31} \mathrm{P},{ }^{125} \mathrm{Te}\right)$ value is reduced by ca. $65 \mathrm{~Hz}$. The $\mathrm{P}-\mathrm{Te}-\mathrm{W}$ bond angle in 35 is $120.1(1)^{\circ}$, which was interpreted to indicate a strong tellurium-tungsten $\pi$-donor interaction. ${ }^{84} \mathrm{~A}$ similar type of $\pi$-bonding was invoked for the cationic complexes $\left[\mathrm{FeCp}(\mathrm{CO})_{2}(\mathrm{TePR})_{3}\right]^{+}(\mathrm{R}=\mathrm{Me}$, $\left.{ }^{\mathrm{i}} \mathrm{Pr},{ }^{\mathrm{t}} \mathrm{Bu}\right)$ on the basis of NMR data. ${ }^{100}$

A bridging role for $\mathrm{R}_{3} \mathrm{PTe}$ ligands was first demonstrated by Zingaro and co-workers in the dimeric cation $\left[\left\{\mathrm{Hg}\left(\mathrm{TeP}^{\mathrm{n}} \mathrm{Bu}_{3}\right)\right\}_{3} \mathrm{Br}_{5}\right]_{2}{ }^{2+}(\mathbf{3 6})$, which was prepared in good yield by reaction of a suspension of elemental tellurium with ${ }^{\mathrm{n}} \mathrm{Bu}_{3} \mathrm{P}$ and $\mathrm{HgBr}_{2}$ in boiling acetone. ${ }^{101}$ The monomeric units in 36 incorporate a six-membered $\mathrm{Hg}_{3} \mathrm{Te}_{3}$ ring with $d(\mathrm{P}-\mathrm{Te})$ in the range $2.444(9)-2.479(10) \AA$ (Figure 16b). In alkaline solution 36 decomposes to give $\mathrm{HgTe}$. Very recently, a series of 
cadmium(II) complexes of phosphine tellurides with a 1:4 stoichiometry $\left[\mathrm{Cd}\left(\mathrm{R}_{3} \mathrm{PTe}\right)_{4}\right][\mathrm{X}]_{2}(\mathrm{R}=$ ${ }^{\mathrm{n}} \mathrm{Bu}, \mathrm{NMe}_{2}$, Pip, Pyrr, Mor; $\mathrm{X}^{-}=\mathrm{Cl}^{-}, \mathrm{ClO}_{4}^{-}$) have been characterized by elemental analyses and multinuclear NMR spectra; the Cd-Te linkages in these adducts are evinced by the observation of ${ }^{1} J\left({ }^{113} \mathrm{Cd},{ }^{125} \mathrm{Te}\right)$ couplings of $878-1040 \mathrm{~Hz} .{ }^{102}$ The values of ${ }^{1} J\left({ }^{31} \mathrm{P},{ }^{125} \mathrm{Te}\right)$ are reduced by ca. $400 \mathrm{~Hz}$ in these Cd complexes compared to those in the free ligands (Table 3).

Complexes of triorganophosphine tellurides with coinage metal halides $\mathrm{MCl}(\mathrm{M}=\mathrm{Cu}, \mathrm{Ag})$ decompose readily with the formation of tellurium, however du Mont and co-workers have structurally characterized several $\mathrm{Ag}(\mathrm{I})$ complexes by using $\mathrm{Ms}_{2} \mathrm{~N}^{-}$(di(methylsulfonyl)amide) or $\mathrm{SbF}_{6}{ }^{-}$counter-ions, e.g. the dimer $\left[\mathrm{Ag}_{2}\left(\mathrm{Ms}_{2} \mathrm{~N}\right)_{2}\left(\mu-{ }^{\mathrm{i}} \mathrm{Pr}_{3} \mathrm{PTe}\right)_{2}\right](37)$ (Figure 16c). ${ }^{103}$ The ${ }^{1} J\left({ }^{31} \mathrm{P},{ }^{125} \mathrm{Te}\right)$ value is reduced by $>300 \mathrm{~Hz}$ for this ligand in a bridging role, although the $\mathrm{P}-\mathrm{Te}$ bond length is only increased by $0.04-0.07 \AA{ }^{88}$ The special bridging ability of $\mathrm{R}_{3}$ PTe ligands is evinced in the $2: 1$ complex $\left[\mathrm{Ag}\left(\mu-{ }^{\mathrm{i}} \mathrm{Pr}_{3} \mathrm{PTe}\right)_{2}\right]\left[\mathrm{SbF}_{6}\right]$, which forms a cationic coordination polymer. ${ }^{103} \mathrm{~A} 3: 1$ complex of the $\mathrm{P}^{\mathrm{III}} / \mathrm{P}^{\mathrm{V}}$ monotelluride $\left[{ }^{\mathrm{t}} \mathrm{Bu}(\mathrm{H}) \mathrm{NP}^{\mathrm{III}}\left(\mu-\mathrm{N}^{\mathrm{t}} \mathrm{Bu}\right)_{2} \mathrm{P}^{\mathrm{V}}(\mathrm{Te}) \mathrm{N}(\mathrm{H})^{\mathrm{t}} \mathrm{Bu}\right]$ with $\mathrm{AgI}$ has been structurally characterized recently. ${ }^{104}$ The three ligands are Te-coordinated to AgI and the mean P-Te distance in the complex is only slightly elongated compared to that in the free ligand (Table 3).

a)

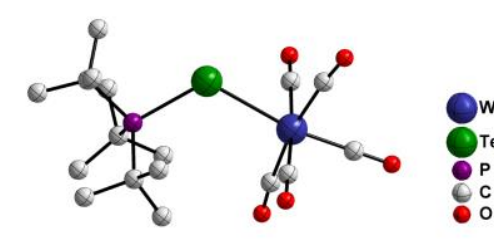

35

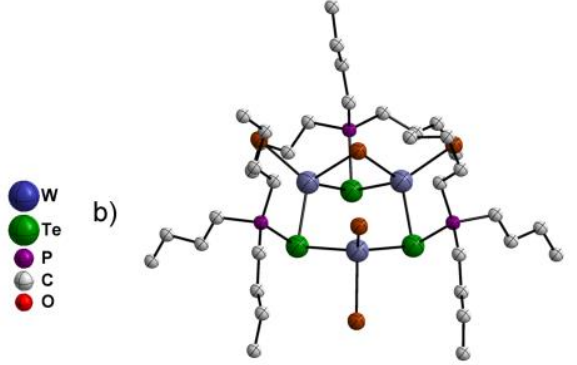

36

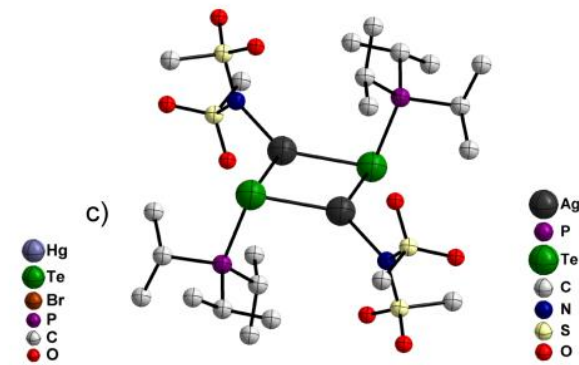

37

Figure 16. Molecular structures of metal complexes of terminal and bridging $\mathrm{R}_{3} \mathrm{PTe}$ ligands; (a) $\mathrm{W}(\mathrm{CO})_{5}\left(\mathrm{TeP}^{\mathrm{t}} \mathrm{Bu}_{3}\right)(\mathbf{3 5}),(\mathrm{b})\left[\left\{\mathrm{Hg}\left(\mathrm{TeP}^{\mathrm{n}} \mathrm{Bu}_{3}\right)\right\}_{3} \mathrm{Br}_{5}\right]_{2}{ }^{2+}(\mathbf{3 6})$ and (c) $\left[\mathrm{Ag}_{2}\left(\mathrm{Ms}_{2} \mathrm{~N}\right)_{2}\left(\mu-{ }^{\mathrm{i}} \mathrm{Pr}_{3} \mathrm{PTe}\right)_{2}\right](\mathbf{3 7})$

\subsection{Applications as Tellurium-Transfer Reagents}


The lability of the terminal $\mathrm{P}=\mathrm{Te}$ functionality in phosphine tellurides has been exploited creatively in applications as tellurium-transfer reagents that are soluble and more reactive than elemental tellurium. ${ }^{72,108}$ As mentioned in Section 5.1.2, the use of ${ }^{\mathrm{n}} \mathrm{Bu}_{3} \mathrm{PTe}$ for insertion of $\mathrm{Te}^{0}$ into the $\mathrm{P}-\mathrm{E}(\mathrm{E}=\mathrm{Si}, \mathrm{Ge}, \mathrm{Sn})$ bond of ${ }^{\mathrm{t}} \mathrm{Bu}_{2} \mathrm{P}-\mathrm{EMe}_{3}$ resulted in the formation of the first acyclic $\mathrm{P}^{\mathrm{III}}-\mathrm{Te}-$ $\mathrm{P}^{\mathrm{III}}$ compound via redistribution of the insertion product ${ }^{\mathrm{t}} \mathrm{Bu}_{2} \mathrm{P}-\mathrm{Te}-\mathrm{EMe}_{3}{ }^{59}$ In a series of papers in the late 1980s and early 1990s Steigerwald and co-workers demonstrated the use of phosphine tellurides for the synthesis of a wide variety of transition-metal-tellurium clusters, e.g. $\left[\mathrm{Fe}_{4} \mathrm{Te}_{4}\left(\mathrm{PR}_{3}\right)_{4}\right]\left(\mathrm{R}=\mathrm{Et},{ }^{\mathrm{i}} \mathrm{Pr}\right),{ }^{109}\left[\mathrm{Fe}_{6} \mathrm{Te}_{8}\left(\mathrm{PMe}_{3}\right)_{6}\right]^{78}$ and $\left[\mathrm{Co}_{6} \mathrm{Te}_{8}\left(\mathrm{PEt}_{3}\right)_{6}\right] .{ }^{110,111}$ By varying reaction conditions and the ratio of the reagents $\mathrm{Co}_{2}(\mathrm{CO})_{8}$ and $\mathrm{Et}_{3} \mathrm{PTe}$, the latter complex was shown to form via the intermediates $\left[\mathrm{CoTe}(\mathrm{CO})_{2}\left(\mathrm{PEt}_{3}\right)_{2}\right]_{2}$ and $\left[\mathrm{Co}_{4} \mathrm{Te}_{2}(\mathrm{CO})_{6}\left(\mathrm{PEt}_{3}\right)_{4}\right] .{ }^{111}$ The final products from reactions of $\mathrm{Fe}(\mathrm{COT})_{2}$ with $\mathrm{Et}_{3} \mathrm{PTe}$ are binary iron tellurides. ${ }^{78}$ Other metal telluride clusters that have been generated by reactions of $\mathrm{Et}_{3} \mathrm{PTe}$ with labile transition-metal complexes include: $\left[\mathrm{Pd}_{6} \mathrm{Te}_{6}\left(\mathrm{PEt}_{3}\right)_{8}\right],{ }^{112}\left[\mathrm{Ni}_{9} \mathrm{Te}_{6}\left(\mathrm{PEt}_{3}\right)_{8}\right],{ }^{113}\left[\mathrm{Ni}_{20} \mathrm{Te}_{18}\left(\mathrm{PEt}_{3}\right)_{12}\right],{ }^{113}\left[\mathrm{Cr}_{6} \mathrm{Te}_{8}\left(\mathrm{PEt}_{3}\right)_{6}\right]^{114}$ and the ditelluride $\left[\left(\mathrm{Et}_{3} \mathrm{P}\right)_{2}(\mathrm{CO})_{3} \mathrm{MnTe}-\right]_{2} ;{ }^{115}$ none of these clusters incorporate intact $\mathrm{Et}_{3} \mathrm{PTe}$ ligands.

The versatility of phosphine tellurides as Te-transfer reagents is further manifested in their multifarious applications, e.g. (a) the synthesis of a bridging uranium telluride (eq 7), ${ }^{116}$ (b) the preparation of terminal transition-metal tellurides (eq 8), ${ }^{117}$ (c) insertion into metal-metal bonds (eq 9 ), ${ }^{118}$ (d) the formation of an $\eta^{2}-\mathrm{Te}_{2}{ }^{2-}$ complex (eq 10), ${ }^{119}$ and (e) chalcogen-exchange reactions to produce tellurometallates from selenometallates. ${ }^{120}$ 
$\left(\mathrm{MeC}_{5} \mathrm{H}_{4}\right)_{3} \mathrm{U} \cdot \mathrm{THF}+\mathrm{TePnBu}_{3} \longrightarrow\left[\left(\mathrm{MeC}_{5} \mathrm{H}_{4}\right)_{3} \mathrm{U}_{2}(\mu-\mathrm{Te})+\mathrm{PnBu}_{3}\right.$

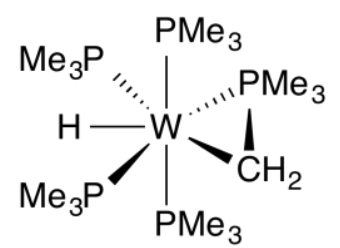

$$
\begin{aligned}
& \mathrm{R}_{2} \mathrm{Ga}-\mathrm{GaR}_{2}+\mathrm{TePEt}_{3} \longrightarrow \mathrm{R}_{2} \mathrm{Ga}-\mathrm{Te}-\mathrm{GaR}_{2}+\mathrm{PEt}_{3} \\
& \left(\mathrm{R}=\mathrm{CH}\left(\mathrm{SiMe}_{3}\right)_{2}\right) \\
& \mathrm{Cp}^{*}{ }_{2} \mathrm{Ti}-\mathrm{Te}-\mathrm{TiCp}^{*}{ }_{2}+\mathrm{TePnBu}_{3} \longrightarrow\left[\mathrm{Cp}^{*}{ }_{2} \mathrm{Ti}_{2}(\mu-\mathrm{TeTe})+\mathrm{PnBu}_{3}\right.
\end{aligned}
$$

The enthalpies of tellurium atom transfer from $\mathrm{Cy}_{3} \mathrm{PTe}$ to the molybdenum(III) complex $\operatorname{Mo}\left(\mathrm{N}\left[{ }^{\mathrm{t}} \mathrm{Bu}\right) \mathrm{Ar}\right)_{3}\left(\mathrm{Ar}=3,5-\mathrm{C}_{6} \mathrm{H}_{3} \mathrm{Me}_{2}\right)$ and to the $N$-heterocyclic carbene IPr have been determined by solution calorimetry. ${ }^{74}$ NMR studies showed that the latter process is rapid and quantitative, but the resulting tellurocarbonyl TeIPr was not isolated; the transfer process is slower for Se. ${ }^{74}$ The calorimetric data provided estimates of 322 and $222 \mathrm{~kJ} \mathrm{~mol}^{-1}$ for the bond dissociation enthalpies of the formal $\mathrm{C}=\mathrm{E}(\mathrm{E}=\mathrm{Se}$ and $\mathrm{Te}$, respectively $)$ double bonds in EIPr.

Tellurium insertion into metal-carbon bonds has been investigated in considerable detail. ${ }^{121-}$ ${ }^{127}$ West and co-workers found that elemental tellurium does not insert directly into the Mn-C bond of $\mathrm{RMn}(\mathrm{CO})_{5}(\mathrm{R}=$ alkyl, aryl $)$ complexes, but the use of $\mathrm{R}_{3}^{\prime} \mathrm{PTe}(\mathrm{R}=\mathrm{Me}, \mathrm{Et})$ reagents generates the tellurolates $\mathrm{RTeMn}(\mathrm{CO})_{3}\left(\mathrm{PR}_{3}\right)_{2}$ via initial substitution of two $\mathrm{CO}$ ligands by $\mathrm{PR}_{3}$ followed by Te insertion. ${ }^{122}$ Piers et al. showed that ${ }^{n} \mathrm{Bu}_{3} \mathrm{PTe}$ can be employed for Te insertion into the scandium-alkyl bonds of $\mathrm{Cp}_{2}{ }_{2} \mathrm{ScR}\left(\mathrm{R}=\mathrm{CH}_{2} \mathrm{SiMe}_{3}, \mathrm{CH}_{2} \mathrm{Ph}\right)$, but the tellurolates so formed readily undergo elimination of $\mathrm{TeR}_{2} \cdot{ }^{123}$ The use of a stereochemical probe established that both steps in this process occur with retention of configuration, implying concerted transition states for the two reactions (eq 11). ${ }^{124,125}$ 
$2 \mathrm{Cp}^{*}{ }_{2} \mathrm{ScR}+2 \mathrm{TePnBu}_{3} \longrightarrow 2 \mathrm{Cp}_{2}{ }_{2} \mathrm{ScTeR} \stackrel{\Delta}{\longrightarrow} \mathrm{Cp}^{*}{ }_{2} \mathrm{Sc}-\mathrm{Te}-\mathrm{ScCp}_{2}{ }_{2}+\mathrm{TeR}_{2}$

Bridging tellurides can also be generated by reaction of metal hydrides with ${ }^{\mathrm{n}} \mathrm{Bu}_{3} \mathrm{PTe}$, e.g. the formation of DpSc-Te-ScDp from $[\mathrm{DpScH}]_{2}\left(\mathrm{Dp}=\right.$ meso- $\left.\mathrm{Me}_{2} \mathrm{Si}\left({ }^{\mathrm{t}} \mathrm{BuC}_{5} \mathrm{H}_{3}\right)_{2}\right) .{ }^{126}$ The titanium catalyst $\mathrm{Cp}^{*}{ }_{2} \mathrm{TiH}$ is particularly effective for the heterodehydrocoupling of ${ }^{\mathrm{n}} \mathrm{Bu}_{3} \mathrm{Sn}$ groups and $\mathrm{Te}$ (eq 12). ${ }^{127}$

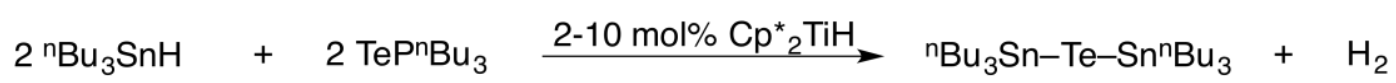

Phosphine tellurides also provide a reactive source of tellurium in the generation of semiconducting metal tellurides, which have applications in devices such as solar cells (group 12), infrared detectors (group 14) or room-temperature thermoelectric generators (group 15), as well as biomarkers (group 12). In an early example, CdTe was electrodeposited on a titanium cathode using a solution of $\mathrm{TeP}^{\mathrm{n}} \mathrm{Bu}_{3}$ and $\mathrm{Cd}^{2+}$ ions in propylene carbonate at ca. $100{ }^{\circ} \mathrm{C} .{ }^{128}$ In a different approach, pure $\mathrm{HgTe}$ was prepared by reaction of $\mathrm{Et}_{3} \mathrm{PTe}$ with $\mathrm{Ph}_{2} \mathrm{Hg}$ in boiling toluene, presumably via the formation of the mercury tellurolate $\mathrm{Hg}(\mathrm{TePh})_{2}$ via $\mathrm{Te}$ insertion into the $\mathrm{Hg}-$ $\mathrm{C}_{\text {aryl }}$ bond; $\mathrm{HgTe}$ is also formed by the direct reaction of metallic mercury with $\mathrm{TePEt}_{3 .}{ }^{129}$

In more recent investigations, tri- $n$-octylphosphine telluride (TOPTe) has been shown to be an excellent source of $\mathrm{Te}^{0} ;{ }^{130}$ much of this work is in the patent literature. ${ }^{131}$ Some examples of the applications of TOPTe from the open literature include the preparation of solutions containing CdTe nanoparticles in butanol by reaction with $\mathrm{Me}_{2} \mathrm{Cd}$ in the presence of TOP and TOPO, ${ }^{132}$ as well as the synthesis of the following nanomaterials that are of technological interest: nanocrystalline $\mathrm{HgTe},{ }^{133}$ colloidal $\mathrm{HgTe}$ quantum dots for mid-IR emission and detection, ${ }^{134}$ hexagonal $\mathrm{Bi}_{2} \mathrm{Te}_{3}$ nanoplatelets with novel thermoelectric properties, ${ }^{135}$ colloidal PbTe nanocrystals, ${ }^{136}$ CdTe quantum wires, ${ }^{137}$ photoconducting CdTe nanotetrapods, ${ }^{138}$ and $\mathrm{CuTe}$ nanocrystals for use as surface-enhanced Raman scattering sensors or photothermal agents. ${ }^{139}$ 


\section{ANIONIC PHOSPHORUS-TELLURIUM LIGANDS}

\subsection{Tellurophosphates}

Potassium $\mathrm{O}, \mathrm{O}^{\prime}$-diethyl tellurophosphate $\mathrm{M}\left[(\mathrm{EtO}){ }_{2} \mathrm{P}(\mathrm{Te}) \mathrm{O}\right](\mathbf{3 8 a}, \mathrm{M}=\mathrm{K})$ was obtained as colorless, hygroscopic needles in 1950 by Foss via treatment of potassium diethylphosphite with tellurium in ethanol. The potassium salt 38a was isolated as "colorless, hygroscopic needles, rapidly darkening in moist air"; no characterization details were given. ${ }^{9}$ Thirty years later Clive and Menchen prepared the $\mathrm{Li}(\mathbf{3 8 b})$ and $\mathrm{Na}(\mathbf{3 8 c})$ salts and showed that these phosphorus-tellurium compounds are effective reagents for the deoxygenation of epoxides (eq 13). ${ }^{141,142}$ The reagent 38c may also be used for the the dehalogenation of $\alpha$-halo ketones. ${ }^{143}$ Although no solid-state structures are available, the anomalously high ${ }^{1} J(\mathrm{P}, \mathrm{Te})$ value of $2115 \mathrm{~Hz}$ for $\mathbf{3 8 c} \mathrm{c}^{142}$ may indicate a short $\mathrm{P}-\mathrm{Te}$ bond, cf. $\left(\mathrm{R}_{2} \mathrm{~N}\right)_{3} \mathrm{PTe}$ derivatives (Table 3).

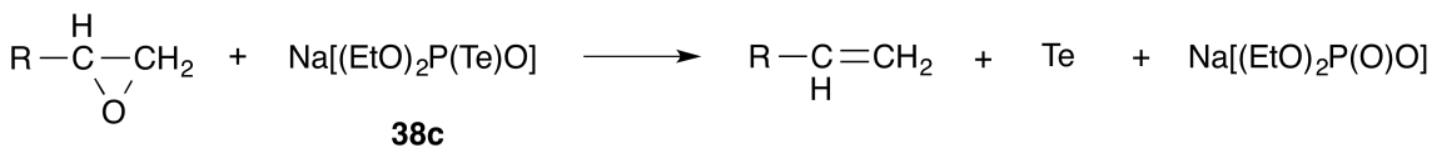

\subsection{Tellurophosphinites and Ditellurophosphinates}

This section describes the anionic species $\mathrm{RPTeR}^{\prime^{-}}(\mathbf{3 9}),{ }^{144} \mathrm{R}_{2} \mathrm{PTe}^{-}(\mathbf{4 0}),{ }^{145}$ and $\mathrm{R}_{2} \mathrm{PTe}_{2}{ }^{2-}$ (41) (Figure 17) which, by analogy with sulfur and selenium analogs, ${ }^{8}$ are potentially interesting ligands.

$$
\mathrm{R}^{\mathrm{P}}-\mathrm{Te}-\mathrm{R}^{\prime}
$$

39<smiles>[R]P([Te])[Te]</smiles>

40<smiles>[R]P([R])([Te])=[Te]</smiles>

41

Figure 17. The anionic species $\mathrm{RPTeR}^{\prime^{-}}(\mathbf{3 9}), \mathrm{R}_{2} \mathrm{PTe}^{-}(\mathbf{4 0})$ and $\mathrm{R}_{2} \mathrm{PTe}_{2}^{-}(\mathbf{4 1})$.

The binuclear iron complex $\left[\mathrm{Fe}_{2}(\mathrm{CO})_{6}(\mu\right.$-TeMes $)\left\{\mu\right.$-P( $\left.\left.\left.{ }^{\mathrm{i}} \mathrm{Pr}\right) \mathrm{TeMes}\right\}\right]$ is a unique example of a complex incorporating an $\mathrm{RPTeR}^{-}$(39) ligand; it exhibits a phosphorus-tellurium bond length of 2.481(5) $\AA$, typical of $\mathrm{P}^{\mathrm{III}}-\mathrm{Te}$ compounds (Table 1), accompanied by both one-bond and two-bond 
phosphorus-tellurium couplings, ${ }^{1} J(\mathrm{P}, \mathrm{Te})=856 \mathrm{~Hz} \quad{ }^{2} J(\mathrm{P}, \mathrm{Te})=353 \mathrm{~Hz} \cdot{ }^{146}$ The isomeric tellurophosphinito ligand $\mathrm{R}_{2} \mathrm{PTe}^{-}(\mathbf{4 0})$ is present in the rhodium complex [ $\left.\mathrm{Bupp}_{2} \mathrm{Ph}_{4}\right] \mathrm{Rh}\left[\eta^{2}-\mathrm{TePCy}_{2}\right.$ ] $\left(\mathrm{Bupp}_{2} \mathrm{Ph}_{4}={ }^{\mathrm{t}} \mathrm{BuP}\left(\mathrm{CH}_{2} \mathrm{CH}_{2} \mathrm{PPh}_{2}\right)_{2}\right)\left({ }^{1} J(\mathrm{P}, \mathrm{Te})=1150 \mathrm{~Hz}\right)$, which is prepared by addition of Te to the Rh-PCy bond. $^{147}$ Other complexes containing an $\mathrm{R}_{2} \mathrm{PTe}^{-}$ligand are $\mathrm{CpNi}\left(\mathrm{TeP}^{\mathrm{t}} \mathrm{Bu}_{2}\right)$, identified by mass spectrometry, ${ }^{148}$ and $\mathrm{C}_{5} \mathrm{R}_{5} \mathrm{~W}(\mathrm{CO})_{2}\left(\mathrm{TeP}(\mathrm{H}){ }^{\mathrm{t}} \mathrm{Bu}\right)\left(\mathrm{R}=\mathrm{H},{ }^{1} J(\mathrm{P}, \mathrm{Te})=1000 \mathrm{~Hz} ; \mathrm{R}=\mathrm{Me},{ }^{1} J(\mathrm{P}, \mathrm{Te})\right.$ $=980 \mathrm{~Hz}){ }^{149}$ the latter was prepared by addition of elemental tellurium to the $\mathrm{W}=\mathrm{P}$ bond of a phosphenium complex.

The anions $\mathrm{R}_{2} \mathrm{PTe}^{-}(\mathbf{4 0 a}, \mathrm{R}=\mathrm{Cy} ; \mathbf{4 0 b}, \mathrm{R}=\mathrm{Ph})$ were generated as lithium derivatives in 1990 by Bildstein and Sladky via reaction of $\mathrm{Li}\left[\mathrm{R}_{2} \mathrm{P}\right]$ with elemental tellurium in THF; at that time characterization was limited to ${ }^{31} \mathrm{P}$ and ${ }^{125} \mathrm{Te} \mathrm{NMR}$ spectra $\left[{ }^{1} J(\mathrm{P}, \mathrm{Te})=565 \mathrm{~Hz}(\mathbf{4 0 a}), 775 \mathrm{~Hz}\right.$ (40b)]. ${ }^{150}$ Chalcogenophosphinates $\mathrm{R}_{2} \mathrm{P}(\mathrm{Ch}) \mathrm{Te}^{-}(\mathrm{Ch}=\mathrm{O}, \mathrm{S}, \mathrm{Se})$ were also obtained by treatment of $\mathrm{Li}\left[\mathrm{R}_{2} \mathrm{P}(\mathrm{Ch})\right]$ with tellurium, but attempts to prepare $\mathrm{RPTe}_{2}{ }^{2-}$ by treatment of $\mathrm{PhPK}_{2}$ with elemental tellurium resulted in a redox process to give the cyclotetraphosphine $(\mathrm{PhP})_{4}$ and $\mathrm{K}_{2}$ Te. ${ }^{150}$ In 2003 Davies and co-workers succeeded in structurally characterizing the monoanions $\mathrm{Ph}_{2} \mathrm{PTe}^{-}$(40b) and $\mathrm{Ph}_{2} \mathrm{PTe}_{2}{ }^{-}(\mathbf{4 1}, \mathrm{R}=\mathrm{Ph})$ as ion-separated species with THF/TMEDA-solvated $\mathrm{Li}^{+}$counter-ions (Figure 18). ${ }^{151}$ The ${ }^{1} J(\mathrm{P}, \mathrm{Te})$ values of 747 and $1530 \mathrm{~Hz}$ for $\mathbf{4 0 b}$ and $\mathbf{4 1}$, respectively, in these salts provide a cogent illustration of the influence of the formal oxidation state of phosphorus on the magnitude of this parameter (Section 2). The mixed-chalcogen anion $\mathrm{Ph}_{2} \mathrm{P}(\mathrm{Se}) \mathrm{Te}^{-}\left({ }^{1} J\left({ }^{31} \mathrm{P},{ }^{125} \mathrm{Te}\right)=\right.$ $1485 \mathrm{~Hz}$ ) was also structurally characterized. ${ }^{151}$ The structure of the related dianion $\left[\mathrm{PhP}(\mathrm{Te})_{2} \mathrm{CH}_{2} \mathrm{CH}_{2} \mathrm{P}(\mathrm{Te})_{2} \mathrm{Ph}\right]^{2-}$ has been determined in a salt with the octanuclear cluster counter-ion $\left[\mathrm{Li}_{8}(\mathrm{OH})_{6}(\mathrm{THF})_{8}\right]^{2+} \cdot 152$ 


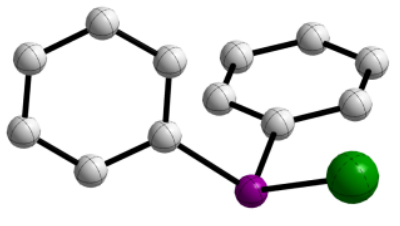

40b

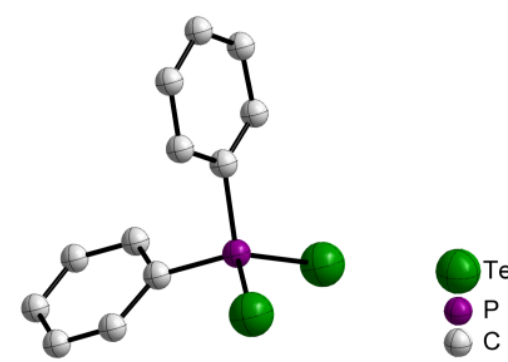

41

Figure 18. Molecular structures of $\mathrm{Ph}_{2} \mathrm{PTe}^{-}\left(\right.$40b) and $\mathrm{Ph}_{2} \mathrm{PTe}_{2}^{-}(\mathbf{4 1}, \mathrm{R}=\mathrm{Ph})$ in THF/TMEDAsolvated $\mathrm{Li}^{+}$salts

In their early work Bildstein and Sladky showed that the reaction of tellurium with diorganylphosphides takes place even when the phosphide is coordinated to a Lewis acid to give the adducts $(\mathrm{L}) \mathrm{PR}_{2} \mathrm{Te}^{-}\left(\mathrm{R}=\mathrm{Ph}, \mathrm{L}=\mathrm{BH}_{3} ; \mathrm{R}={ }^{\mathrm{t}} \mathrm{Bu}, \mathrm{Cr}(\mathrm{CO})_{5}\right) .{ }^{150}$ More recently, Wagner and coworkers obtained the potassium salts of $\left[\left(\mathrm{H}_{3} \mathrm{~B}\right) \mathrm{PR}_{2} \mathrm{Te}\right]^{-}\left[\mathrm{H}_{3} \mathrm{~B} \cdot \mathbf{4 0}, \mathrm{R}=\mathrm{Ph},{ }^{\mathrm{t}} \mathrm{Bu}\right]$ in almost quantitative yields and structurally characterized the $\left[\mathrm{K}(18 \text {-crown-6) }]^{+}\right.$adducts; the anionic ligand in the $\mathrm{R}=\mathrm{Ph}$ derivative binds to $\mathrm{K}^{+}$through the $\mathrm{B}$ atom as well as the Te center. ${ }^{77}$ The high yield of $\left[\left(\mathrm{H}_{3} \mathrm{~B}\right) \mathrm{PPh}_{2} \mathrm{Te}\right]^{-}$is in distinct contrast to the reluctance of the neutral, isolectronic phosphine $\mathrm{H}_{3} \mathrm{CPPh}_{2}$ to react with $\mathrm{Te}_{\infty}$ (Section 6.1) and presumably reflects the increased nucleophilicity of the anionic species towards chalcogens (Section 7.3.1).

\subsection{Telluroimidophosphinites, Tellurobisimidophosphinates, Mono- and Di-}

\section{Telluroimidodiphosphinates $^{153}$}

\subsubsection{Alkali-Metal Derivatives}

Similarly to neutral phosphine tellurides (Section 6.1), the introduction of an amido or imido substituent markedly enhances the thermal stability of anionic phosphorus-tellurium species of the type $\quad\left[\mathrm{R}_{2} \mathrm{P}(\mathrm{Te}) \mathrm{NR}\right]^{-} \quad(\mathbf{4 2}, \quad$ telluroimidophosphinites $), \quad\left[\mathrm{RP}(\mathrm{Te})(\mathrm{NR})_{2}\right]^{2-}$

tellurobisimidophosphonates $), \quad\left[\mathrm{N}\left(\mathrm{PR}_{2}\right)\left(\mathrm{PR}_{2} \mathrm{Te}\right)\right]^{-} \quad(\mathbf{4 4}, \quad$ telluroimidodiphosphinates $)$, and 
$\left[\mathrm{N}\left(\mathrm{PR}_{2} \mathrm{Te}\right)_{2}\right]^{-}(\mathbf{4 5}$, ditelluroimidodiphosphinates) (Figure 19). The coordination chemistry of 45 is particularly extensive. ${ }^{15}$

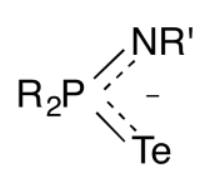

42

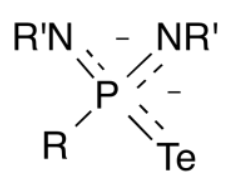

43<smiles></smiles>

44<smiles>[R7][Te]=[Te]=[Te]</smiles>

45

Figure 19. Imidophosphorus-tellurium anions (a) $\left[\mathrm{R}_{2} \mathrm{P}(\mathrm{Te})(\mathrm{NR})\right]^{-}(\mathbf{4 2})\left[\mathrm{RP}(\mathrm{Te})\left(\mathrm{NR}^{\prime}\right)_{2}\right]^{2-}(\mathbf{4 3})$, (b) $\left[\mathrm{N}\left(\mathrm{PR}_{2}\right)\left(\mathrm{PR}_{2} \mathrm{Te}\right)_{2}{ }^{-}(\mathbf{4 4})\right.$, and $\left[\mathrm{N}\left(\mathrm{PR}_{2} \mathrm{Te}\right)_{2}\right]^{-}(\mathbf{4 5})$.

In view of the relatively low reactivity of neutral phosphines such as ${ }^{\mathrm{t}} \mathrm{Bu}_{2} \mathrm{PNHR}^{\prime}\left(\mathrm{R}^{\prime}=\right.$ alkyl), $\mathrm{PhP}\left(\mathrm{NHR}^{\prime}\right)_{2}$ and $\left(\mathrm{Ph}_{2} \mathrm{P}\right)_{2} \mathrm{NH}$ towards elemental tellurium (Section 6.1), it is necessary to generate the corresponding anions via deprotonation prior to reaction with elemental tellurium $\left(\mathrm{Te}_{\infty}\right)$ in order to generate $\mathrm{P}-\mathrm{Te}$ functionalities. Thus, Bochmann et al. reported that treatment of $\mathrm{Li}\left[{ }^{\mathrm{t}} \mathrm{Bu}_{2} \mathrm{PNR}^{\prime}\right]$ with tellurium powder in THF at $0{ }^{\circ} \mathrm{C}$ generates yellow solutions of $\mathrm{Li42}\left(\mathrm{R}={ }^{\mathrm{t}} \mathrm{Bu}, \mathrm{R}^{\prime}\right.$ $\left.={ }^{\mathrm{i}} \mathrm{Pr}, \mathrm{Cy}\right) .{ }^{95}$ By using this "metallation-first" approach, the dilithium derivative $\left\{[\mathrm{Li}(\mathrm{THF})]_{2} \mathbf{4 3}\right\}_{2}(\mathrm{R}$ $=\mathrm{Ph}, \mathrm{R}^{\prime}={ }^{\mathrm{t}} \mathrm{Bu}$ ) is obtained in low yield (eq 14). ${ }^{154}$ The monomeric units in this dimer incorporate $N, N^{\prime}$ - and $N, T e$-coordinated $[\mathrm{Li}(\mathrm{THF})]^{+}$cations that are linked through $\mathrm{Li}-\mathrm{Te}$ contacts to form a central transoid $\mathrm{Li}_{2} \mathrm{Te}_{2} \operatorname{ring}, d(\mathrm{P}-\mathrm{Te})=2.4935(12) \AA,{ }^{1} J\left({ }^{31} \mathrm{P},{ }^{125} \mathrm{Te}\right)=1212 \mathrm{~Hz}$.

$$
\begin{aligned}
& \left.2 \mathrm{Li}\left[\mathrm{PhPN}{ }^{\mathrm{B} B u}\right)_{2}\right]+2 \mathrm{Te} \longrightarrow\left\{[\mathrm{Li}(\mathrm{THF})]_{2}\left[\mathrm{PhP}(\mathrm{Te})\left(\mathrm{N} \mathrm{NBu}_{2}\right]\right\}_{2}\right. \\
& \left\{[\mathrm{Li}(\mathrm{THF})]_{2} \mathbf{4 3}\right\}_{2}\left(\mathrm{R}=\mathrm{Ph}, \mathrm{R}^{\prime}={ }^{\mathrm{t}} \mathrm{Bu}\right)
\end{aligned}
$$

Similarly, Chivers and co-workers showed that the reagents $\mathrm{Na}\left[\mathrm{N}\left(\mathrm{PR}_{2}\right)_{2}\right]$ react with tellurium in hot toluene in the presence of TMEDA to produce sodium salts of the anions $\left[\mathrm{N}\left(\mathrm{PR}_{2} \mathrm{Te}\right)_{2}\right]^{-}\left(\mathbf{4 5}, \mathrm{R}=\mathrm{Ph},{ }^{155}{ }^{\mathrm{i}} \mathrm{Pr},{ }^{156}{ }^{\mathrm{t}} \mathrm{Bu}^{157}\right)$ (Scheme 11). In the solid state the phenyl derivative exists as a centrosymmetric dimer $\left\{[\mathrm{Na}(\mathrm{TMEDA})]\left[\mathrm{N}\left(\mathrm{PPh}_{2} \mathrm{Te}\right)_{2}\right]\right\}_{2}$ in which the ligand is $T e, T e^{\prime}-$ chelated to TMEDA-solvated $\mathrm{Na}^{+}$ions and the monomer units are linked by strong $\mathrm{Na}-\mathrm{Te}$ 
interactions to form an approximately square $\mathrm{Na}_{2} \mathrm{Te}_{2}$ ring. ${ }^{155}$ The synthesis of the lithium derivative Li44 $\left(\mathrm{R}={ }^{\mathrm{i}} \mathrm{Pr}\right.$ ) by metallation of the monotelluride 28 (Figure 10) with ${ }^{\mathrm{n}} \mathrm{BuLi}$ in THF requires low temperatures $\left(-78{ }^{\circ} \mathrm{C}\right)$ to avoid disproportionation (Scheme 11); under these conditions the telluroimidodiphosphinate $44\left(\mathrm{R}={ }^{\mathrm{i}} \mathrm{Pr}\right)$ can be used as an in situ reagent for metathetical reactions (Section 7.3.3). ${ }^{158}$ This protocol is also the preferred procedure for the preparation of lithium derivatives of the mixed-chalcogen anions $\left[N\left(\mathrm{P}^{\mathrm{i}} \mathrm{Pr}_{2} \mathrm{E}\right)\left(\mathrm{P}^{\mathrm{i}} \mathrm{Pr}_{2} \mathrm{Te}\right)\right]^{-}(\mathrm{E}=\mathrm{S}, \mathrm{Se})$ via treatment of $\mathrm{Li44}$ $\left(\mathrm{R}={ }^{\mathrm{i}} \mathrm{Pr}\right)$ with sulfur or selenium in THF (Scheme 11). ${ }^{159}$

\section{Scheme 11. Synthesis of Alkali-Metal Salts of Mono and Ditelluridoimidodiphosphinates.}

Adapted from ref. 15. Copyright 2010 American Chemical Society.

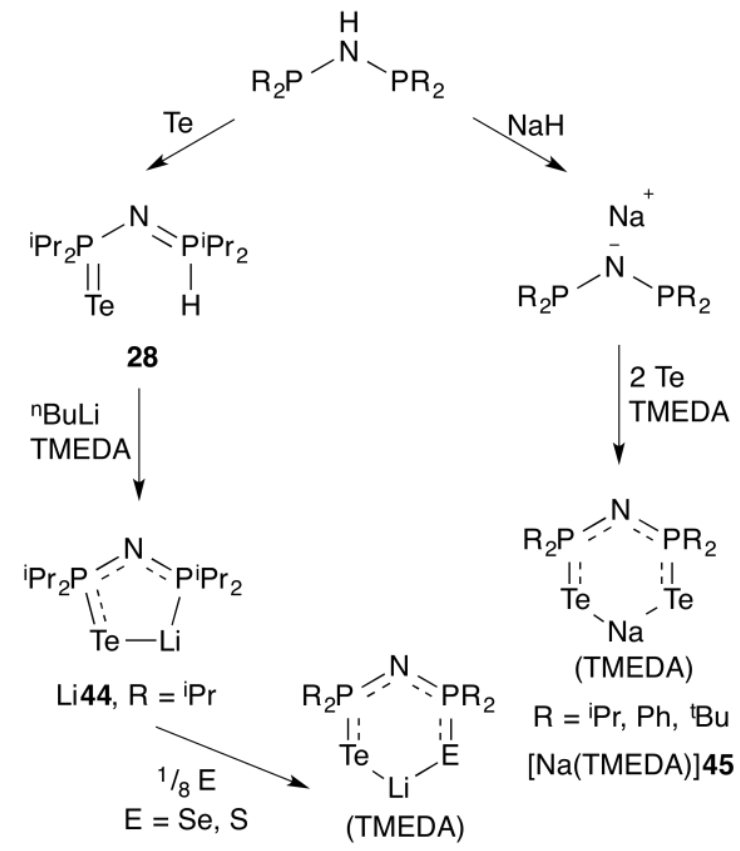

The ion-separated salt $\mathrm{Cp}_{2} \mathrm{Co}\left[\mathrm{N}\left(\mathrm{P}^{\mathrm{i}} \mathrm{Pr}_{2} \mathrm{Te}\right)_{2}\right]$ (Figure 20) is obtained by the two-electron reduction of the corresponding cation $\left[\mathrm{N}\left(\mathrm{P}^{\mathrm{i}} \mathrm{Pr}_{2} \mathrm{Te}\right)_{2}\right]^{+}$with cobaltocene. ${ }^{160}$ The related mixedchalcogen systems $\mathrm{Cp}_{2} \mathrm{Co}\left[\mathrm{N}\left(\mathrm{P}^{\mathrm{i}} \mathrm{Pr}_{2} \mathrm{E}\right)\left(\mathrm{P}^{\mathrm{i}} \mathrm{Pr}_{2} \mathrm{Te}\right)\right]$ are prepared by using a similar synthetic protocol. The ${ }^{1} J\left({ }^{31} \mathrm{P},{ }^{125} \mathrm{Te}\right)$ values of $1540-1570 \mathrm{~Hz}$ in these ion-separated salts are ca. 100-125 Hz larger than those in the corresponding lithium derivatives and, consistently, the Te-P bond lengths in the free anions are ca. $0.1 \AA$ shorter. The extremely air-sensitive, ion-separated salt 
$\left[\mathrm{Me}_{2} \mathrm{Al}(\mathrm{TMEDA})\right]\left[\mathrm{N}\left(\mathrm{P}^{\mathrm{i}} \mathrm{Pr}_{2} \mathrm{Te}\right)_{2}\right]$, which has been structurally characterized in the solid state, also incorporates the anion $45\left(\mathrm{R}={ }^{\mathrm{i}} \mathrm{Pr}\right)$ and exhibits a similar ${ }^{1} J\left({ }^{31} \mathrm{P},{ }^{125} \mathrm{Te}\right)$ value of $1560 \mathrm{~Hz} .{ }^{161}$

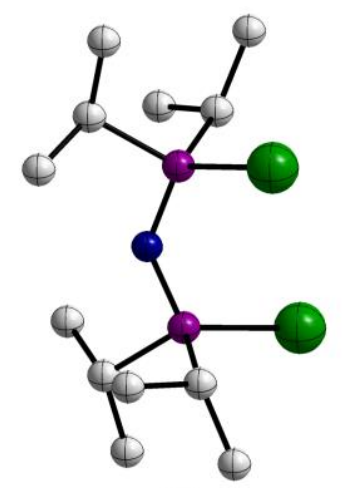

45

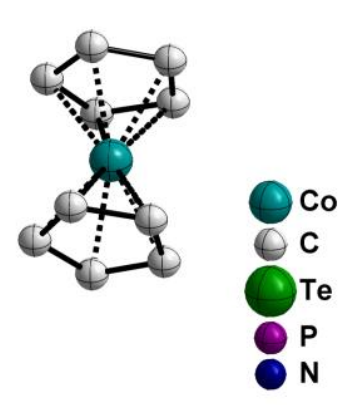

$\mathrm{N}$

Figure 20. Molecular structure of the $\left[\mathrm{N}\left(\mathrm{P}^{\mathrm{i}} \mathrm{Pr}_{2} \mathrm{Te}\right)_{2}\right]^{-}$anion $45\left(\mathrm{R}={ }^{\mathrm{i}} \mathrm{Pr}\right)$ in the $\mathrm{Cp}_{2} \mathrm{Co}^{+}$salt

\subsubsection{Redox Chemistry}

The structures of the dimers formed upon one electron-oxidation of the anions $\left[\mathrm{N}\left(\mathrm{PR}_{2} \mathrm{Te}\right)_{2}\right]^{-}$ with iodine are strongly influenced by the nature of the $\mathrm{R}$ group. When $\mathrm{R}={ }^{\mathrm{i}} \mathrm{Pr}$, the ditelluride (DT) $\mathbf{1}$ is formed in which the central Te-Te linkage is elongated by ca. $8 \%{ }^{30}$ compared with the mean value of $2.72 \AA$ (range 2.66-2.78 $\AA$ ) for typical ditellurides RTe-TeR. ${ }^{162}$ DFT calculations for the model system $\left(\mathrm{TePMe}_{2} \mathrm{NPMe}_{2} \mathrm{PTe}-\right)_{2}$ have provided insight into the nature of the $\mathrm{Te}-\mathrm{Te}$ bond in $\mathbf{1}$, which is shown to result from the bonding interaction between the SOMOs of two radicals (Figure 21).

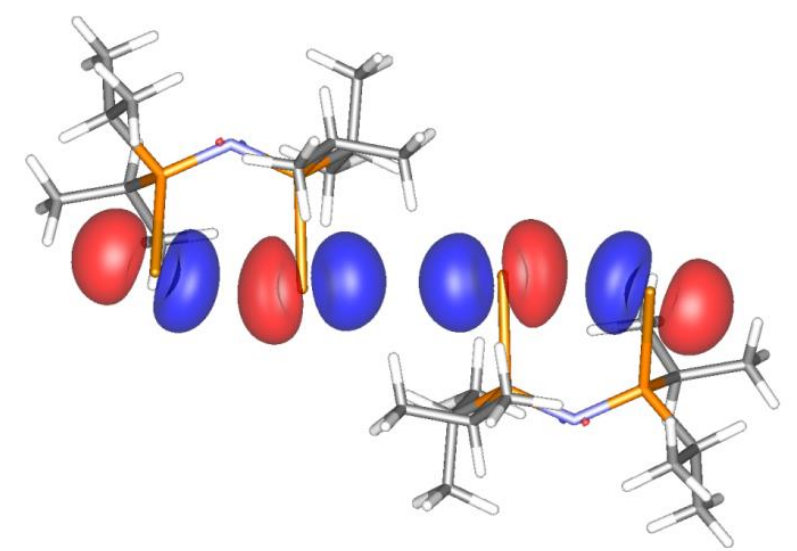


Figure 21. The SOMO-SOMO bonding interaction of two $\left[\mathrm{TePMe}_{2} \mathrm{NPMe}_{2} \mathrm{PTe}\right]^{\circ}$ radicals. Adapted from ref. 15. Copyright 2010 American Chemical Society.

By contrast, oxidation of the tert-butyl derivative $\left[\mathrm{N}\left(\mathrm{P}^{t} \mathrm{Bu}_{2} \mathrm{Te}\right)_{2}\right]^{-}$gives the unique spirocyclic compound 46 (Figure 22). ${ }^{157}$ The dimer 46 may be viewed as a contact ion pair (CIP) in which the $\left[\mathrm{N}\left(\mathrm{P}^{t} \mathrm{Bu}_{2} \mathrm{Te}\right)_{2}\right]^{-}$anion is $T e, T e^{\prime}$-chelated to one tellurium atom of the cyclic $\left[\mathrm{N}\left(\mathrm{P}^{\mathrm{t}} \mathrm{Bu}_{2} \mathrm{Te}\right)_{2}\right]^{+}$cation as a result of an internal redox process. The Te-Te-Te unit in $\mathbf{4 6}$ is almost linear with long Te-Te distances of 2.981 and $3.102 \AA$. The elongation of the Te-Te bond in the five-membered cation is the result of the donation of electron density from the anionic part of the dimer into the LUMO $\left[\sigma^{*}(\mathrm{Te}-\mathrm{Te})\right]$ of the cation (vide infra). ${ }^{157}$ The anion-cation interaction also results in a disparity of $0.19 \AA$ in the $\mathrm{P}-\mathrm{Te}$ bond lengths of the cationic part of $\mathbf{4 6}$. Consistent with the experimental findings, DFT calculations of the relative energies of the two structural types reveal that the CIP is more stable than the DT isomer for $\mathrm{R}={ }^{\mathrm{t}} \mathrm{Bu}$ by ca. $20 \mathrm{~kJ} \mathrm{~mol}^{-1}$, whereas the two structural arrangements are similar in energy for $\mathrm{R}={ }^{\mathrm{i}} \mathrm{Pr} .{ }^{157}$ The ${ }^{31} \mathrm{P}$ NMR spectrum of 46 exhibits four singlet resonances at low temperature, consistent with the four different phosphorus environments in the solid-state structure, ${ }^{157}$ whereas the ${ }^{31} \mathrm{P}$ NMR spectrum of the structural isomer 1, which is a centrosymmetric dimer in the solid state, is comprised of mutually coupled doublets. ${ }^{30}$

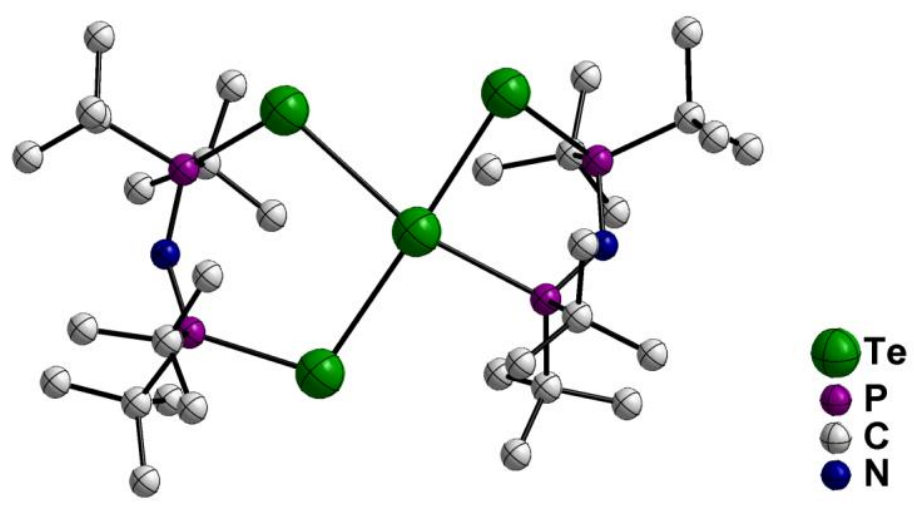

46

Figure 22. Molecular structure of the spirocyclic contact ion pair $\left(\mathrm{TeP}^{t} \mathrm{Bu}_{2} \mathrm{NP}^{t} \mathrm{Bu}_{2} \mathrm{PTe}\right)_{2}$ (46) 
Although oxidation of the mixed chalcogen anions $\left[\mathrm{N}\left(\mathrm{P}^{\mathrm{i}} \mathrm{Pr}_{2} \mathrm{E}\right)\left(\mathrm{P}^{\mathrm{i}} \mathrm{Pr}_{2} \mathrm{Te}\right)\right]^{-}(\mathrm{E}=\mathrm{S}, \mathrm{Se})$ does not proceed cleanly, one-electron reduction of the corresponding cyclic cations $\left[\mathrm{N}\left(\mathrm{P}^{\mathrm{i}} \mathrm{Pr}_{2} \mathrm{E}\right)\left(\mathrm{P}^{\mathrm{i}} \mathrm{Pr}_{2} \mathrm{Te}\right)\right]^{+}$(vide infra) with cobaltocene produces the corresponding ditellurides, $\left(\mathrm{EP}^{\mathrm{i}} \mathrm{Pr}_{2} \mathrm{NP}^{\mathrm{i}} \mathrm{Pr}_{2} \mathrm{PTe}-\right)_{2}{ }^{160}$ The elongation of the Te-Te bond in these mixed chalcogen systems is less pronounced than that in the all-tellurium system because the SOMO of the neutral radicals $\left[\mathrm{EP}^{\mathrm{i}} \mathrm{Pr}_{2} \mathrm{NP}^{\mathrm{i}} \mathrm{Pr}_{2} \mathrm{PTe}\right]^{\bullet}(\mathrm{E}=\mathrm{S}, \mathrm{Se})$ will be polarized toward the more electropositive tellurium center (Figure 21).

Two-electron oxidation of the anions $\left[\mathrm{N}\left(\mathrm{PR}_{2} \mathrm{Te}\right)_{2}\right]^{-}$with $\mathrm{I}_{2}$ produces the corresponding cyclic cations $\left[\mathrm{N}\left(\mathrm{PR}_{2} \mathrm{Te}\right)_{2}\right]^{+}$with iodide counter-ions. ${ }^{163,164}$ The solid-state structures of these iodide salts depend on the nature of the substituent on the $\mathrm{P}$ atoms. Thus, the isopropyl derivative $47 \mathbf{a}$ forms an infinite chain of non-planar cations linked by Te $\cdots$ I interactions (Figure 23a), ${ }^{163}$ whereas the phenyl derivative $\mathbf{4 7} \mathbf{b}$ is dimeric (Figure 23b). ${ }^{164}$ The Te-Te bond lengths in $47 \mathbf{a}(2.840 \AA)$ and 47b (2.846 $\AA$ ) are slightly elongated as a result of electron donation from the $\mathrm{I}^{-}$counter-ion into the LUMO $\left[\sigma^{*}(\mathrm{Te}-\mathrm{Te})\right]$ of the cation (Figure 24$)$. In support of this explanation, the replacement of the iodide counterion in $\mathbf{4 7 a}$ by $\mathrm{SbF}_{6}{ }^{-}$produces an ion-separated salt with a typical Te-Te distance of $2.716 \AA^{164}$ The mixed chalcogen cations $\left[\mathrm{N}\left(\mathrm{P}^{\mathrm{i}} \mathrm{Pr}_{2} \mathrm{E}\right)\left(\mathrm{P}^{\mathrm{i}} \mathrm{Pr}_{2} \mathrm{Te}\right)\right]^{+}$, which are prepared by stoichiometric oxidation of the corresponding anions with $\mathrm{I}_{2}$, exhibit preferential bonding of the iodide counter-ion to tellurium because the LUMO depicted in Figure 24 is polarized towards the more electropositive chalcogen. ${ }^{160}$

a)

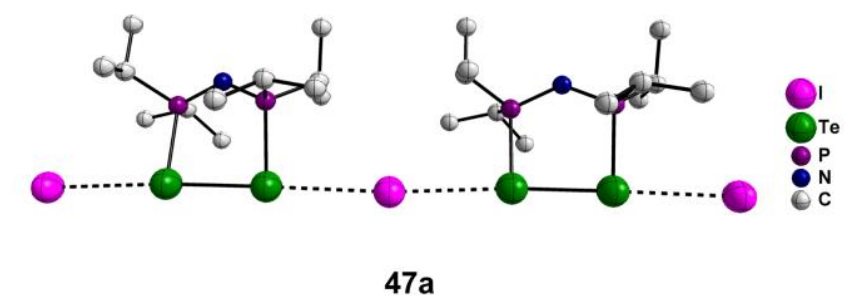

b)

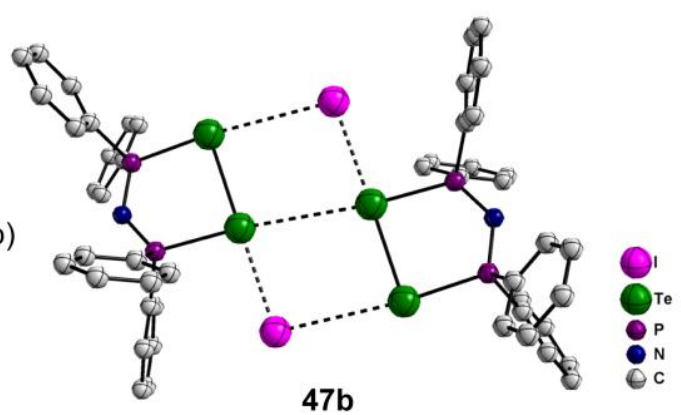


Figure 23. Molecular structures of (a) $\left[\mathrm{N}\left(\mathrm{P}^{\mathrm{i}} \mathrm{Pr}_{2} \mathrm{Te}\right)_{2}\right] \mathrm{I}(\mathbf{4 7 a})$ and (b) $\left[\left(\mathrm{NPPh}_{2} \mathrm{Te}\right)_{2}\right] \mathrm{I}(\mathbf{4 7 b})$

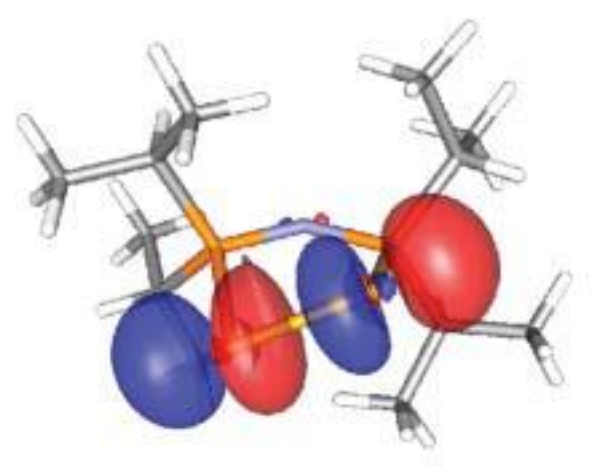

LUMO

Figure 24. The LUMO of the cation $\left[\left(\mathrm{NP}^{\mathrm{i}} \mathrm{Pr}_{2} \mathrm{Te}\right)_{2}\right]^{+}$. Adapted from ref. 15. Copyright 2010 American Chemical Society.

The five-membered cation $\left[\left(\mathrm{NP}^{\mathrm{i}} \mathrm{Pr}_{2} \mathrm{Te}\right)_{2}\right]^{+}$is formally a $6 \pi$-electron system, but the net $\pi$ bond order is close to zero because the bonding effect of the Te-Te $\pi$-bonding orbital (HOMO-2) is approximately canceled by the occupation of the Te-Te $\pi^{*}$-antibonding orbital (HOMO); the third occupied $\pi$-orbital (HOMO-1) is primarily a nonbonding nitrogen-centered orbital. ${ }^{15,163}$

\subsection{3 p-Block, d-Block and f-Block Metal Complexes}

Recent interest in metal complexes of anionic P-Te ligands of the type 42-45 was spurred by the possibility of using them as single-source precursors for the generation of metal telluride thin films or quantum dots (Section 8). ${ }^{16}$ In early work Bochmann and co-workers developed methods for the preparation of several thermally stable, homoleptic complexes of $\mathbf{4 2}$ with divalent metals (48, $\mathrm{M}=\mathrm{Zn}, \mathrm{Cd}, \mathrm{Cr}, \mathrm{Mn}, \mathrm{Fe}, \mathrm{Co})$ via protolysis of the metal amides $\mathrm{M}\left[\mathrm{N}\left(\mathrm{SiMe}_{3}\right)_{2}\right]_{2}$ with a phosphinotelluroic amide (Scheme 12). ${ }^{165,166}$ The complexes 48 were investigated as potential sources of the corresponding binary metal tellurides (Section 8).

\section{Scheme 12. Synthesis of Metal Complexes of Telluroimidophosphinites}


$\mathrm{M}\left[\mathrm{N}\left(\mathrm{SiMe}_{3}\right)_{2}\right]_{2}+2{ }_{\mathrm{t}}^{\mathrm{B} u}$

$48\left(\mathrm{M}=\mathrm{Zn}, \mathrm{Cd}, \mathrm{Cr}, \mathrm{Mn}, \mathrm{Fe}, \mathrm{Co} ; \mathrm{R}={ }^{\mathrm{i}} \mathrm{Pr}, \mathrm{Cy}\right)$

Extensive studies of the metathetical reactions of alkali-metal derivatives of the ditelluroimidodiphosphinates $45\left(\mathrm{R}={ }^{\mathrm{i}} \mathrm{Pr}\right)$ with main group, transition-metal, lanthanide, and actinide halides have generated homoleptic complexes $\mathrm{M}\left[\mathrm{N}\left(\mathrm{P}^{\mathrm{i}} \mathrm{Pr}_{2} \mathrm{Te}\right)_{2}\right]_{\mathrm{n}}{ }^{15,161}$ with square-planar (49, $\left.\mathrm{n}=2, \mathrm{M}=\mathrm{Ni},{ }^{167} \mathrm{Pd},{ }^{168} \mathrm{Pt}^{168}\right)$, distorted tetrahedral $(\mathbf{5 0}, \mathrm{n}=2, \mathrm{M}=\mathrm{Zn}, \mathrm{Cd}, \mathrm{Hg}),{ }^{156}$ distorted octahedral $\left(\mathbf{5 1}, \mathrm{n}=3, \mathrm{M}=\mathrm{Sb},{ }^{156} \mathrm{Bi},{ }^{156} \mathrm{La},{ }^{169} \mathrm{U},{ }^{169} \mathrm{Pu},{ }^{170} \mathrm{Ce}^{170}\right)$ or pseudo-trigonal bipyramidal (52, $\mathrm{n}=2, \mathrm{M}=\mathrm{Sn},{ }^{171} \mathrm{~Pb}^{171}$ ) geometries (Fogure 25). In contrast to the monomeric structures of 49-52, the thallium(I) complex $\left\{\mathrm{Tl}\left[\mathrm{N}\left(\mathrm{P}^{\mathrm{i}} \mathrm{Pr}_{2} \mathrm{Te}\right)_{2}\right]\right\}_{\infty}$, which is prepared from $[\mathrm{Na}(\mathrm{TMEDA})] 45$ and $\mathrm{TlOEt}$, forms infinite chains linked by $\mathrm{Tl} \cdots \mathrm{Te}$ interactions in which six-coordinate $\mathrm{Tl}$ centers are bridged by two different $\left[\mathrm{N}\left(\mathrm{P}^{\mathrm{i}} \mathrm{Pr}_{2} \mathrm{Te}\right)_{2}\right]^{-}$ligands arranged approximately perpendicular to each other. ${ }^{172}$ The structure of the square-planar tellurium(II) complex $\mathrm{Te}\left[\mathrm{N}\left(\mathrm{P}^{\mathrm{i}} \mathrm{Pr}_{2} \mathrm{Te}\right)_{2}\right]_{2}$ has been reported recently. ${ }^{173}$

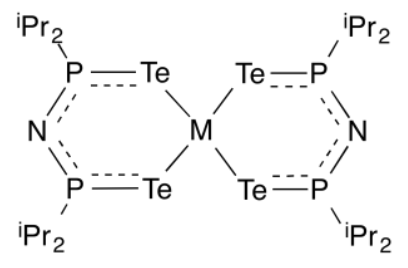

$49(\mathrm{M}=\mathrm{Ni}, \mathrm{Pd}, \mathrm{Pt})$

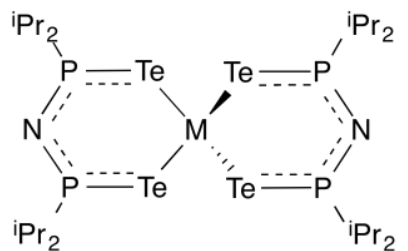

$50(\mathrm{M}=\mathrm{Zn}, \mathrm{Cd}, \mathrm{Hg})$

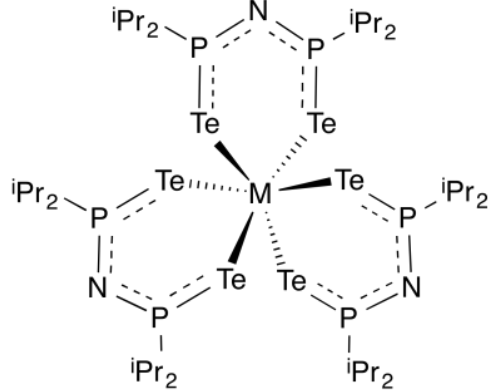

$51(M=S b, B i, L a, U, P u)$

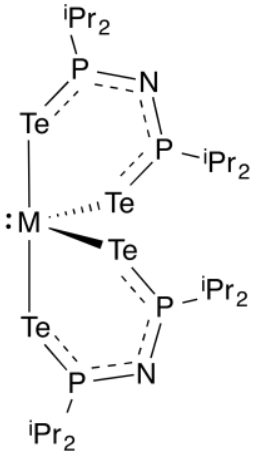

$52(\mathrm{M}=\mathrm{Sn}, \mathrm{Pb})$

Figure 25. Metal Complexes of $45\left(\mathrm{R}={ }^{\mathrm{i}} \mathrm{Pr}\right)$. Adapted from ref. 15. Copyright 2010 American Chemical Society. 
Coinage metal complexes provide a cogent example of the proclivity of the telluriumcentered ligands $\mathbf{4 5}$ to adopt a doubly bridging mode. ${ }^{174}$ For example, one of the ligands in the trimeric copper(I) complex $\left\{\mathrm{Cu}\left[\mathrm{N}\left(\mathrm{P}^{\mathrm{i}} \mathrm{Pr}_{2} \mathrm{Te}\right)_{2}\right]\right\}_{3}$ (53) exhibits this behavior (Figure 26a). The flexibility of the ditellurido ligands $\mathbf{4 5}$ is also evident in the hexameric silver(I) complex $\left\{\mathrm{Ag}\left[\mathrm{N}\left(\mathrm{P}^{\mathrm{i}} \mathrm{Pr}_{2} \mathrm{Te}\right)_{2}\right]\right\}_{6}$ (54), which forms a twelve-membered $\mathrm{Ag}_{6} \mathrm{Te}_{6}$ ring (Figure 26b). ${ }^{174}$ By contrast, a change of the substituents on phosphorus from ${ }^{\mathrm{i}} \mathrm{Pr}$ to $\mathrm{Ph}$ generates the tetramer $\left\{\mathrm{Ag}\left[\mathrm{N}\left(\mathrm{PPh}_{2} \mathrm{Te}\right)_{2}\right]\right\}_{4}(\mathbf{5 5})$ in the form of a centrosymmetric chair-shaped $\mathrm{Ag}_{4} \mathrm{Te}_{4}$ ring (Figure 26c). ${ }^{174}$
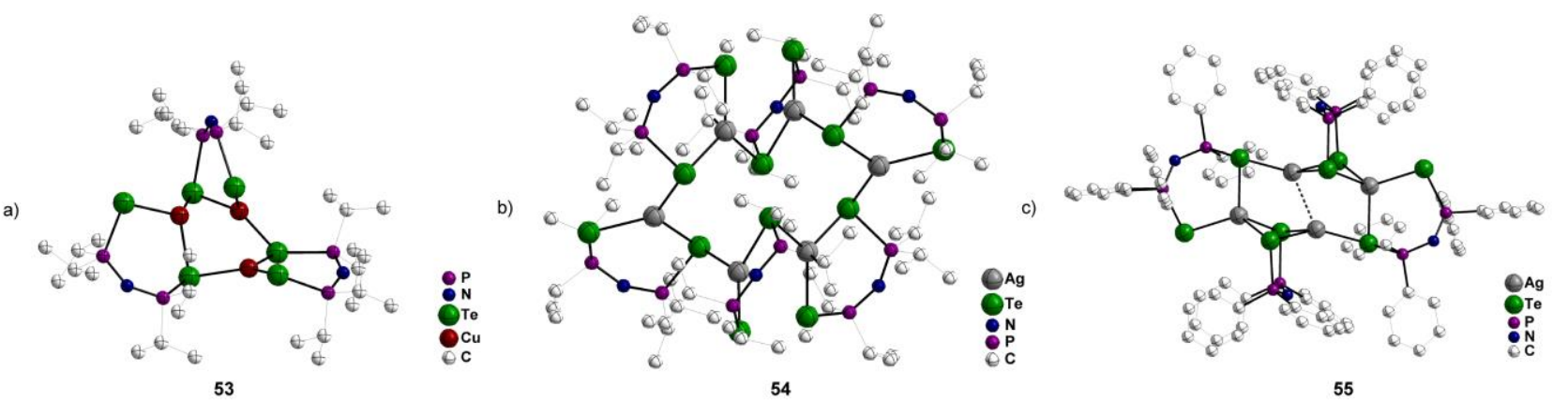

Figure 26. Molecular structures of (a) $\left\{\mathrm{Cu}\left[\mathrm{N}\left(\mathrm{P}^{\mathrm{i}} \mathrm{Pr}_{2} \mathrm{Te}\right)_{2}\right]\right\}_{3}(\mathbf{5 3})$ (b) $\left\{\mathrm{Ag}\left[\mathrm{N}\left(\mathrm{P}^{\mathrm{i}} \mathrm{Pr}{ }_{2} \mathrm{Te}\right)_{2}\right]\right\}_{6}(\mathbf{5 4})$ and (c) $\left\{\mathrm{Ag}\left[\mathrm{N}\left(\mathrm{PPh}_{2} \mathrm{Te}\right)_{2}\right]\right\}_{4}(\mathbf{5 5})$

The lability of the P-Te bond is illustrated by the outcome of the attempted synthesis of homoleptic complexes of $\mathrm{Ga}(\mathrm{III})$, In(III) and $\mathrm{Au}(\mathrm{I})$ via metathesis. ${ }^{175,176}$ In all three cases a tellurium-transfer process occurs to give the novel metal-tellurium rings $\{\mathrm{Ga}(\mu$ $\left.\mathrm{Te})\left[{ }^{\mathrm{i}} \operatorname{Pr}_{2} \mathrm{PN}^{\mathrm{i}} \mathrm{Pr}_{2} \mathrm{PTe}\right]\right\}_{2}$ (56) (Figure 27a), ${ }^{175}\left\{\operatorname{In}(\mu-\mathrm{Te})\left[\mathrm{N}\left(\mathrm{P}^{\mathrm{i}} \operatorname{Pr}_{2} \mathrm{Te}\right)_{2}\right]\right\}_{3}$ (57) (Figure 27b), ${ }^{175}$ and $\left\{\mathrm{Au}(\mu-\mathrm{Te})\left[\mathrm{R}_{2} \mathrm{PNR}{ }_{2} \mathrm{PTe}\right]\right\}_{2}\left(\mathbf{5 8}, \mathrm{R}=\mathrm{Ph},{ }^{\mathrm{i}} \mathrm{Pr},{ }^{\mathrm{t}} \mathrm{Bu}\right)($ Scheme 13$) .{ }^{176}$ Both 56 and $\mathbf{5 8}$ are formed as a mixture of cis and trans isomers. ${ }^{175,176}$ Interestingly, in the case of the gold system the tellurium transfer, which involves an intramolecular oxidative addition, can be reversed. Thus, addition of $\mathrm{Ph}_{3} \mathrm{P}$ to the $\mathrm{Au}{ }^{\mathrm{III}}$ complexes 58 produces the $\mathrm{Au}^{\mathrm{I}}$ complexes $\mathrm{Au}\left(\mathrm{PPh}_{3}\right)\left[\mathrm{N}\left(\mathrm{PR}_{2} \mathrm{Te}\right)_{2}\right](\mathbf{5 9})(\mathrm{Scheme}$ 
14), which are also formed via metathesis of $[\mathrm{Na}(\mathrm{TMEDA})] 45$ with $\mathrm{AuCl}$ in the presence of triphenylphosphine. ${ }^{176}$

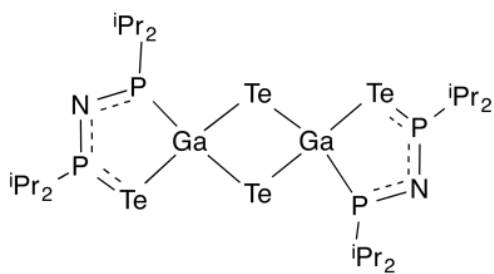

56

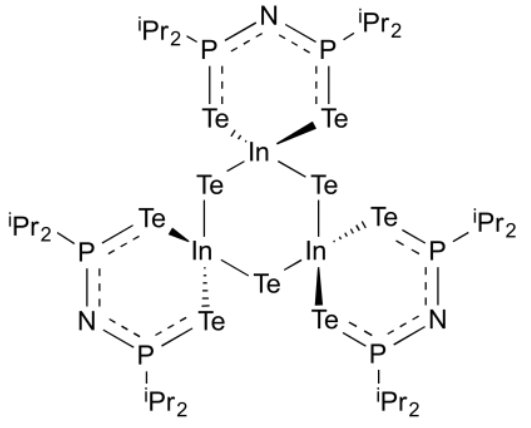

57

Figure 27. Group 13 complexes formed by tellurium transfer

Scheme 13. Reversible Tellurium Transfer in Gold Complexes. Adapted from ref. 176. Copyright 2009 Canadian Science Publishing (NRC Research Press).

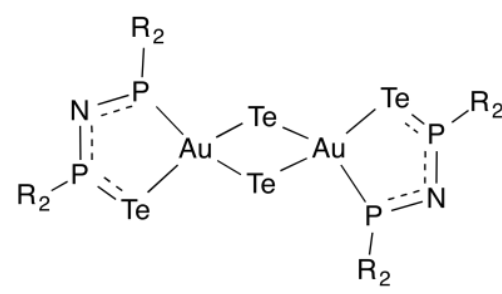

$58(\mathrm{R}=\mathrm{Ph}, \mathrm{i} P r, \mathrm{~B} u)$<smiles>[R2][P]1=N[Te](P)=[Te][Te][Te]1</smiles>

59

Homoleptic group 10 complexes of the mixed chalcogen ligands $\mathrm{M}\left[\mathrm{N}\left(\mathrm{P}^{\mathrm{i}} \mathrm{Pr}_{2} \mathrm{E}\right)\left(\mathrm{P}^{\mathrm{i}} \mathrm{Pr}_{2} \mathrm{Te}\right)\right]_{2}(\mathrm{M}$ $=\mathrm{Ni}, \mathrm{Pd} ; \mathrm{E}=\mathrm{S}, \mathrm{Se}$ ) are prepared by metathesis between the corresponding Li reagents (Scheme 11) and $\mathrm{NiBr}_{2}(\mathrm{DME})^{177}(\mathrm{DME}=$ dimethoxyethane $)$ or $\mathrm{MCl}_{2}(\mathrm{COD})(\mathrm{COD}=1,5$-cycloctadiene $) .{ }^{168}$ The $\mathrm{Pd}$ and Pt complexes exist as a mixture of cis and trans isomers in solution, ${ }^{168}$ whereas the $\mathrm{Ni}^{\mathrm{II}}$ complexes are isolated as the square-planar trans isomers. ${ }^{177}$ By contrast the closely related mixed chalcogen $\mathrm{Ni}^{\mathrm{II}}$ complex $\mathrm{Ni}\left[\mathrm{N}\left(\mathrm{P}^{\mathrm{i}} \mathrm{Pr}_{2} \mathrm{~S}\right)\left(\mathrm{P}^{\mathrm{i}} \mathrm{Pr}_{2} \mathrm{Se}\right)\right]_{2}$ adopts a tetrahedral structure in the solid state. ${ }^{178}$ 
The monotellurido reagent $\mathrm{Li44}\left(\mathrm{R}={ }^{\mathrm{i}} \mathrm{Pr}\right.$, Figure 19) can be used as an in situ reagent at low temperatures for the preparation of homoleptic metal complexes via metathesis (Section 7.3.1). ${ }^{158}$ Under these conditions homoleptic complexes of the type $\mathrm{M}\left(\mathrm{TeP}^{\mathrm{i}} \mathrm{Pr}_{2} \mathrm{~N}^{\mathrm{i}} \mathrm{Pr}_{2} \mathrm{P}\right)_{2}$ with distorted tetrahedral $(\mathrm{M}=\mathrm{Zn}, \mathrm{Cd}, \mathrm{Hg})^{158}$ or square-planar $\left(\mathrm{M}=\mathrm{Ni},{ }^{177} \mathrm{Pd},{ }^{168} \mathrm{Pt}^{168}\right)$ structures are obtained. The Ni complex is formed exclusively as the trans isomer, ${ }^{177}$ whereas cis and trans isomers can be separated by fractional crystallization for the Pd analogue. ${ }^{168}$

The trimeric group 11 complexes $\left[\mathrm{M}\left(\mathrm{TeP}^{\mathrm{i}} \operatorname{Pr}_{2} \mathrm{~N}^{\mathrm{i}} \operatorname{Pr}_{2} \mathrm{P}\right)\right]_{3}(\mathbf{6 0 a}, \mathrm{M}=\mathrm{Cu} ; \mathbf{6 0 b}, \mathrm{M}=\mathrm{Ag})$ adopt interesting architectures in which the tellurium centers bridge two metal atoms to give highly distorted chair-like $\mathrm{M}_{3} \mathrm{Te}_{3}$ rings, which readily undergo chalcogen insertion reactions (into the $\mathrm{Cu}-$ $\mathrm{P}$ bond) to give the mixed-chalcogen complexes $\left[\mathrm{Cu}\left(\mathrm{TeP}^{\mathrm{i}} \operatorname{Pr}_{2} \mathrm{~N}^{\mathrm{i}} \operatorname{Pr}_{2} \mathrm{PE}\right)\right]_{3}(\mathbf{6 1 a}, \mathrm{E}=\mathrm{O} ; \mathbf{6 1 b}, \mathrm{E}=\mathrm{S}$; 61c, $\mathrm{E}=\mathrm{Se}$ ) in which the tellurium sites occupy bridging positions (Scheme 14). ${ }^{179}$

\section{Scheme 14. Synthesis of Mixed Chalcogen Complexes $\left[\mathrm{Cu}\left(\operatorname{TeP}^{\mathrm{i}} \operatorname{Pr}_{2} \mathrm{~N}^{\mathrm{i}} \operatorname{Pr}_{2} \mathrm{PE}\right)\right]_{3}$}

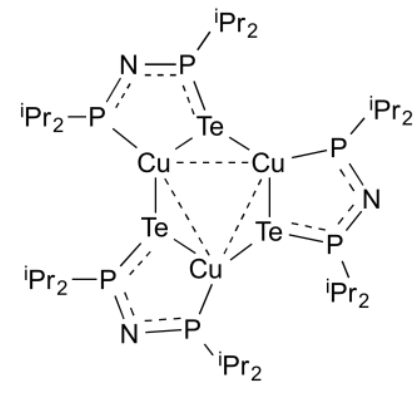

$60 \mathrm{a}$

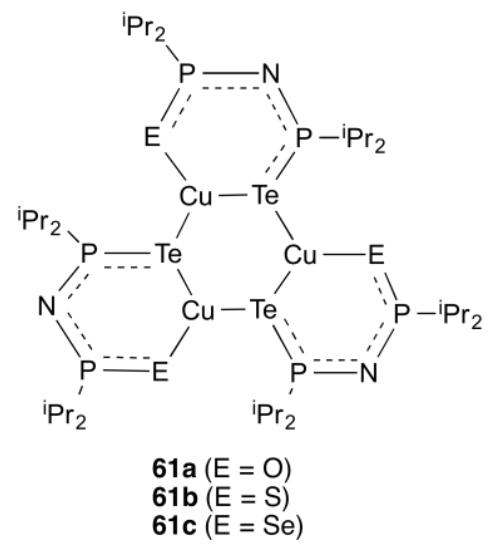

\subsection{PCP-Bridged Tellurium-Centered Anions}

The PCP-bridged anions $\left[\mathrm{HC}\left(\mathrm{PR}_{2}\right)\left(\mathrm{PR}_{2} \mathrm{Te}\right)\right]^{-}$and $\left[\mathrm{HC}\left(\mathrm{PR}_{2} \mathrm{Te}\right)_{2}\right]^{-}$are formally isoelectronic with the PNP-bridged anions $\left[\mathrm{N}\left(\mathrm{PR}_{2}\right)\left(\mathrm{PR}_{2} \mathrm{Te}\right)\right]^{-}(\mathbf{4 4})$ and $\left[\mathrm{N}\left(\mathrm{PR}_{2} \mathrm{Te}\right)_{2}\right]^{-}(\mathbf{4 5})$, which were discussed in Section 7.3.1. In 1987 Lusser and Peringer reported the formation of the lithium reagent $\mathrm{Li}\left[\mathrm{HC}\left(\mathrm{PPh}_{2}\right)\left(\mathrm{PPh}_{2} \mathrm{Te}\right)\right]($ 62) via the metallation-first approach and used it as an in situ reagent to prepare the homoleptic mercury complex $\mathrm{Hg}\left[\mathrm{HC}\left(\mathrm{PPh}_{2}\right)\left(\mathrm{PPh}_{2} \mathrm{Te}\right)\right]_{2}\left((\mathrm{Scheme} 15) .{ }^{180}\right.$ More than 20 
years later, Konu and Chivers isolated TMEDA.62 as a yellow powder in high yield. ${ }^{181}$ In the solid state $\mathbf{6 2}$ exists as a centrosymmetric dimer with an intermolecular Te $\cdots$ Te close contact of $3.514 \AA$ (Figure 28). The calculated bond order indicates that the Li-Te contact approaches a covalent bond with a value of 0.9 . The reaction of TMEDA $\cdot \mathrm{Li}\left[\mathrm{HC}\left(\mathrm{PPh}_{2}\right)_{2}\right]$ with two equivalents of tellurium produces the thermally unstable ditelluro anion $\left[\mathrm{HC}\left(\mathrm{PR}_{2} \mathrm{Te}\right)_{2}\right]^{-}\left({ }^{1} J\left({ }^{31} \mathrm{P},{ }^{125} \mathrm{Te}=1376 \mathrm{~Hz}\right)\right.$, but the lithium derivative could not be isolated in the solid state. ${ }^{181}$

\section{Scheme 15. Synthesis of $\mathrm{Hg}\left[\mathrm{HC}\left(\mathrm{PPh}_{2}\right)\left(\mathrm{PPh}_{2} \mathrm{Te}\right)\right]_{2}$ from 62}

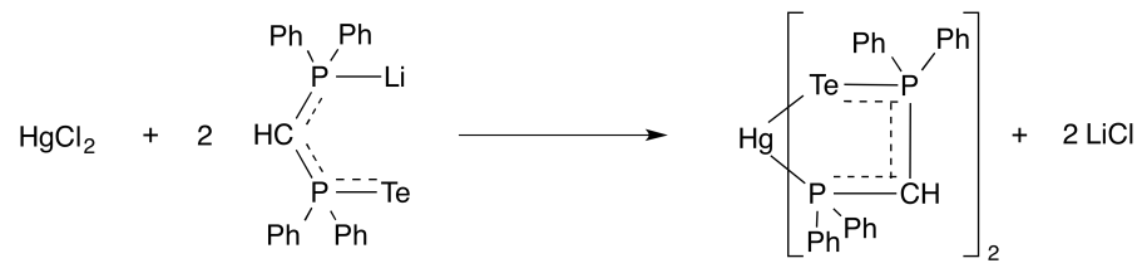

62

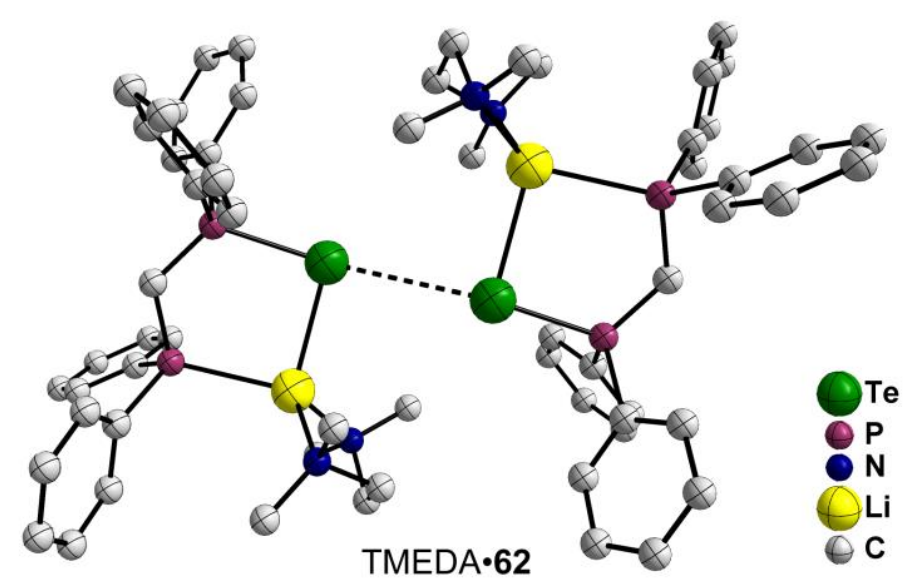

Figure 28. Molecular structure of TMEDA·Li $\left[\mathrm{HC}\left(\mathrm{PPh}_{2}\right)\left(\mathrm{PPh}_{2} \mathrm{Te}\right)\right](\mathrm{TMEDA} \cdot 62)$

\subsection{A Carbon-Bridged P-Te-Al Heterocycle}

The intriguing, dark red heterocycle $\mathbf{6 3}$ is obtained in good yield by oxidation of the $\mathrm{P}^{\mathrm{III}}$ center in the frustrated Lewis pair (FLP) $\mathrm{Mes}_{2} \mathrm{PC}\left(=\mathrm{CHC}_{6} \mathrm{H}_{5}\right) \mathrm{Al}^{\mathrm{t}} \mathrm{Bu}_{2}$ with tellurium at $100{ }^{\circ} \mathrm{C}$ in toluene (Scheme 16). ${ }^{182}$ 


\section{Scheme 16. Synthesis of the Carbon-Bridged P-Te-Al Heterocycle 63}

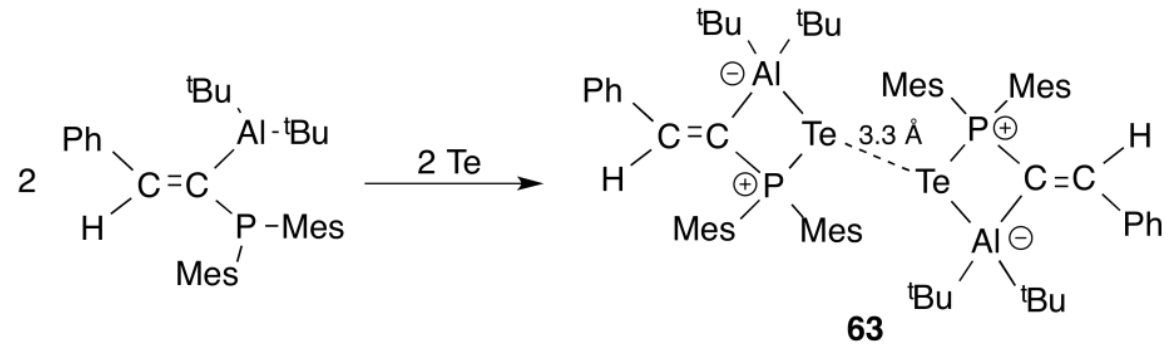

In the solid state the structure of $\mathbf{6 3}$ (Figure 29) resembles that of TMEDA.62 (Figure 28) in exhibiting a dimeric structure with a short intermolecular Te $\cdots$ Te contact of $3.33 \AA$. The P-Te bond length of 2.4651(4) $\AA$ is ca. $0.06 \AA$ longer than that in TMEDA.62. Consistently, the values of ${ }^{1} J\left({ }^{31} \mathrm{P},{ }^{125} \mathrm{Te}\right)$ differ substantially, $938 \mathrm{~Hz}^{182}$ vs. $1358 \mathrm{~Hz} .{ }^{181}$ The value observed for $\mathbf{6 3}$ is notably smaller than those observed for organophosphine tellurides with one-coordinate tellurium (Table 3), but it is comparable to that found for the bridging $\mathrm{P}^{\mathrm{V}}-\mathrm{Te}$ unit in the dimer $\left(\mathrm{TeP}^{\mathrm{i}} \mathrm{Pr}_{2} \mathrm{NP}^{\mathrm{i}} \mathrm{Pr}_{2} \mathrm{PTe}-\right)_{2}$ (1) for which ${ }^{1} J\left({ }^{31} \mathrm{P},{ }^{125} \mathrm{Te}\right)=1026 \mathrm{~Hz}$ and $d(\mathrm{P}-\mathrm{Te})=2.489(2) \AA$ and the Te center is twocoordinate (Section 2 and Table 3). In view of the known difficulties in the synthesis of triarylphosphine tellurides (Section 6.1), and their thermal instability, the high-yield synthesis of $\mathbf{6 3}$ is remarkable and suggests that the Al-Te interaction provides a stabilizing influence on the $\mathrm{P}-\mathrm{Te}$ bond. $^{182}$

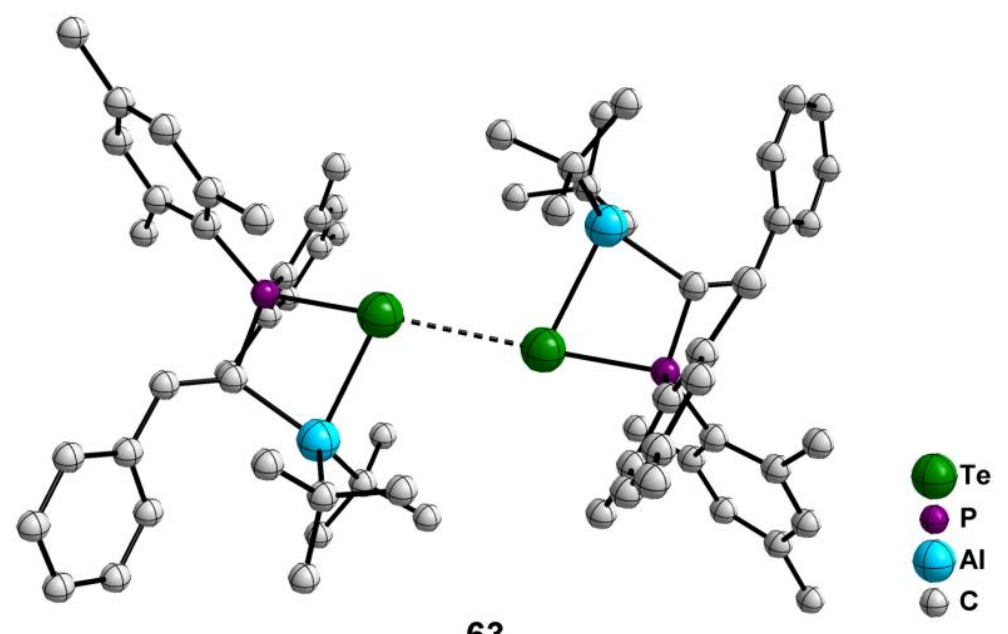

63 
Figure 29. Molecular structure of the carbon-bridged $\mathrm{P}-\mathrm{Te}-\mathrm{Al}$ heterocycle $\mathbf{6 3}$

\subsection{Tellurium-Centered Anions Supported by a $\mathbf{P}_{2} \mathbf{N}_{2}$ Ring}

\subsubsection{Alkali Metal Derivatives}

The tellurium-centered dianionic ligand $\left[{ }^{t} \mathrm{BuN}(\mathrm{E}) \mathrm{P}\left(\mu-\mathrm{N}^{\mathrm{t}} \mathrm{Bu}\right)_{2} \mathrm{P}(\mathrm{E}) \mathrm{N}^{\mathrm{t}} \mathrm{Bu}\right]^{2-}(\mathbf{6 4}, \mathrm{E}=\mathrm{Te})$ resembles the ditellurimidodiphosphinates 44 (Figure 19) with the important difference that the former has a double negative charge. Furthermore, the two tellurium centers in $\mathbf{6 4}$ are bridged by a fourmembered $\mathrm{P}_{2} \mathrm{~N}_{2}$ ring with exocyclic NR substituents, whereas those in $\mathbf{4 4}$ are linked by a PNP unit. Consequently, the dianion 64 may adopt a variety of bonding modes with metal centers as illustrated by the solid-state structures of the alkali-metal derivatives. The dilithium compound $[\mathrm{Li}(\mathrm{TMEDA})]_{2} \mathbf{6 4}(\mathrm{E}=\mathrm{Te})$ exhibits asymmetric $T e, T e^{\prime}$ and $N, T e$ coordination to the $\mathrm{Li}^{+}$ions, ${ }^{155}$ whereas the disodium analog $[\mathrm{Na}(\mathrm{TMEDA})]_{2} 64(\mathrm{E}=\mathrm{Te})$ adopts a symmetric $N, N^{\prime}$ and $T e, T e^{\prime}$ arrangement (Figure 30) ${ }^{183}$ reminiscent of the structures of the sulfur and selenium analogs $\left[\mathrm{Na}(\mathrm{THF})_{2}\right]_{2} \mathbf{6 4}(\mathrm{E}=\mathrm{S}, \mathrm{Se}){ }^{184,185}$

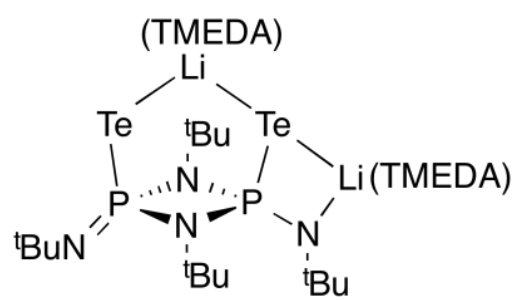

$[\mathrm{Li}(\mathrm{TMEDA})]_{2} 64$

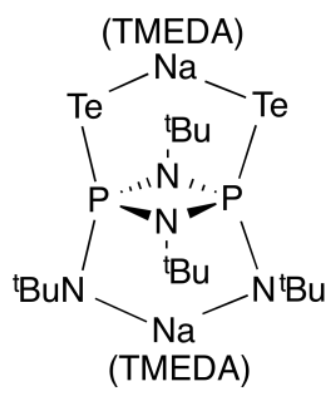

$[\mathrm{Na}(\mathrm{TMEDA})]_{2} 64$

Figure 30. Bonding modes of alkali-metal complexes of $64(\mathrm{E}=\mathrm{Te})$

\subsubsection{Redox Chemistry}


The behavior of the dianions 64 upon oxidation is markedly dependent on the nature of the chalcogen. The two-electron oxidation of $\left[\mathrm{Na}(\mathrm{THF})_{2}\right]_{2} \mathbf{6 4}(\mathrm{E}=\mathrm{S}, \mathrm{Se})$ with $\mathrm{I}_{2}$ produces the macrocycles 65 in which a planar $\mathrm{P}_{6} \mathrm{E}_{6}(\mathrm{E}=\mathrm{S}, \mathrm{Se})$ framework is anchored by perpendicular $\mathrm{P}_{2}{ }_{2} \mathrm{~N}_{2}$ rings (Scheme 17). ${ }^{186}$

\section{Scheme 17. Formation of Macrocycles upon Oxidation of $\left[\mathrm{Na}(\mathrm{THF})_{2}\right]_{2} 64(\mathrm{E}=\mathrm{S}, \mathrm{Se})$}

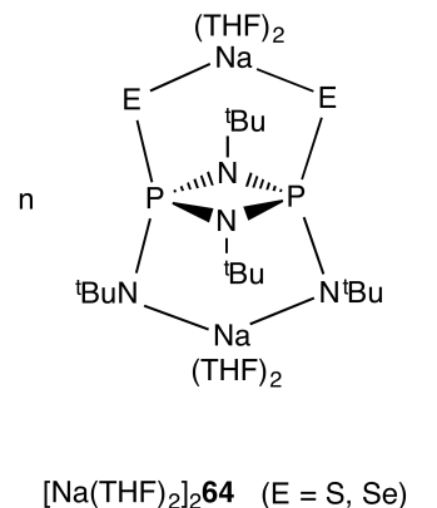

$\left[\mathrm{Na}(\mathrm{THF})_{2}\right]_{2} 64 \quad(\mathrm{E}=\mathrm{S}, \mathrm{Se})$

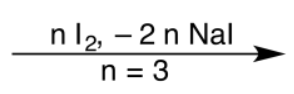

By contrast, the outcome of the $\mathrm{I}_{2}$ oxidation of $64(\mathrm{E}=\mathrm{Te})$ reflects the greater lability of the $\mathrm{P}-\mathrm{Te}$ bond. Two intermediates have been isolated and structurally characterized, viz. the planar dianionic ditelluride $\mathbf{6 6}^{183}$ and the spirocyclic dianion 67 with a central $\mathrm{Te}_{5}$ motif (Figure 31 ). ${ }^{187}$ The final product is the cyclic tritelluride $\mathbf{6 8}$ (Figure 30$).{ }^{183}$ The complex $[\mathrm{Li}(\mathrm{TMEDE})]_{2} \mathbf{6 6}$ is a rare example of a planar ditelluride. In this case, the planarity is attributed to packing effects, ${ }^{183}$ however a planar conformation may also be imposed either by very bulky substituents or via intramolecular heteroatom-tellurium interactions. ${ }^{162}$ A possible source of the spirocyclic dianion 67 is the reaction of the dianion $64(\mathrm{E}=\mathrm{Te})$ with in situ-generated cyclic tritelluride $\mathbf{6 8}$. The potentially versatile coordination behavior of the hard $(\mathrm{N})$ and soft $(\mathrm{Te})$ donor centers in 67 is illustrated by comparing the $\operatorname{bis}\left(N, N^{\prime}\right)$ coordination observed in the sodium derivative $[\mathrm{Na}(\mathrm{TMEDE})]_{2} \mathbf{6 7}$ with the tridentate $\left(T e, T e^{\prime}, T e^{\prime \prime}\right)$ bonding found in the rhodium(III) complex Cp*Rh67. ${ }^{187}$ 


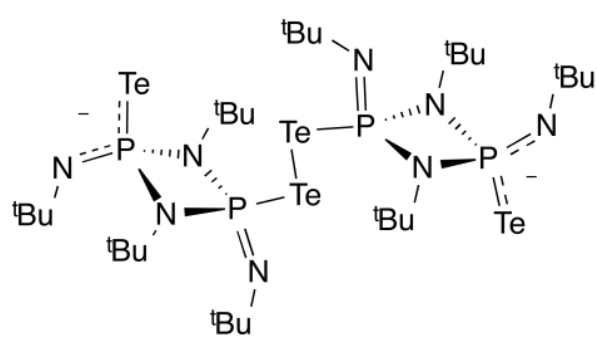

66

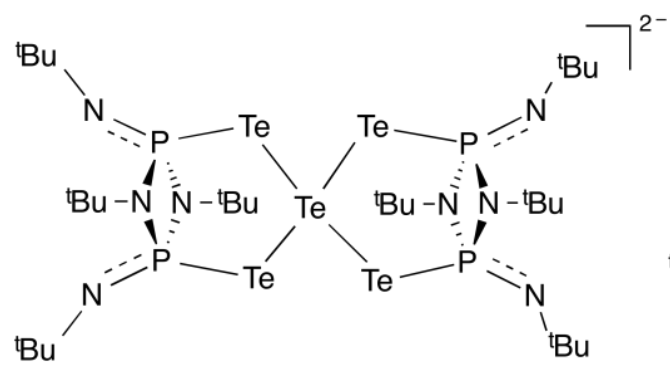

67

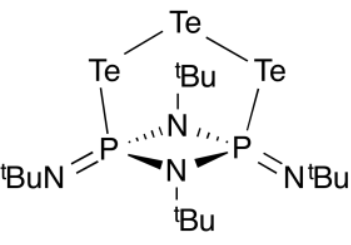

68

Figure 31. Products of the oxidation of alkali-metal complexes of $64(\mathrm{E}=\mathrm{Te})$ with $\mathrm{I}_{2}$.

\subsection{3 p-Block Metal Complexes}

The potential of the ditelluro dianion $64(\mathrm{E}=\mathrm{Te})$ for the incorporation of other p-block elements into phosphorus-tellurium ring systems has been previously indicated in Section 5.2 with the synthesis of organophosphorus(III)-tellurium via metathesis between $\mathrm{RPCl}_{2}\left(\mathrm{R}=\mathrm{Ad},{ }^{\mathrm{t}} \mathrm{Bu}\right)$ and $[\mathrm{Li}(\mathrm{TMEDA})]_{2} \mathbf{6 4}(\mathrm{E}=\mathrm{Te})$ to give the RP-bridged derivatives $\mathbf{1}($ Scheme $9 \mathrm{~b}) .{ }^{14}$ Another example is the preparation of the cyclic tritelluride 68 by reaction of $[\mathrm{Na}(\mathrm{TMEDA})]_{2} \mathbf{6 4}(\mathrm{E}=\mathrm{Te})$ with $\mathrm{TeCl}_{2} \cdot \mathrm{TMTU}^{183}$ The results of a broader investigation of the metathetical reactions of $[\text { Li(TMEDA) }]_{2} \mathbf{6 3}$ with p-block element halides are depicted in Scheme $18 .^{188}$

In summary, those studies revealed that the dianion $64(\mathrm{E}=\mathrm{Te})$ engages in $T e, T e^{\prime}$-chelation to the metal in $\mathrm{Ph}_{2} \mathrm{Ge}(\mathbf{6 9})$ and $\mathrm{R}_{2} \mathrm{Sn}\left(\mathbf{7 0}, \mathrm{R}={ }^{\mathrm{t}} \mathrm{Bu},{ }^{\mathrm{n}} \mathrm{Bu}, \mathrm{Ph}\right)$ derivatives. In the reaction with $\mathrm{Se}_{2} \mathrm{Cl}_{2}$ the products $\mathbf{7 1}$ and 72, in which either one or two selenium atoms occupy the bridging positions, were characterized by a combination of multinuclear NMR spectroscopy and X-ray analysis. ${ }^{188}$ The lability of the $\mathrm{P}-\mathrm{Te}$ bond is evident, however, in reactions with group 13 trihalides $\mathrm{MCl}_{3}(\mathrm{M}=\mathrm{Ga}$, In), which generate the neutral spirocyclic complexes $73(\mathrm{M}=\mathrm{Ga}$, In) in which the loss of a Te atom leaves a terminal $\mathrm{P}^{\mathrm{III}}$ center in one of the ligands. ${ }^{188}$

Scheme 18. p-Block Element-Tellurium Heterocycles Supported by $\mathbf{P}_{2} \mathbf{N}_{2}$ Rings. Adapted from ref. 188. Copyright 2015 American Chemical Society. 


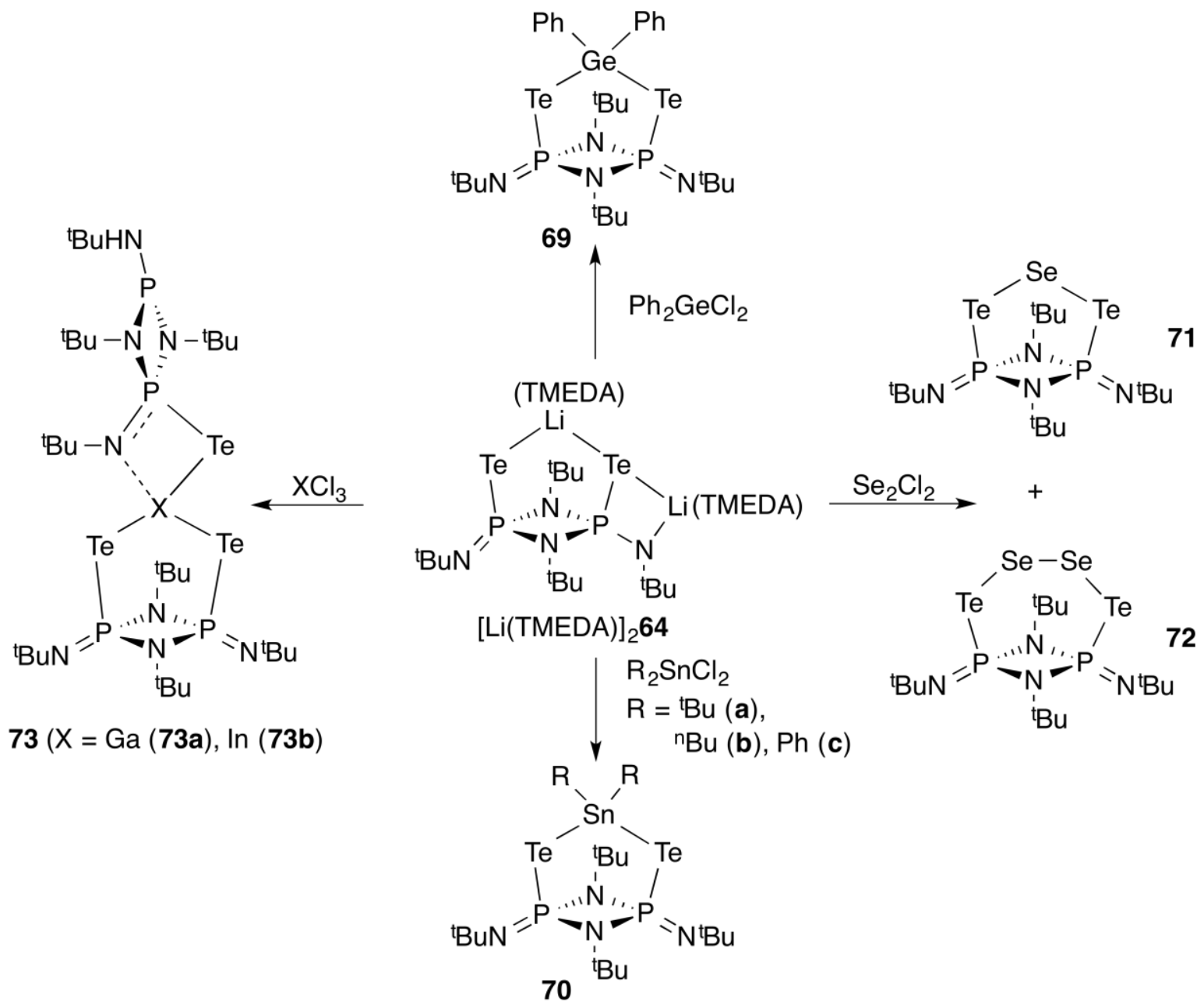

\section{SINGLE-SOURCE PRECURSORS FOR METAL TELLURIDE THIN FILMS}

There is considerable current interest in the fabrication of thin films of metal tellurides, notably $\mathrm{CdTe}, \mathrm{Sb}_{2} \mathrm{Te}_{3}, \mathrm{PbTe}$, and in their formation as quantum dots because of potential applications as low-band gap semiconducting materials in solar cells, thermoelectric devices, and telecommunications. In Section 6.7 examples of the use of phosphine tellurides, especially, tri- $n$ octylphosphine telluride, as a reactive source of tellurium for generating tellurides of group 11,12 and 14 metals in the form of nanomaterials or quantum wires were presented. In this section the applications of metal complexes of telluroimidophosphinites (42) and ditelluroimidodiphosphinates (45) as single-source precursors for the generation of binary metal tellurides are discussed.

In the mid-1990s Bochmann and co-workers synthesized several homoleptic metal complexes of the type $\mathrm{M}(\mathbf{4 2})_{2}\left(\mathrm{R}={ }^{\mathrm{t}} \mathrm{Bu}, \mathrm{R}^{\prime}={ }^{\mathrm{i}} \mathrm{Pr}, \mathrm{Cy} ; \mathrm{M}=\mathrm{Zn}, \mathrm{Cd}, \mathrm{Cr}, \mathrm{Mn}, \mathrm{Fe}, \mathrm{Co}\right)$ (Section 
7.3.3). ${ }^{165,166}$ The thermolysis of the transition-metal complexes produced thin films of metal ditellurides $\mathrm{MTe}_{2}(\mathrm{M}=\mathrm{Fe}, \mathrm{Mn}, \mathrm{Co}) .{ }^{166}$ Thermally stable, sublimable group 12 complexes were shown to produce thin films of MTe $(\mathrm{M}=\mathrm{Zn}, \mathrm{Cd})$ free from phosphorus contamination. ${ }^{189,190}$

More recently, O'Brien and co-workers have carried out an extensive evaluation of the suitability of homoleptic complexes of $\mathbf{4 5}\left(\mathrm{R}={ }^{\mathrm{i}} \mathrm{Pr}\right)$ with group $11,12,14$ and 15 metals (Scheme 13), as well as the group 13 complex $\mathbf{5 7}$, as single-source precursors for metal tellurides using the aerosol-assisted chemical vapor deposition (AACVD) technique. ${ }^{16}$ The results are summarized in Table 4. Under appropriate conditions the AACVD technique was successful for producing pure thin films of cubic CdTe from $\mathbf{5 0}(\mathrm{M}=\mathrm{Cd})$, however a similar approach resulted in decomposition of the corresponding mercury complex $\mathbf{5 0}(\mathrm{M}=\mathrm{Hg})$ to hexagonal tellurium. ${ }^{191}$ In a subsequent study the use of atmospheric pressure CVD generated CdTe in the form of epitaxial rods. ${ }^{192}$ The AACVD technique was also successful for the synthesis of rhombohedral $\mathrm{Sb}_{2} \mathrm{Te}_{3}$ in the form of hexagonal-shaped nanoplates ${ }^{193}$ and phase-pure $\mathrm{PbTe}^{171}$ from $51(\mathrm{M}=\mathrm{Sb})$ and $\mathbf{5 2}(\mathrm{M}=\mathrm{Pb})$, respectively. By contrast, however, the congeners $51(\mathrm{M}=\mathrm{Bi})$ and $52(\mathrm{M}=\mathrm{Sn})$ produced only elemental tellurium. ${ }^{171,193}$ The coinage metal precursors $\mathbf{5 3}, \mathbf{5 4}$ and $\mathbf{5 9}\left(\mathrm{R}={ }^{\mathrm{i}} \mathrm{Pr}\right)$ generated a metal telluride admixed with tellurium (Table 4). ${ }^{174}$ The formation of elemental tellurium presumably results from the high $\mathrm{Te} / \mathrm{M}$ ratio in the precursors. However, the use of the homoleptic $\mathrm{Hg}^{\mathrm{II}}$ complex of the monotellurido ligand $44, \mathrm{Hg}\left(\mathrm{TeP}^{\mathrm{i}} \operatorname{Pr}_{2} \mathrm{~N}^{\mathrm{i}} \mathrm{Pr}_{2} \mathrm{P}\right)_{2}$, did not produce pure HgTe. ${ }^{158}$

The AACVD of the indium complex 57 provided the first report of the generation of pure cubic $\mathrm{In}_{2} \mathrm{Te}_{3}$ from a molecular precursor. ${ }^{194}$ By contrast, the gallium analog $\mathbf{5 6}$ produced a mixture of $\mathrm{Ga}_{2} \mathrm{Te}_{3}$, GaTe and tellurium. ${ }^{194}$ The production of metal tellurides (and tellurium) from the AACVD of complexes of $\mathbf{4 5}$ presumably results from the lability of the P-Te bond in the singlesource precursors. In the specific case of $\mathbf{5 7}$, some insight into the process that generates $\operatorname{In}_{2} \mathrm{Te}_{3}$ was gleaned from the electrospray mass spectrum (ESMS) of the precursor in THF, which displayed peaks attributable to the homoleptic cation $\left[\operatorname{In}\left\{\mathrm{N}\left(\mathrm{P}^{\mathrm{i}} \mathrm{Pr}_{2} \mathrm{Te}\right)_{2}\right\}_{2}\right]^{+}$and the fragment anion 
$\left[\mathrm{N}\left(\mathrm{P}^{\mathrm{i}} \mathrm{Pr}_{2} \mathrm{Te}\right)_{2}\right]^{-}$in the form of the diprotonated species. ${ }^{194}$ These observations suggest that the deposition of $\mathrm{In}_{2} \mathrm{Te}_{3}$ occurs directly from the central $\mathrm{In}_{3} \mathrm{Te}_{3}$ ring in 57.

Complexes of the mixed chalcogen ligands $\left[N\left(P^{i} \operatorname{Pr}_{2} E\right)\left(P^{i} \operatorname{Pr}_{2} T e\right)\right]^{-}(E=S, S e)$ are potential single-source precursors of ternary metal chalcogenides that incorporate two different chalcogens. This possibility was investigated for the AACVD of the nickel(II) complex $\mathrm{Ni}\left[\mathrm{N}\left(\mathrm{P}^{\mathrm{i}} \mathrm{Pr}_{2} \mathrm{Se}\right)(\right.$ $\left.\mathrm{P}^{\mathrm{i}} \mathrm{Pr}_{2} \mathrm{Te}\right)$ ], but only $\mathrm{NiTe}_{2}$ was generated. ${ }^{177}$

Table 4. Metal Telluride Formation from Complexes of $45\left(R={ }^{i} \operatorname{Pr}\right)$

Precursor Metal Telluride Products

$50(\mathrm{M}=\mathrm{Cd}) \quad$ Cubic CdTe

$50(\mathrm{M}=\mathrm{Cd}) \quad$ Epitaxial CdTe Rods

$50(\mathrm{M}=\mathrm{Hg}) \quad$ Hexagonal $\mathrm{Te}$

$51(\mathrm{M}=\mathrm{Sb}) \quad$ Rhombohedral $\mathrm{Sb}_{2} \mathrm{Te}_{3}$

$52(\mathrm{M}=\mathrm{Pb}) \quad$ Cubic PbTe

53

54

$59\left(\mathrm{R}={ }^{\mathrm{i}} \mathrm{Pr}\right) \quad$ Monoclinic $\mathrm{AuTe}_{2}+\mathrm{Te}$

56

57
Orthorhombic CuTe $+\mathrm{Te}$

174

Hexagonal Plates of $\mathrm{Ag}_{7} \mathrm{Te}_{4}+\mathrm{Te}$

174

174

Cubic $\mathrm{Ga}_{2} \mathrm{Te}_{3}, \mathrm{GaTe}+\mathrm{Te}$

194

194 


\section{CONCLUSIONS AND PROSPECTS}

Organophosphorus-tellurium chemistry has developed slowly over the past 65 years in comparison with the chemistry of sulfur and selenium analogues. ${ }^{1-6}$ In part, this tardiness can be attributed to the thermal and photochemical lability of phosphorus-tellurium bonds that makes many of these compounds difficult to manipulate. Significantly, there is no tellurium counterpart of the Lawesson's or Woollins' reagents, which contain both bridging $(\mathrm{P}-\mathrm{E})$ and terminal $\mathrm{P}=\mathrm{E}(\mathrm{E}=\mathrm{S}, \mathrm{Se}$, respectively) functionalities; the latter reagents find wide applications in organic chemistry for the conversion of $\mathrm{C}=\mathrm{O}$ to $\mathrm{C}=\mathrm{E}$ groups. On the other hand, there are numerous recent examples in which the lability of the $\mathrm{P}=\mathrm{Te}$ bond in triorganophosphine tellurides has been employed creatively as a reactive source of tellurium( $(0)$ to generate binary metal tellurides in the form of quantum dots or nanomaterials with unusual properties for applications in inter alia IR detection, thermoelectric materials and solar cells (Section 6.7). Several recent studies have established that the introduction of a negative charge confers added stability on P-Te bonds (Sections 3 and 7) and the coordination chemistry of the resulting anions has been widely explored. In many cases the resulting metal complexes serve as efficient single-source precursors of pure main group or transition-metal tellurides in the form of thin films or quantum dots. The exploitation of the lability of the P-Te bond in the generation of semi-conductors with novel properties will continue to have an important impact in materials science.

NMR studies of phosphorus-tellurium compounds and, in particular, the magnitude of the one-bond coupling constant ${ }^{1} J\left({ }^{31} \mathrm{P},{ }^{125} \mathrm{Te}\right)$ are of considerable interest. The value of this parameter can range from as low as $100 \mathrm{~Hz}$ in organophosphorus(III)-tellurium compounds (Table 1 and Section 5) to as high as $2290 \mathrm{~Hz}$ in organophosphorus(V)-tellurium compounds (Table 3 and Section 6.2). The anomalously high values in the range 1210-1360 Hz observed for weak ("through

space") P $\cdots$ Te interactions $(d(\mathrm{P} \cdots \mathrm{Te})=3.09-3.20 \AA)$ in peri-substituted compounds have been explained satisfactorily in terms of three-center four-electron interactions (Section 5.3). However, 
the nature of phosphorus-tellurium bonding in both organophosphorus(III)- and organophosphorus(V)-tellurium systems awaits a modern theoretical treatment in order to detremine the relative contributions of the factors that determine the disparate values of ${ }^{1} J\left({ }^{31} \mathrm{P},{ }^{125} \mathrm{Te}\right)$ not only between organophosphorus(III) and and organophosphorus(V) compounds, but also the large variations within those two series.

From a fundamental perspective, binary phosphorus-tellurium cations are reasonable synthetic targets in view of the recent report of the preparation of the intriguing phosphorusselenium cation $\left[\mathrm{P}_{3} \mathrm{Se}_{4}\right]^{+}$by three different routes, ${ }^{195}$ two of which are applicable to P-Te systems. In a similar vein the characterization of the binary anionic species $\left[\mathrm{P}_{4} \mathrm{Te}_{2}\right]^{2-}($ Section 3$)$ suggests that similar $\mathrm{P}-\mathrm{Te}$ anions may be generated by reactions of polyphosphides, e.g $\mathrm{P}_{7}^{3-}$ and $\mathrm{P}_{5}^{-}$, with tellurium. Finally, in terms of applications, the further exploitation of the labile nature of the $\mathrm{P}-\mathrm{Te}$ bond combined with the oxophilicity of $\mathrm{P}^{\mathrm{III}}$ centers in organic synthesis (Section 7.1) warrants further investigation in the light of recent results and the historical context provided in this review.

\section{ACKNOWLEDGMENTS}

TC thanks the NSERC (Canada) for continuing funding. JDW is grateful to the University of St Andrews for support. AN thanks the EPSRC for financial support. We also acknowledge helpful comments from Prof. J. S. Ritch (University of Winnipeg).

\section{AUTHOR INFORMATION}

\section{Corresponding Author}

*E-mail: chivers@ ucalgary.ca. Phone: 403-220-5741

\section{Notes}

The authors declare no competing financial interest.

\section{Biographies}




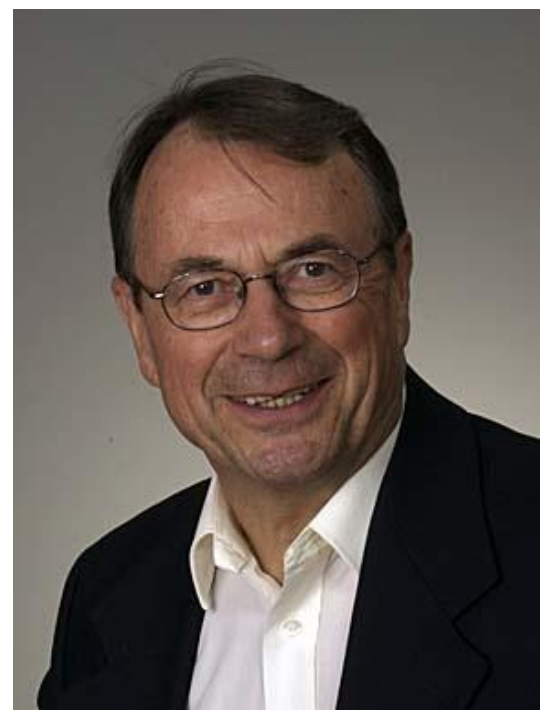

Tristram Chivers, a native of Bath, England, received his BSc, $\mathrm{PhD}$ and DSc degrees all from the University of Durham (UK). He joined the University of Calgary in 1969 and served as Head of the Chemistry Department from 1977 to 1982. He currently holds the title of Faculty Professor and Professor Emeritus of Chemistry. His primary research interests are in the general area of main group element chemistry with emphasis on chalcogen chemistry and inorganic ring systems. He is the author of two books: "A Guide to Chalcogen-Nitrogen Chemistry" and (with I. Manners) "Inorganic Rings and Polymers of the p-Block Elements: From Fundamentals to Applications". He received the Alcan Lecture Award of the Canadian Society for Chemistry (CSC) in 1987, the Royal Society of Chemistry Award (UK) for Main-Group Element Chemistry in 1993, and the E.W.R. Steacie Award from the CSC in 2001. He was elected a Fellow of the Royal Society of Canada in 1991. He was awarded an honorary DSc from the University of Oulu, Finland in 2006. In 2008 he was the recipient of the ASTech Outstanding Leadership in Alberta Science Award.

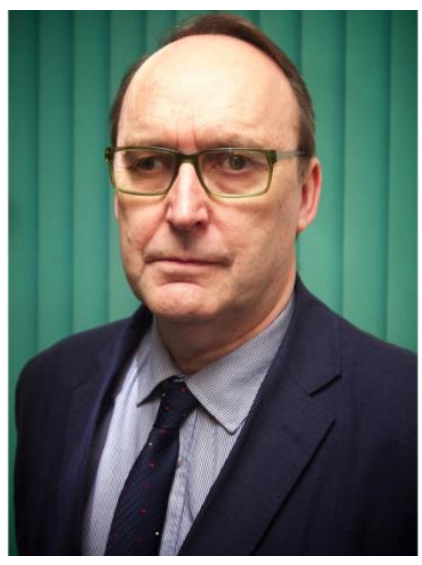

J. Derek Woollins was born in Cleethorpes and educated at the University of East Anglia (Norwich), where he went on to carry out his $\mathrm{PhD}$ under the supervision of Andrew Thomson and Roger Grinter. He carried out postdoctoral work with Bill Cullen (UBC, Vancouver), Barnett Rosenberg (MSU, Michigan) and Norman Greenwood (Leeds, England) before being appointed as a lecturer at Imperial College London. After 12 years at Imperial College, he moved to Loughborough as the Chair in Inorganic Chemistry, where he stayed for 5 years 
before moving to St Andrews as the Chair in Synthetic Chemistry in 1999. He is currently Vice Principal (Research) and Provost at St Andrews. Woollins has published over 500 research papers in main group chemistry and three books. His research interests center around group 15/16 chemistry including the use of P-Se compounds (such as Woollins' Reagent) in synthesis and structural science. He was elected to Fellowship of the Royal Society of Edinburgh in 2002, to the European Academy of Sciences in 2008 and to the European Academy of Science and Arts in 2012.

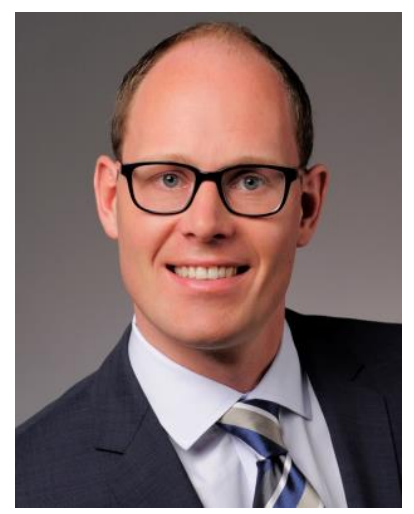

Andreas Nordheider was born and raised in Melle, Germany and received his degrees in Chemistry and Biochemistry (BSc) as well as his MSc in Chemistry from the Ludwig-Maximilians-University (LMU) Munich. He conducted research on heterocyclic nitrogen-rich explosives under the supervison of Prof. Thomas Klapötke and investigated niobium complexes and the activation of white phosphorus at the Massachusetts Institute of Technology under the guidance of Prof. C. Cummins. His PhD was completed 2014 at the University of St Andrews, Scotland working on "Phosphorus-Tellurium Heterocycles and Their Lighter Chalcogen Analogues From Small Molecules to Macrocycles" in the group of Prof. J. Derek Woollins. As a part of his PhD he moved to the University of Calgary, Canada to work with Prof. Tristram Chivers focusing on $\mathrm{P}_{2} \mathrm{~N}_{2}$-supported chalcogen systems. He received an EPSRC postdoctoral fellowship prize in 2014 and, subsequently, joined a Management Consulting Company, where he is a Consultant for Operational Excellence and Organizational Transformation.

\section{ABBREVIATIONS}

AACVD aerosol-assisted chemical vapor deposition

Ad adamantyl

$\mathrm{Bbt}$ 2,6-bis[bis(trimethylsilyl)methyl]-4-[tris(trimethylsilyl)methyl]phenyl

${ }^{\mathrm{t}} \mathrm{Bu}_{2} \mathrm{Im}$ 1,3-di-tert-butyl-imidazolin-2-ylidine

$\operatorname{Bupp}_{2} \mathrm{Ph}_{4} \quad\left({ }^{\mathrm{t}} \mathrm{BuP}\left(\mathrm{CH}_{2} \mathrm{CH}_{2} \mathrm{PPh}_{2}\right)_{2}\right)$

Ch chalcogen

CIP contact ion pair

COD 1,5-cyclooctadiene

COT cyclooctatetraene

$\mathrm{Cp} \quad$ cyclopentadienyl $\left(\mathrm{C}_{5} \mathrm{H}_{5}\right)$ 


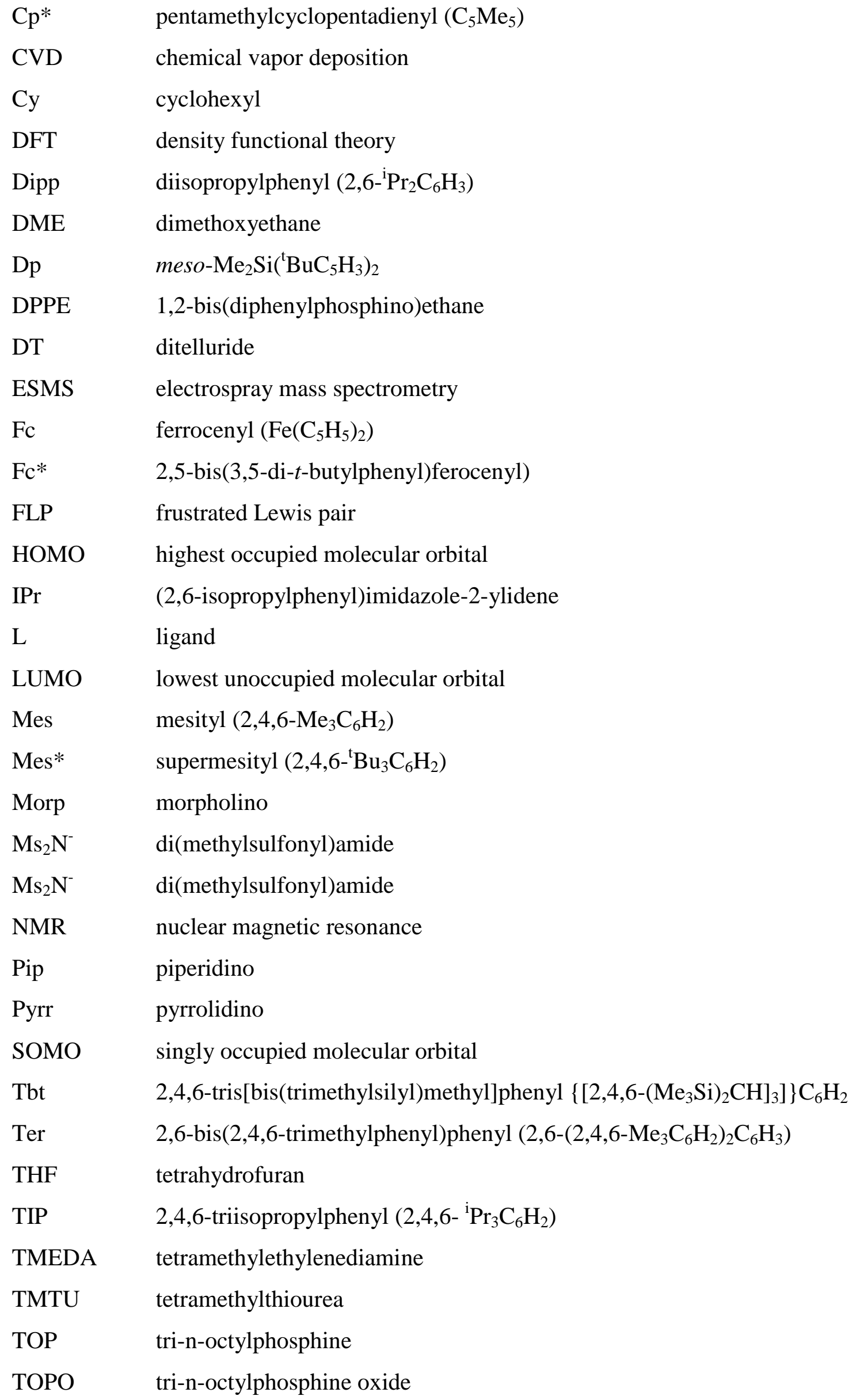


TOPTe tri-n-octylphosphine telluride

Trit trityl (triphenylmethyl) $\left(\mathrm{Ph}_{3} \mathrm{C}\right)$

UV ultra-violet 


\section{Dedication}

This article is dedicated to Professor Ralph A. Zingaro and Professor Dr. Wolf-Walther du Mont in recognition of their seminal contributions to the development of organophosphorus(V)-tellurium and organophosphorus(III) - tellurium chemistry, respectively.

\section{REFERENCES}

(1) Jesberger, M.; T. P. Davis, T. P.; Barner, L. Applications of Lawesson's Reagent in Organic and Organometallic Syntheses. Synthesis 2003, 13, 1929-1958.

(2) Foreman, M. S.; Woollins, J. D. Organo-P-S and P-Se Heterocycles. J. Chem. Soc., Dalton Trans. 2000, 1533-1543.

(3) Cava, M. P.; Levinson, M. I. Thionation Reactions of Lawesson's Reagent. Tetrahedron 1985, 41, 5061-5087.

(4) Cherkasov, R. A.; Kutyre, G. A.; Pudovik, A. N. Organothiophosphorus Reagents in Organic Synthesis. Tetrahedron 1985, 41, 2567-2624.

(5) Woollins, J. D. How Not to Discover a New Reagent. The Evolution and Chemistry of Woollins' Reagent. Synlett. 2012, 1154-1169, and references cited therein.

(6) Hua, G.; Woollins J. D. Organic Phosphorus-Selenium Chemistry, in Selenium and Tellurium Chemistry: From Small Molecules to Biomolecules and Materials, Eds. Woollins, J. D.; Laitinen, R.S. Springer, Heidelberg, 2011, Ch.1, pp. 1-39.

(7) The structure of the pyridine-stabilized monomer $\mathrm{PhP}(=\mathrm{Se})_{2} \bullet p y r$ has been reported recently. Ascherl, L.; Nordheider, A.; Athukorala Arachchige, K. S.; Slawin, A. M. Z.; Woollins, J. D. The Activation of Woollins` Reagent. Isolation of Pyridine-Stabilised $\mathrm{PhPSe}_{2}$. Chem. Commun. 2014, 50, 6214-6216.

(8) Davies, R.; Patel, L. Chalcogen-Phosphorus (and Heavier Congener) Compounds, in "Handbook of Chalcogen Chemistry: New Perspectives in Sulfur, Selenium and Tellurium”, 
$2^{\text {nd }}$ Edn., Devillanova, F. A.; du Mont W-W. Eds., RSC Publishing, 2013, Vol.1, Ch. 5, pp. 238-306.

(9) Foss, O. The Action of Cyanide on Selenopentathionate and Telluropentathionate. Acta Chem. Scand., 1950, 4, 1241-1245.

(10) Zingaro, R. A. Tributylphosphine Telluride. J. Organomet. Chem. 1963, 1, 200.

(11) Zingaro, R. A. Steeves, B. H.; Irgolic, K. Phosphine Tellurides. J. Organomet. Chem. 1965, 4, 320-323.

(12) Rotter, C.; Schuster, M.; Karaghiosoff, K. An Unusual Binary Phosphorus-Tellurium Anion and its Seleno- and Thio-Analogues; $\mathrm{P}_{4} \mathrm{Ch}_{2}{ }^{2-}(\mathrm{Ch}=\mathrm{S}, \mathrm{Se}, \mathrm{Te})$. Inorg. Chem. 2009, 48, $7531-7533$

(13) Jörgens, S.; Johrendt, D.; Mewis, A. $\mathrm{BaP}_{4} \mathrm{Te}_{2}-\mathrm{A}$ Ternary Telluride with $\mathrm{P}-\mathrm{Te}$ Bonds and a Structural Fragment of Black Phosphorus. Chem.-Eur. J. 2003, 9, 2405-2410.

(14) Nordheider, A.; Chivers, T.; Schön, O.; Karaghiosoff, K.; Athukorala Arachchige, K. S.; Slawin, A. M. Z.; Woollins, J. D. Isolatable Organophosphorus(III)-Tellurium Heterocycles. Chem. -Eur. J. 2014, 20, 704-712.

(15) Chivers, T.; Ritch, J. S.; Robertson, S. D.; Konu, J.; Tuononen, H. M. New Insights into the Chemistry of Imidodiphosphinates from Investigations of Tellurium-Centered Systems. Acc. Chem. Res. 2010, 43, 1053-1062.

(16) Ritch, J. S.; Chivers, T.; Afzaal, M.; O’Brien, P. The Single Molecular Precursor Approach to Metal Telluride Thin Films: Imino-bis(diisopropylphosphine tellurides) as Examples. Chem. Soc. Rev. 2007, 36, 1622-1631.

(17) Dube, J. W.; Hänninen, M. M.; Dutton, J. L.; Tuononen, H. M.; Ragogna, P. J. Homoleptic Pnictogen-Chalcogen Coordination Complexes. Inorg. Chem. 2012, 51, 88978903. 
(18) Nordheider, A.; Hupf, E.; Chalmers, B. A.; Knight, F. R.; Bühl, M.; Mebs, S.; Chęcińska, L.; Lork, E.; Sanz Camacho, P.; Ashbrook, S. E.; Athukorala Arachchige, K. S.; David Cordes, D. B.; Slawin, A. M. Z.; Beckmann, J; Woollins, J. D. Peri-Substituted Phosphorus-Tellurium Systems - An Experimental and Theoretical Investigation of the

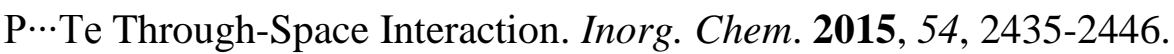

(19) Do, G. T; Hupf, E.; Nordheider, A.; M.; Lork, E.; Slawin, A.M.Z.; Makarov, S.; Ketkov, S.; Mebs, S.; Woollins, J. D; Beckmann, J. Intramolecularly-Group 15 Stabilized Aryltellurium Cations. Organometallics, 2015, submitted.

(20) Sandblom, N.; Ziegler, T.; Chivers, T. A Density Functional Study of the Bonding in Tertiary Phosphine Chalcogenides and Related Molecules. Can. J. Chem. 1996, 74, 23632371.

(21) Capps, K. B.; Wixmerten, B.; Bauer, A.; Hoff, C. D. Thermochemistry of Sulfur Atom Transfer. Enthalpies of Reaction of Phosphines with Sulfur, Selenium, and Tellurium, and of Desulfurization of Triphenylarsenic Sulfide, Triphenylantimony Sulfide, and Benzyl Trisulfide. Inorg. Chem. 1998, 37, 2861-2864.

(22) Pyykkö. P.; Atsumi, M. Molecular Single-Bond Radii for Elements 1-118. Chem.Eur. J. 2009, 15, 186-197.

(23) Pyykkö. P.; Atsumi, M. Chem. Eur. J. Molecular Double-Bond Radii for Elements Li-E112. 2009, 15, 12770-12779.

(24) Cordero, B.; Gómez, V.; Platero-Prats, A. E.; Revés, M.; Escheverria, J.; Cremades, E.; Barragàn, F.; Alvarez, S. Covalent Radii Revisited. Dalton Trans. 2008, 2832-2838.

(25) Bondi, A. van der Waals Volumes and Radii. J. Phys. Chem. 1964, 68, 441-451.

(26) Alcock, N. W. Secondary Bonding to Nonmetallic Elements. Adv. Inorg. Chem. Radiochem. 1972, 15, 1-58. 
(27) Pauling, L. The Nature of the Chemical Bond, $3^{\text {rd }}$ edn, Cornell University Press, 1960, p. 260.

(28) $K_{P T e},=4 \pi^{2} J_{P T e} / h \gamma^{31} P \gamma^{125} T e$ : Ebsworth, E. A. V.; Rankin, D. W. H.; Cradock, S. Structural Methods in Inorganic Chemistry, Blackwell Scientific Publications, Oxford, UK, 1987, p. 53.

(29) Jones, C. H. W.; Sharma, R. D. ${ }^{125}$ Te NMR and Mössbauer Spectroscopy of Tellurium-Phosphine Complexes and the Tellurocyanates. Organometallics 1987, 6, 14191423.

(30) Chivers, T.; Eisler, D.J.; Ritch, J. S.; Tuononen, H. M. An Unusual Ditelluride: Synthesis and Molecular and Electronic Structures of the Dimer of the Tellurium-Centered Radical [TeP $\left.{ }^{\mathrm{i}} \mathrm{Pr}_{2} \mathrm{~N}^{\mathrm{i}} \mathrm{Pr}_{2} \mathrm{PTe}\right]^{\bullet}$. Angew. Chem., Int. Ed. 2005, 44, 4953-4956.

(31) du Mont, W.-W.; Severengiz, T.; Meyer, B. Small Heterocycles Containing Phosphorus and Tellurium. Angew. Chem., Int. Ed. 1983, 22, 983-984.

(32) du Mont, W.-W.; Severengiz, T. 2,3-Di-tert-butyl-1-telluradiphosphorane and Related Phosphorus-Tellurium Heterocycles. Z. Anorg. Allg. Chem. 1993, 619, 1083-1087.

(33) Grimm, S.; Karaghiosoff, K.; Mayer, P.; Ross, D. New Phosphorus-Tellurium Heterocycles in the Quasi-Binary System RP/Te. Phosphorus Sulfur Silicon Relat. Elem. 2001, 169, 51-54.

(34) Lux, K.; Schön, O.; Karaghiosoff, K. New $\mathrm{CF}_{3}$ Substituted Phosphorus-Tellurium Heterocycles. Z. Anorg. Allg. Chem. 2009, 635, 2465-2469.

(35) Nagahora, N.; Sasamori, T.; Tokitoh, N. Chalcogenation Reactions of a Stable Ferrocenyldiphosphene: Formation of Thia-, Selena-, and Telluradiphosphiranes. Heteroatom. Chem. 2008, 19, 443-449. 
(36) Al-Ktaifani, M. M.; Chapman, D. P.; Francis, M. D.; Hitchcock, P. B.; Nixon, J. F.; Nyulászi, L. The Hexaphosphapentaprismane $\mathrm{P}_{6} \mathrm{C}_{4}{ }^{t} \mathrm{Bu}_{4}$ : A "Jaws-Like“ Cage Molecule That Bites. Angew. Chem., Int. Ed. 2001, 40, 3474-3477.

(37) Francis, M. D.; Jones, C.; Morley, C. P. A Novel Synthetic Route to ChalcogenSubstituted Diphospholes. Tetrahedron Lett. 1999, 40, 3815-3816.

(38) Chremos, G. N.; Zingaro, R. A. The Synthesis and Infrared Spectra of Some Group Va Chalcogenides. J. Organomet. Chem. 1970, 22, 637-646.

(39) Watari, F. Vibrational Spectra of Trimethylphosphine Telluride and the P-Te Stretching Force Constant. Inorg. Chem. 1981, 20, 1776-1779.

(40) Rømming, C.; Iversen, A. J.; Songstad, J. The Crystal Structure of Tris(morpholino)phosphine Telluride. The Tellurium Basicity of Tervalent Phosphorus Species. Acta Chem. Scand. A 1980, 34, 333-342.

(41) Rauchle, F.; Pohl, W.; Blaich, B.; Goubeau, J. Schwingungsspektren und Kraftkonstanten der Verbindungen des Typus XP(N(CH$\left.)_{2}\right)_{3}$. Ber. Bunsenges. Phys. Chem. 1971, 75, 66-71.

(42) Housecroft, C.; Sharpe, A. G. Inorganic Chemistry, Pearson Education Ltd., $2^{\text {nd }}$ ed. 2005, pp. 426-427.

(43) Baldus, H. P.; Blachnik, R. Neue $\mathrm{A}_{4} \mathrm{~B}_{3}$-Moleküle: $\mathrm{P}_{3} \mathrm{SbS}_{3}, \mathrm{P}_{4} \mathrm{~S}_{2}$ Te und $\mathrm{P}_{4} \mathrm{STe}_{2}$. Z Naturforsch. 1990, 45b, 1605-1609.

(44) Petragnani, M.; Moura Campos, M. Reaction of Arylselenenyl Bromides and 2Naphthyltellurenyl Iodide with Triethylamine and Trivalent Phosphorus Compounds. Tetrahedron 1965, 21, 13-17.

(45) Boyle, P. D.; Cross, W.I.; Godfrey, S. M.; McAuliffe, C. A.; Pritchard, R. G.; Sarwar, S.; Sheffield, J. M. Synthesis and Characterization of $\mathrm{Ph}_{4} \mathrm{Te}_{4} \mathrm{I}_{4}$, Containing a $\mathrm{Te}_{4}$ Square, and $\mathrm{Ph}_{3} \mathrm{PTe}(\mathrm{Ph}) \mathrm{I}$. Angew. Chem., Int. Ed. 2000, 39, 1796-1798. 
(46) Kuhn, N.; Schumann, H. Tellurophosphonium-Kationen. Phosphorus and Sulfur, 1986, 26, 199-201.

(47) Kollemann, C.; Sladky, F. Phosphanstabilisierte Organyltellurenylkationen, $\left[\mathrm{RTe}\left(\mathrm{PR}_{3}^{\prime}\right)\right]^{+}$. J. Organomet. Chem. 1990, 396, C1-C3.

(48) Sugamata, K.: Sasamori, T.; Tokitoh, N. Generation of an Organotellurium(II) Cation. Eur. J. Inorg. Chem. 2012, 775-778.

(49) Beckmann, J.; Bolsinger, J.; Duthie, A.; Finke, P.; Lork, E.; Lüdtke, C.; Mallow, O.; Mebs, S. Mesityltellurenyl Cations Stabilized by Triphenylpnictogens $\left[\operatorname{MesTe}\left(\mathrm{EPh}_{3}\right)\right]^{+}(\mathrm{E}=$ P, As, Sb). Inorg. Chem. 2012, 51, 12395-12406.

(50) Dutton, J. L.; Ragogna, P. J. Donor-Acceptor Chemistry at Heavy Chalcogen Centers. Inorg. Chem. 2009, 48, 1722-1730.

(51) Kuhn, N.; Schumann, H.; Boese, R. Oxidative Coupling of Tellurophosphoranes, a Route to Phosphine-Stabilised Tritellurium Cations. J. Chem. Soc., Chem. Commun. 1987, 1257-1258.

(52) Kuhn, N.; Schumann, H.; Wolmerhäuser, G. $\left(\text { tert }-\mathrm{C}_{4} \mathrm{H}_{9}\right)_{3} \mathrm{PTe}-\mathrm{A}$ Typical Tellurophosphorane? Z. Naturforsch. B 1987, 42, 674-678.

(53) Dehnert, P.; Grobe, J.; Hildebrandt, W.; le Van, D. Preparation and Characterization of Organoelement Element Compounds of the Type $\mathrm{R}_{\mathrm{n}} \mathrm{E}-\mathrm{ER}_{\mathrm{m}}\left(\mathrm{R}=\mathrm{CH}_{3}, \mathrm{CF}_{3} ; \mathrm{E}=\mathrm{P}, \mathrm{As}, \mathrm{S}\right.$, Se, Te; $\mathrm{n}, \mathrm{m}=1,2)$. Z. Naturforsch. 1979, 34b, 1646-1652.

(54) Grobe, J.; Le Van, D. Preparation and Spectroscopic Investigations of $\mathrm{Cr}(\mathrm{CO})_{5} \mathrm{~L}$ Complexes $\left(\mathrm{L}=\mathrm{R}_{2} \mathrm{EER}_{2}^{\prime}, \mathrm{R}_{2} \mathrm{EE}^{\prime} \mathrm{R} ; \mathrm{R}, \mathrm{R}^{\prime}=\mathrm{CH}_{3}, \mathrm{CF}_{3} ; \mathrm{E}=\mathrm{P}, \mathrm{As} ; \mathrm{E}^{\prime}=\mathrm{S}, \mathrm{Se}, \mathrm{Te}\right) . \mathrm{Z}$. Naturforsch. 1979, 34b, 1653-1660.

(55) du Mont, W-W.; Kubiniok, S.; Severengiz, T. Dismutation Reactions of Di-ptolylditelluride with Tetra-tert-butyldiphosphane and Tetra-iso-propyldiphosphane Z. Anorg. Allg. Chem. 1985, 531, 21-25. 
(56) du Mont, W-W.; Kroth, H-J. ${ }^{125}$ Te NMR Shifts and Te-P Coupling Constants of Phosphane Tellurides, Tellurophosphanes, and Tellurophosphane Complexes. Z. Naturforsch. 1981, 36b, 332-334.

(57) Francis, M. D.; Hibbs, D. E.; Hitchcock, P. B.; Hursthouse, M. B.; Jones, C.; Mackewitz, T.; Nixon, J. F.; Nyalaszi, L.; Regitz, M.; Sakarya, N. First Structural Characterization of 1,2,4-Selenadiphosphole and 1,2,4-Telluradiphosphole Ring Systems. Crystal and Molecular Structure of the $\eta^{1}$ Complexes $\left[\mathrm{M}(\mathrm{CO})_{5}\left(\mathrm{P}_{2} \mathrm{SeC}_{2}{ }^{\mathrm{t}} \mathrm{Bu}_{2}\right)\right](\mathrm{M}=\mathrm{Cr}, \mathrm{W})$ and $\left[\mathrm{W}(\mathrm{CO})_{5}\left(\mathrm{P}_{2} \mathrm{TeC}_{2}{ }^{\mathrm{t}} \mathrm{Bu}_{2}\right)\right]$. J. Organomet. Chem. 1999, 580, 156-160.

(58) Mahnke, J.; Bugnariu, D.; Du Mont, W-W.; Ruthe, F.; Jones, P. G. Metastable PTellurium-Substituted Phosphaalkenes: Formation, ${ }^{125} \mathrm{Te}-$ and ${ }^{31} \mathrm{P}-\mathrm{NMR}$ Spectroscopic Characterization and Decomposition. Phosphorus, Sulfur and Silicon, 2014, 189, 963-976.

(59) du Mont, W.-W. Bis(di-tert-butylphosphino)tellurium(II): A Derivative of Phosphinous Anhydride Exhibiting Umpolung. Angew. Chem., Int. Ed. 1980, 19, 554-555.

(60) du Mont, W-W.; Hensel, R.; McFarlane, W.; Colquhoun, I. J.; Ziegler, M. L.; Serhadli, O. Telluration and Selenation of Tetra-tert-butyldiphosphane. Chem. Ber. 1989, $122,37-41$

(61) du Mont, W-W.; Hensel, R. Reversible Telluration of Tetra-iso-propyldiphosphane, Stabilisation of Tellurobis(di-iso-propylphosphane) as Tetracarbonylchromium Complex. Z. Anorg. Allg. Chem. 1989, 579, 134-138.

(62) Hill, N. J.; Reeske, G.; Cowley, A. H. Reactions of the Persistent Phosphinyl Radical •P $\left[\mathrm{CH}\left(\mathrm{SiMe}_{3}\right)_{2}\right]_{2}$ with Elemental Chalcogens. Main Group Chem. 2010, 9, 5-10.

(63) Westermann, H.; Nieger, M.; Niecke, E. Synthesis and Structure of Bis[bis(di-isopropylamino)phosphino]chalcogenides. Chem. Ber. 1991, 124, 13-16.

(64) Giffin, N. A.; Hendsbee, A. D.; Roemmele, T. L.; Lumsden, M. D.; Pye, C. C.; Masuda, J. D. Preparation of a Diphosphine with Persistent Phosphinyl Radical Character in 
Solution: Characterization, Reactivity with $\mathrm{O}_{2}, \mathrm{~S}_{8}, \mathrm{Se}$, Te and $\mathrm{P}_{4}$ and Electronic Structure Calculations. Inorg. Chem. 2012, 51, 11837-11850.

(65) Giffin, N. A.; Hendsbee, A. D.; Roemmele, T. L.; Lumsden, M. D.; Pye, C. C.; Masuda, J. D. Correction to Preparation of a Diphosphine with Persistent Phosphinyl Radical Character in Solution: Characterization, Reactivity with $\mathrm{O}_{2}, \mathrm{~S}_{8}, \mathrm{Se}, \mathrm{Te}$ and $\mathrm{P}_{4}$ and Electronic Structure Calculations. Inorg. Chem. 2013, 52, 527.

(66) Hensel, R.; du Mont, W.-W.; Boese, R.; Wewers, D.; Weber, L. Four-membered Chelate Complexes of Tellurobis(di-tert-butylphosphane) with Tetracarbonylmetal(VIA) Acceptors. Chem. Ber. 1985, 118, 1580-1587.

(67) du Mont, W-W.; Nordhoff, E. Tetracarbonyl[telluro-bis(di-tertbutylphosphan)]chrom(0). Der Erste Tellurophosphan-Chelatkomplex J. Organomet. Chem. 1980, 198, C58-C60.

(68) du Mont, W-W.; Hensel, R.; Severengiz, T. Telluration and De-telluration: New Ways for the Cleavage and Formation of P-P Bonds. Phosphorus and Sulfur 1983, 18, 7376.

(69) Hensel, R.; du Mont, W-W. Preparation of cis-Dichloro[telluro(di-tertbutylphosphane)]platinum(II). Chem. Ber. 1985, 118, 5016-5017.

(70) Sasamori, T.; Suzuki, Y.; Sakagami, M.; Miyake, H.; Tokitoh, N. Structure of Stable Telluradiphosphirane Bearing Bulky Ferrocenyl Ligands. Chem. Lett. 2014, 43, 1464-1466. (71) Hinz, A.; Kuzora, R.; Rosenthal, U.; Schulz, A.; Villinger, A. Activation of Small Molecules by Phosphorus Biradicaloids. Chem.-Eur. J. 2014, 45, 14659-14673.

(72) Sadekov, I. D.; Maksimenko, A. A.; Nivorozhkin, V. L. Organic Derivatives of Monocoordinated Tellurium. Russ. Chem. Rev. 1998, 67, 193-208.

(73) Brodie, A. M.; Rodley, G. A.; Wilkins, C. J. Cobalt(II) Complexes of Trimethylphosphine Selenide. J. Chem. Soc. A 1969, 2927-2929. 
(74) McDonough, J. E.; Mendiratta, A.; Curley, J. J.; Fortman, G. C.; Fantasia, S.; Cummins, C. C.; Rybak-Akimova, E. V.; Nolan, S. P.; Hoff, C. D. Thermodynamic, Kinetic, and Computational Study of Heavier Chalcogen (S, Se, and Te) Terminal Multiple Bonds to Molybdenum, Carbon, and Phosphorus. Inorg. Chem. 2008, 2133-2141.

(75) du Mont, W-W. The Reaction of Tri-tert-butylphosphane and Tri-tert-butylarsane with Selenium and Tellurium: Formation of Inert and Labile Chalcogenophosphoranes and arsoranes. Z. Naturforsch. 1985, 40b, 1453-1456.

(76) Jeremias, L.; Babiak, M.; Kubát, V.; Calhodra, M. J.; Trávníček, Z. Novosad, J. Successful Oxidation of $\mathrm{Ph}_{2} \mathrm{P}\left(\mathrm{CH}_{2}\right)_{n} \mathrm{PPh}_{2} \quad(\mathrm{n}=2,4,6)$ by Tellurium Leading to $\mathrm{Ph}_{2} \mathrm{P}(\mathrm{Te})\left(\mathrm{CH}_{2}\right)_{\mathrm{n}} \mathrm{P}(\mathrm{Te}) \mathrm{Ph}_{2}$. RSC Advances, 2014, 4, 15428-15430.

(77) Dornhaus, F.; Bolte, M.; Lerner, H-W.; Wagner, M. A Comparative Study of Chalcogenated Phosphanylborohydrides $\left[\mathrm{EPR}_{2} \mathrm{BH}_{3}\right]^{-}\left(\mathrm{R}=\mathrm{Ph},{ }^{\mathrm{t}} \mathrm{Bu}\right)$ and Triorganophosphane Chalcogenides $\mathrm{EPPh}_{2} \mathrm{CH}_{3}(\mathrm{E}=\mathrm{O}, \mathrm{S}, \mathrm{Se}, \mathrm{Te})$.Eur. J. Inorg Chem. 2006, 5138-5147.

(78) Steigerwald, M. L.; Siegrist, T.; Gyorgy, E. M.; Hessen, B.; Kwon, Y.-U.; Tanzler, S. M. S. M. Effect of Diverse Ligands on the Course of a Molecules-to-Solids Process and Properties of Its Intermediates. Inorg. Chem. 1994, 33, 3389-3395.

(79) Elder, P. J. W.; Chivers, T.; Thirumoorthi, R. Experimental and Computational Investigations of Tautomerism and Fluxionality in PCP- and PNP-Bridged Heavy Chalcogenides. Eur. J. Inorg. Chem. 2013, 2867-2876.

(80) Austad, T.; Rød, T.; Ase, K.; Songstad, J.; Norbury, A. H. The Adduct between Triphenylphosphine and Triphenylphosphine Telluride. A Tellurium(0) Compound. Acta Chem. Scand. 1973, 27, 1939-1949.

(81) Mardersteig, H. G.; Nöth, H. Einige Reaktionen des N-Diphenylphosphinotriphenylphosphazens. Z. Anorg. Allg. Chem. 1970, 375, 272-280. 
(82) Dean, P. A. W. Nuclear Magnetic Resonance Studies of the Solvation of Phosphorus(V) Selenides, 1,2-bis(diphenylphosphino)ethane, and Tris(dimethylamino)phosphine Telluride by Sulfur Dioxide. Can. J. Chem. 1979, 57, 754761.

(83) Grechkin, N. P.; Nuretdinov, I. A.; Buina, N. A. Reactions of Amides of Trivalent Phosphorus Acids with Tellurium. Russ. Chem. Bull., 1969, 18, 162-162.

(84) Nuretdinov, I. A.; Loginova, E. I. Spin-Spin Coupling of ${ }^{31} \mathrm{P}$ and ${ }^{125} \mathrm{Te}$ Nuclei in Organophosphorus Compounds of Tellurium. Russ. Chem. Bull. 1973, 22, 2765-2768.

(85) Rømming, C.; Maartmann-Moe, K.; Songstad, J. Crystal Structure of Tris(pyrrolidino)phosphine Selenide and Tris(pyrrolidino)phosphine Telluride Acta Chem. Scand. A 1984, 38, 349-357.

(86) Diemert, K.; Kuchen, W.; Kutter, J. Bifunktionelle Aminophosphane $\left(\mathrm{Et}_{2} \mathrm{~N}\right)_{2} \mathrm{P}\left(\mathrm{CH}_{2}\right)_{\mathrm{n}} \mathrm{P}\left(\mathrm{NEt}_{2}\right)_{2}$ and $\left(\mathrm{Et}_{2} \mathrm{~N}\right)_{2}(\mathrm{R}) \mathrm{P}\left(\mathrm{CH}_{2}\right)_{\mathrm{n}} \mathrm{P}(\mathrm{R})\left(\mathrm{NEt}_{2}\right)_{2}$. Phosphorus and Sulfur 1983, $15,155-164$.

(87) Scherer, O. J.; Schnabl, G. New Diazadiphosphetidines. Chem. Ber. 1976, 109, 2996-3004.

(88) Keat, R.; Thompson, D. G. Exchange Effects on the ${ }^{1} \mathrm{H}$ and ${ }^{31} \mathrm{P}$ NMR Spectra of Cyclodiphosph(III)azane Selenides and Tellurides. J. Organomet. Chem. 1977, 141, C13C16.

(89) Brown, D. H.; Cross, R. J.; Millington, D. Photolysis of Diorganoditellurides in the Presence of Tertiary Phosphines. J. Organomet. Chem. 1977, 125, 219-223.

(90) du Mont, W-W.; Kroth, H-J. Zur Reaktion von Organophosphinene mit Chalcogenen und Halogenen: Rasche Übertragung von Tellur und Jod Zwischen Phosphinen. J. Organomet. Chem. 1976, 113, C35-C37. 
(91) Scherer, O. J.; Schnabl, G. Cis-2-telluro-1,3,2 $2 \lambda^{5}, 4 \lambda^{3}$-diazadiphosphetidine - A Fluxional Redox System. Angew. Chem. Int. Ed. Engl. 1977, 16, 486.

(92) Bain, A. D. Dynamic NMR, in Modern NMR Techniques for Synthetic Chemistry, Ed. Fisher, J. CRC Press, 2014, Ch. 2, pp. 15-61.

(93) Beckmann, J.; Lork, E.; Mallow. O. Molecular Structure of $n$-Tributylphosphine Telluride. Main Group Metal Chem. 2012, 35, 187-188.

(94) Kuhn, N.; Henkel, G.; Schumann, H.; Fröhlich, R. The Nature of the Bonding in Phosphane Tellurides. An Empirical NMR Study and the Crystal Structure of (iso$\left.\mathrm{C}_{3} \mathrm{H}_{7}\right)_{3}$ PTe. Z. Naturforsch. B 1990, 45, 1010-1018.

(95) Bochmann, M.; Bwembya, G. C.; Whilton, N.; Song, X.; Hursthouse, M. B.; Coles, S. J.; Karaulov, A. Synthesis of Selenophosphinic and Tellurophosphinic Amides and Amidato Complexes. Crystal Structure of ${ }^{\mathrm{t}} \mathrm{Bu}_{2} \mathrm{P}(\mathrm{Te}) \mathrm{NH}\left(\mathrm{C}_{6} \mathrm{H}_{11}\right)$. J. Chem. Soc., Dalton Trans. 1995, 1887-1892.

(96) Pohl, S. Cis-trans Isomers of Diazadiphosphetidine Derivatives: Five Crystal and Molecular Structures. Z. Naturforsch. 1979, 34b, 256-261.

(97) Konu, J.; Chivers, T. Synthesis, Spectroscopic and Structural Characterization of Tertiary Phosphine Tellurium Dihalides $\mathrm{Et}_{3} \mathrm{PTeX}_{2}(\mathrm{X}=\mathrm{Cl}, \mathrm{Br}, \mathrm{I})$. Dalton Trans. 2006, 3941-3946.

(98) Naktode, K.; Das Gupta, S.; Kundu, A.; Jana, S.K.; Pada Mayek, H.; Mallik, B. S.; Panda, T. K. Functionalisation of Imidazolin-2-imine to Corresponding Phosphinamine, Chalcogenide (O, S, Se, Te), and Borane Compounds. Aust. J. Chem. 2015, 68, 127-136.

(99) Kuhn, N.; Schumann, H.; Wolmershauser, G. $\mathrm{M}(\mathrm{CO})_{5}\left(\mathrm{R}_{3} \mathrm{PTe}\right)(\mathrm{M}=\mathrm{Cr}, \mathrm{Mo}, \mathrm{W} ; \mathrm{R}=$ $\left.{ }^{\mathrm{t}} \mathrm{Bu}\right)$ : The First Stable Tellurophosphorane Complexes. J. Chem. Soc., Chem. Commun. 1985, 1595-1597. 
(100) Kuhn, N.; Schumann, H. Cyclopentadienyliron Tellurophosphorane Complexes: Tellurium-bridged Iron Phosphine Compounds. J. Chem. Soc., Dalton Trans. 1987, 541544.

(101) Huang, L.; Zingaro, R. A.; Meyers, E. A.; Reibenspies, J. H. Reaction of Mercury(II) Dibromide with Tris(n-butyl)phosphine Telluride: Formation of an Unusual (HgTe) ${ }_{3}$ Ring System. Heteroatom. Chem. 1996, 7, 57-65.

(102) Mallek, R.; Sanhoury, M. A. K.; Ben Dhia, M. T.; Khaddar, M. R. Cadmium(II) Complexes with Phosphine Tellurides: Synthesis and Multinuclear $\left({ }^{31} \mathrm{P},{ }^{125} \mathrm{Te}\right.$, and $\left.{ }^{113} \mathrm{Cd}\right)$ NMR Characterization in Solution. J. Coord. Chem. 2014, 67, 1541-1549.

(103) Daniliuc, C.; Druckenbrodt, C.; Hrib, C. G.; Ruthe, F.; Blaschette, A.; Jones, P. G.; du Mont, W-W. The First Trialkylphosphane Telluride Complexes of Ag(I): Molecular, Ionic and Supramolecular Structural Alternatives. Chem. Commun. 2007, 2060-2062.

(104) Nordheider, A.; Slawin, A. M. Z.; Woollins, J. D.; Chivers, T. A Silver(I) Iodide Complex of a Tellurophosphorane. Z. Anorg. Allg. Chem. 2015, 641, 405-407.

(105) Briand, G. G.; Chivers, T.; Parvez, M.; Schatte, G. Experimental and Theoretical Investigations of Lithium and Magnesium Derivatives of Bis(tertbutylamido)cyclodiphosph(III/V) and (V/V)azane Mono- and Ditellurides. Inorg. Chem. 2003, 42, 525-531.

(106) Ritch, J. S.; Robertson, S. D.; Risto, M.; Chivers, T. Synthesis, Multinuclear NMR Spectra, and X-ray Structures of ${ }^{t} \mathrm{Bu}_{2} \mathrm{PNP}(\mathrm{I}){ }^{\mathrm{t}} \mathrm{Bu}_{2}$ and $\mathrm{EPR}_{2} \mathrm{NP}(\mathrm{I}) \mathrm{R}_{2}\left(\mathrm{E}=\mathrm{Se}, \mathrm{Te} ; \mathrm{R}={ }^{\mathrm{i}} \mathrm{Pr}\right.$, $\left.{ }^{\mathrm{t}} \mathrm{Bu}\right)$. Inorg. Chem. 2010, 49, 4681-4686.

(107) Pohl, S. Cis-2-tellurium-1,3,2 $\lambda^{5}, 4 \lambda^{3}$-diazadiphosphetidine - Crystal Structure of a Redox System Fluctuating in Solution. Z. Naturforsch. 1978, 33b, 610-613.

(108) Chivers, T. Tellurium Compounds of the Main Group Elements: Progress and Prospects. J. Chem. Soc., Dalton Trans. 1996, 1185-1194. 
(109) Steigerwald, M.L; Siegrist, T.; Stuczynski, S. M.; Kwon, Y-U. $\left(\mathrm{Et}_{3} \mathrm{P}\right)_{4} \mathrm{Fe}_{4} \mathrm{Te}_{4}$ : An Intermediate between Molecular Reagents and Solid-State Products. J. Am. Chem. Soc. 1992, 114, 3155-3156.

(110) Steigerwald,

M.L; $\quad$ Siegrist, $\quad$ T.; $\quad$ Stuczynski,

S. $\quad$ M.

Octatelluridohexakis(triethylphosphine)hexacobalt and a Connection between Chevrel Clusters and the NiAs Structure. Inorg.Chem. 1991, 30, 2256-2257.

(111) Steigerwald, M.L; Siegrist, T.; Stuczynski, S. M. Initial Stages in the MoleculeBased Growth of the Solid-State Compound CoTe. Inorg.Chem. 1991, 30, 4940-4945.

(112) Brennan, J. G.; Steigerwald, M.L; Siegrist, T.; Stuczynski, S. M. Cluster Intermediates in an Organometallic Synthesis of Palladium Telluride PdTe. J. Am. Chem. Soc. 1990, 112, 9233-9236.

(113) Brennan, J. G.; Steigerwald, M.L; Siegrist, T.; Stuczynski, S. M. The Transition from Molecules to Solids: Molecular Syntheses of $\mathrm{Ni}_{9} \mathrm{Te}_{6}\left(\mathrm{PEt}_{3}\right)_{8}, \mathrm{Ni}_{20} \mathrm{Te}_{18}\left(\mathrm{PEt}_{3}\right)_{12}$ and $\mathrm{NiTe}$. J. Am. Chem. Soc. 1989, 111, 9240-9241.

(114) Hessen, B.; Siegrist, T.; Palestra, T.; Tanzler, S. M.; Steigerwald, M. L. $\mathrm{Cr}_{6} \mathrm{Te}_{8}\left(\mathrm{PEt}_{3}\right)_{6}$ and a Molecule-Based Synthesis of $\mathrm{Cr}_{3} \mathrm{Te}_{4}$. Inorg. Chem. 1993, 32, 51655169.

(115) Steigerwald, M. L.; Rice, C. E. Organometallic Synthesis of Manganese Telluride. Isolation and Characterization of $\left[\left(\mathrm{Et}_{3} \mathrm{P}\right)_{2}(\mathrm{CO})_{3} \mathrm{MnTe}\right]_{2}$. J. Am. Chem. Soc. 1988, 110, 42284231.

(116) Brennan, J. G.; Andersen, R. A.; Zalkin, A. Chemistry of Trivalent Uranium Metallocenes: Electron-Transfer Reactions. Synthesis and Characterization of $\left[\left(\mathrm{MeC}_{5} \mathrm{H}_{4}\right)_{3} \mathrm{U}\right]_{2} \mathrm{E}(\mathrm{E}=\mathrm{S}, \mathrm{Se}, \mathrm{Te})$ and the Crystal Structures of $\left[\left(\mathrm{MeC}_{5} \mathrm{H}_{4}\right)_{3} \mathrm{U}\right]_{2} \mathrm{~S}$ and $\left(\mathrm{MeC}_{5} \mathrm{H}_{4}\right)_{3} \mathrm{UOPPh}_{3}$. Inorg. Chem. 1986, 25, 1761-1765. 
(117) Rabinovich, D.; Parkin, G. Synthesis and Structure of $\mathrm{W}\left(\mathrm{PMe}_{3}\right)_{4}(\mathrm{Te})_{2}$ : The First Transition-Metal Complex with a Terminal Tellurido Ligand. J. Am. Chem. Soc. 1991, 113, 9421-9422.

(118) Uhl, W.; Schutz, U.; Hiller, W.; Heckel, M. Synthesis and Crystal Structure of a Monomeric Tetraalkyldigallium Telluride with a Bent Ga-Te-Ga Group. Organometallics 1995, 14, 1073-1075.

(119) Fischer, J. M.; Piers, W.; MacGillivray, L. R.; Zawarotko, M. J. Permethyltitanocene Tellurides and Ditellurides. X-ray Structures of $\left[\left(\mathrm{C}_{5} \mathrm{Me}_{5}\right)_{2} \mathrm{Ti}\right]_{2}(\mu-\mathrm{Te})$ and $\left(\mathrm{C}_{5} \mathrm{Me}_{5}\right)_{2} \mathrm{Ti}\left(\eta^{2}-\right.$ $\mathrm{Te}_{2}$ ). Inorg. Chem. 1995, 34, 2499-2450.

(120) McConnachie, J. M.; Bollinger, J. C.; Ibers, J. A. Chalcogenide Substitution Reactions. Inorg. Chem. 1993, 32, 3923-3927.

(121) McGregor, K.; Deacon, G. B.; Dickson, R. S.; Fallon, G. D.; Rowe, R. S.; West, B. O. Insertion of Tellurium into an Alkylpentacarbonylmanganese Complex and a Convenient New Route to Manganese Telluride. J. Chem. Soc., Chem. Commun. 1990, 1293-1294.

(122) Coleman, A.P.; Dickson, R. S.; Deacon, G. B.; Fallon, G. D.; Ke, M.; McGregor, K.; West, B. O. The Synthesis of Some Alkyltelluride-Manganese(I) Complexes, and an Assessment of their Suitability for MOCVD Applications. Polyhedron 1994, 13, 1277-1290. (123) Piers, W.; MacGillivray, L. R.; Zawarotko, M. J. Reversible Interconversion of Permethylscandocene Tellurolates and Tellurides. X-ray Structure of $\left[\left(\mathrm{C}_{5} \mathrm{Me}_{5}\right)_{2} \mathrm{Sc}\right]_{2}(\mu-\mathrm{Te})$. Organometallics 1993, 12, 4723-4725.

(124) Piers, W. Evidence for Concerted Extrusion of $\mathrm{TeR}_{2}$ from Permethylscandocene Tellurolates. J. Chem. Soc., Chem. Commun. 1994, 309-310.

(125) Piers, W.; Parks, D. J.; MacGillivray, L. R.; Zawarotko, M. J. Mechanistic Aspects of the Thermal and Photochemical Interconversion of Permethylscandocene Tellurolates and 
Tellurides. X-ray Structures of $\left(\mathrm{C}_{5} \mathrm{Me}_{5}\right)_{2} \mathrm{ScTeCH}_{2} \mathrm{C}_{6} \mathrm{H}_{5}, \quad\left[\left(\mathrm{C}_{5} \mathrm{Me}_{5}\right)_{2} \mathrm{Sc}\right]_{2}(\mu$-Te), and $\left.\left[\mathrm{C}_{5} \mathrm{Me}_{5}\right)_{2} \mathrm{Sc}\right]_{2}(\mu-\mathrm{Se})$. Organometallics 1994, 13, 4547-4558.

(126) Piers, W.; Ferguson, G.; Gallagher, J. F. Sterically Enforced Linearity in a Bridging Telluride Ligand. X-ray Structure of $\left.\left\{\left(\mathrm{CH}_{3}\right)_{2} \mathrm{Si}\left[t-\mathrm{C}_{4} \mathrm{H}_{9}\right) \mathrm{C}_{5} \mathrm{H}_{3}\right]_{2} \mathrm{Sc}\left(\mathrm{PMe}_{3}\right)\right\}_{2}(\mu-\mathrm{Te}) \cdot \mathrm{C}_{6} \mathrm{H}_{6}$. Inorg. Chem. 1994, 33, 3784-3787.

(127) Fischer, J. M.; Piers, W.; Batchilder, S. D. P.; Zawarotko, M. J. Titanium-Mediated Heterohydrocoupling of Tributylstannane and Tellurium. X-ray Structure of $\left(\mathrm{C}_{5} \mathrm{Me}_{5}\right)_{2} \mathrm{TiTeSn}\left(\mathrm{C}_{6} \mathrm{H}_{5}\right)_{3}$. J. Am. Chem. Soc. 1996, 118, 283-284.

(128) Drakowski, A.; Cocivera, M. Electrodeposition of Cadmium Telluride Using Phosphine Telluride. J. Electrochem. Soc. 1985, 132, 2768-2771.

(129) Steigerwald, M. L.; Sprinkle, C. R. Application of Phosphine Tellurides to the Preparation of Group II-VI (2-16) Semiconductor Materials. Organometallics 1988, 7, 245246.

(130) Murray, C. B.; Norris, D. J.; Bawendi, M. G. Synthesis and Characterization of Nearly Monodisperse CdE $(\mathrm{E}=\mathrm{S}, \mathrm{Se}, \mathrm{Te})$ Semiconductor Nanocrystallites. J. Am. Chem. Soc. 1993, 115, 8706-8715.

(131) For example, see Bawendi, M. G.; Kim, S.; Mikulec, F. V. Tellurium-Containing Nanocrystalline Materials. US Patent WO2001007689 A2, Feb 1, 2001.

(132) Pehnt, M.; Schulz, D. L.; Curtis, C. J.; Jones, K. M.; Ginley, D. S. Nanoparticle Precursor Route to Low-Temperature Spray Deposition of CdTe Thin Films, Appl. Phys. Lett. 1995, 67, 2176-2178.

(133) Green, M.; Wakefield, G.; Dobson, P. J. A Simple Metalorganic Route to Organically Passivated Mercury Telluride Nanocrystals. J. Mater. Chem. 2003, 13, 10761978. 
(134) Keuleyan, S.; Lhuillier, E.; Guyot-Sionnest, P. Synthesis of Colloidal HgTe Quantum Dots for Narrow Mid-IR Emission and Detection. J. Am. Chem. Soc. 2011, 133, $16422-16424$.

(135) Keuleyan, S.; Guyot-Sionnest, P.; Delerue, C.; Allan, G. Mercury Telluride Colloidal Quantum Dots: Electronic Structure, Size-Dependent Spectra, and Photocurrent Detection up to $12 \mu \mathrm{m}$. ACSNano 2014, 8, 8676-8682.

(136) Lu, W.; Ding, Y.; Chen, Y.Wang, Z. L.; Fang, J. Bismuth Telluride Hexagonal Nanoplatelets and Their Two-Step Epitaxial Growth. J. Am. Chem. Soc. 2005, 127, 1011210116.

(137) Murphy, J. E.; Beard, M. C.; Norman, A. G.; Ahrenkiel, S. P.; Johnson, J. C.: Yu, P.; Mićić, O. I.; Ellingson, R. J.; Nozik, A. J. PbTe Colloidal Nanocrystals: Synthesis, Characterization, and Multiple Exciton Generation. J. Am. Chem. Soc. 2006, 128, 32413247.

(138) Sun, J.; Wang, L-W.; Buhro, W. E. Synthesis of Cadmium Telluride Quantum Wires and the Similarity of Their Effective Band Gaps to Those of Equidiameter Cadmium Telluride Quantum Dots. J. Am. Chem. Soc. 2008, 130, 7997-8005.

(139) Sugunan, A.; Jafri, S. H. M.; Qin, J.; Blom, T.; Toprak, M. S.; Leifer, K.; Muhammed, M. Low-Temperature Synthesis of Photoconducting CdTe Nanotetrapods. $J$. Mater. Chem. 2010, 20, 1208-1214.

(140) Li, W.; Zamani, R.; Gil, P. R.; Pelaz, B.; Ibáñez, M.; Cadavid, D.; Shavel, A.; Alvarez-Puebla, R. A.; Parak, W. J.; Arbiol, J.; Cabot, A. CuTe Nanocrystals: Shape and Size Control, Plasmonic Properties, and Use as SERS Probes and Photothermal Agents. $J$. Am. Chem. Soc. 2013, 135, 7098-7101. 
(141) Clive, D. L. J.; Menchen, S. M. New and Selective Method for Deoxygenating Epoxides: Use of the Organic Tellurium Reagent Sodium $O, O$-Diethyl Phosphorotelluroate. J. Chem. Soc., Chem. Commun. 1977, 658-659.

(142) Clive, D. L. J.; Menchen, S. M. Alkali Metal $O, O$-Diethyl Phosphorotelluroates, a Reagent Class for Deoxygenation of Epoxides, Especially Terminal Epoxides. J. Org. Chem. 1980, 45, 2347-2354.

(143) Clive, D. L. J.; Beaulieu, P. L. Dehalogenation of $\alpha$-Chloro and $\alpha$-Bromo Ketones. Use of Sodium O,O-Diethyl Phosphorotelluroate. J. Org. Chem. 1982, 47, 1124-1126.

(144) The anion RPTeR ${ }^{\prime-}$ has not been named in the literature; since the $\mathrm{P}$ atom carries the negative charge, the substitutive name is organyltellanylorganylphosphanide(-1).

(145) The anion $\mathrm{R}_{2} \mathrm{PTe}^{-}$is referred to as a tellurophosphinite in the literature; since the negative charge resides on tellurium, the substitutive name is diorganylphosphanyltellurolate(-1).

(146) Buchholz, D.; Huttner, G.; Zsolnai, L.; Omhof, W. Neue Methoden zur Einführung von $\mu_{3}$-Chalkogenbausteinen in Carbonylmetalcluster, $\mathrm{XCN}^{-}\left(\mathrm{X}=\mathrm{S}, \mathrm{Se}\right.$. Te) und $\mathrm{R}^{\prime} \mathrm{XXR}^{\prime}(\mathrm{X}$ $=\mathrm{Se}, \mathrm{Te})$ als Selektive Reagenzien. J. Organomet. Chem. 1989, 377, 25-41.

(147) Dahlenburg, L.; Höck, N.; Berke, H. Chelatphosphan-stabilisierte Rhodium(I)Komplexe mit Terminalen Phosphido-Liganden: Synthese, Reaktionen und Elektronenstruktur. Chem. Ber. 1988, 121, 2083-2093.

(148) Hensel, R. Dissertation, Universität Oldenburg, 1987.

(149) Malisch, W.; Grün, K.; Hirth, U-A.; Noltemeyer. M. PH-Funktionalisierte Phosphametallacyclen $\mathrm{C}_{5} \mathrm{R}_{5}(\mathrm{CO})_{2} \mathrm{WPH}\left({ }^{\mathrm{t}} \mathrm{Bu}\right) \mathrm{X}(\mathrm{R}=\mathrm{H}, \mathrm{Me} ; \mathrm{X}=\mathrm{S}, \mathrm{Se}, \mathrm{Te})$ mit Dreiringstruktur. J. Organomet. Chem. 1996, 513, 31-36. 
(150) Bildstein, B.; Sladky, F. Novel Anionic Chalcogeno Ligands: Tellurophosphinites $\mathrm{R}_{2} \mathrm{PTe}^{-}$and Chalcogenotellurophosphinites $\mathrm{R}_{2} \mathrm{P}(\mathrm{Ch}) \mathrm{Te}^{-}(\mathrm{Ch}=\mathrm{O}, \mathrm{S}, \mathrm{Se}, \mathrm{Te})$. Phosphorus, Sulfur, and Silicon 1990, 47, 341-347.

(151) Davies, R. P.; Martinelli, M. G.; Wheatley, A. E. H.; White, A. J. P.; Williams, D. J. Structural Studies of Lithium Telluro- and Seleno-Phosphorus Compounds. Eur. J. Inorg. Chem. 2003, 3409-3416.

(152) Davies, R. P.; Martinelli, M. G.; Patel, L.; White, A. J. P. Facile Synthesis of Bis(dichalcogenophosphinate)s and a Remarkable $\left[\mathrm{Li}_{8}(\mathrm{OH})_{6}\right]^{2+}$ Polyhedron. Inorg. Chem. 2010, 49, 4626-4631.

(153) For the nomenclature of imidophosphorus-tellurium anions, see ref. 8, p. 239.

(154) Briand, G.G.; Chivers, T.; Krahn, M.; Parvez, M. Synthesis and X-ray Structures of Dilthium Complexes of the Phosphonate Anions $\left[\mathrm{PhP}(\mathrm{E})\left(\mathrm{N}^{\mathrm{t} B u}\right)_{2}\right]^{2-}(\mathrm{E}=\mathrm{O}, \mathrm{S}, \mathrm{Se}, \mathrm{Te})$ and Dimethylaluminum Derivatives of $\left[\mathrm{PhP}(\mathrm{E})\left(\mathrm{N}^{t} \mathrm{Bu}\right)\left(\mathrm{NH}^{\mathrm{t}} \mathrm{Bu}\right)\right]^{-}(\mathrm{E}=\mathrm{S}, \mathrm{Se})$. Inorg. Chem. 2002, $41,6808-6815$.

(155) Briand, G.G.; Chivers, T.; Parvez, M. A New Approach to Metalated Imido and Amido Tellurophosphoranes. Angew. Chem., Int. Ed. 2002, 41, 3468-3470.

(156) Chivers, T.; Eisler, D. J.; Ritch, J. S. Synthesis and Structures of $\mathrm{M}\left[\mathrm{N}\left(\mathrm{TeP}^{\mathrm{i}} \mathrm{Pr}_{2}\right)_{2}-T e\right.$, $\left.T e^{\prime}\right]_{\mathrm{n}}(\mathrm{n}=2, \mathrm{M}=\mathrm{Zn}, \mathrm{Cd} ; \mathrm{n}=3, \mathrm{M}=\mathrm{Sb}, \mathrm{Bi})$ : The First Ditelluroimidodiphosphinato $\mathrm{p}$ - and d-Block Metal Complexes. Dalton Trans. 2005, 2675-2677.

(157) Ritch, J. S.; Chivers, T.; Eisler, D. J.; Tuononen, H. M. Experimental and Theoretical Investigations of Structural Isomers of Dichalcogenoimidodiphosphinate Dimers: Dichalcogenides or Spirocyclic Contact Ion Pairs? Chem. -Eur. J. 2007, 13, 46434653. 
(158) Ritch, J. S.; Chivers, T. Coordination Chemistry of a New P,Te-Centred Ligand: Synthesis, NMR Spectra and X-ray Structures of $\mathrm{M}\left(\mathrm{TeP}^{\mathrm{i}} \operatorname{Pr}_{2} \mathrm{NP}^{\mathrm{i}} \operatorname{Pr}_{2}\right)_{2}(\mathrm{M}=\mathrm{Zn}, \mathrm{Cd}, \mathrm{Hg})$. Dalton Trans. 2008, 957-962.

(159) Robertson, S. D.; Chivers, T. Synthesis, NMR Characterisation and X-ray Structures of Mixed Chalcogenido PNP Ligands Containing Tellurium: Crystal Structures of $\mathrm{Se}^{\mathrm{i}} \mathrm{Pr}_{2} \mathrm{PNP}(\mathrm{H})^{\mathrm{i}} \mathrm{Pr}_{2}$ and $\left[\mathrm{NaN}\left(\mathrm{EP}^{\mathrm{i}} \mathrm{Pr}_{2}\right)_{2}\right]_{\infty}(\mathrm{E}=\mathrm{Se}, \mathrm{Te})$. Dalton Trans. 2008, 1765-1772.

(160) Robertson, S. D.; Chivers, T.; Tuononen, H. M. Experimental and Theoretical Investigations of the Redox Behavior of the Heterodichalcogenido Ligands $\left[\left(\mathrm{EP}^{\mathrm{i}} \mathrm{Pr}_{2}\right)\left(\mathrm{TeP}^{\mathrm{i}} \mathrm{Pr}_{2}\right) \mathrm{N}\right]^{-}(\mathrm{E}=\mathrm{S}, \mathrm{Se})$ : Cyclic Cations and Acyclic Dichalcogenide Dimers. Inorg. Chem. 2008, 47, 10634-10643.

(161) Chivers, T.; Konu, J.; Ritch, J. S.; Copsey, M. C.; Eisler, D. J.; Tuononen, H. M. New Tellurium-Containing Ring Systems. J. Organomet. Chem. 2007, 692, 2658-2668.

(162) Chivers, T.; Laitinen, R.S. Tellurium: A Maverick Among the Chalcogens. Chem. Soc. Rev. 2015, 44, 1725-1739.

(163) Konu, J.; Chivers, T.; Tuononen, H. M. The Cyclic $\left[\mathrm{N}\left(\mathrm{P}^{\mathrm{i}} \mathrm{Pr}_{2} \mathrm{E}\right)_{2}\right]^{+}(\mathrm{E}=\mathrm{Se}, \mathrm{Te})$ Cations: A New Class of Inorganic Ring System. Chem. Commun. 2006, 1634-1636.

(164) Konu, J.; Chivers, T.; Tuononen, H. M. Synthesis, Spectroscopic, and Structural Investigations of the Cyclic $\left[\mathrm{N}\left(\mathrm{PR}_{2} \mathrm{E}\right)_{2}\right]^{+}$Cations $\left(\mathrm{E}=\mathrm{Se}, \mathrm{Te} ; \mathrm{R}={ }^{\mathrm{i}} \mathrm{Pr}, \mathrm{Ph}\right)$ : The Effect of Anion and R-Group Exchange. Inorg. Chem. 2006, 45, 10678-10687.

(165) Bochmann, M.; Bwembya, G. C.; Hursthouse, M. B.; Coles. S. J. Synthesis of Phosphinochalcogenoic Amidato Complexes of Zinc and Cadmium. The Crystal and Molecular Structure of $\left[\mathrm{Zn}\left\{{ }^{t} \mathrm{Bu}_{2} \mathrm{P}(\mathrm{Se}) \mathrm{N}^{\mathrm{i}} \mathrm{Pr}\right\}_{2}\right]$. J. Chem. Soc., Dalton Trans. 1995, 28132817. 
(166) Song, X.; Bochmann, M. Synthesis of Phosphinochalcogenoic Amidato Complexes of Divalent Transition Metals and Their Thermolysis to Metal Selenide and Telluride Phases. J. Chem. Soc., Dalton Trans. 1997, 2689-2692.

(167) Levasanos, N.; Robertson, S. D.; Maganas, D.; Raptopoulou, C. P.; Terzis, A.; Kyritsis, P.; Chivers, T. Ni $\left[\left(\mathrm{EP}^{\mathrm{i}} \mathrm{Pr}_{2}\right)_{2} \mathrm{~N}\right]_{2}$ Complexes: Stereoisomers $(\mathrm{E}=\mathrm{Se})$ and SquarePlanar Coordination (E = Te). Inorg. Chem. 2008, 47, 2949-2951.

(168) Robertson, S. D.; Ritch, J. S.; Chivers, T. Palladium and Platinum Complexes of Tellurium-Containing Imidodiphosphinate Ligands: Nucleophilic Attack of $\operatorname{Li}\left[\left(\mathrm{P}^{\mathrm{i}} \mathrm{Pr}_{2}\right)\left(\mathrm{TeP}^{\mathrm{i}} \mathrm{Pr}_{2}\right) \mathrm{N}\right]$ on Coordinated 1,5-Cyclooctadiene. Dalton Trans. 2009, 8582-8592.

(169) Gaunt, A. J.; Scott, B. L.; Neu, M P. A Molecular Actinide-Tellurium Bond and Comparison of Bonding in $\left[\mathrm{M}^{\mathrm{III}}\left\{\mathrm{N}\left(\mathrm{TeP}^{\mathrm{i}} \mathrm{Pr}_{2}\right)_{2}\right\}_{3}\right](\mathrm{M}=\mathrm{U}, \mathrm{La})$. Angew. Chem. Int. Ed. 2006, $45,1638-1641$.

(170) Gaunt, A. J.; Reilly, S. D.; Enriquez, A. E.; Scott, B. L.; Ibers, J. A.; Sekar, P.; Ingram, K. I. M.; Kaltsoyannis, N.; Neu, M P. Experimental and Theoretical Comparison of Actinide and Lanthanide Bonding in $\mathrm{M}\left\{\mathrm{N}\left(\mathrm{EPR}_{2}\right)_{2}\right]_{3}$ Complexes $(\mathrm{M}=\mathrm{U}, \mathrm{Pu}, \mathrm{La}, \mathrm{Ce} ; \mathrm{E}=\mathrm{S}$, Se, Te; $\left.\mathrm{R}=\mathrm{Ph},{ }^{\mathrm{i}} \mathrm{Pr}, \mathrm{H}\right)$. Inorg. Chem. 2008, 47, 29-41.

(171) Ritch, J. S.; Chivers, T.; Ahmad, K.; Afzaal, M.; O’Brien, P. Synthesis, Structures, and Multinuclear NMR Spectra of Tin(II) and $\mathrm{Pb}$ (II) Complexes of Tellurium-Containing Imidodiphosphinate ligands: Preparation of Two Morphologies of Phase-Pure PbTe from a Single-Source Precursor. Inorg. Chem. 2010, 48, 1198-1205.

(172) Ritch, J. S.; Chivers, T. Thallium (I) Complexes of Dichalcogenido Imidodiphosphinates $\left\{\mathrm{Tl}\left[\left(\mathrm{EP}^{\mathrm{i}} \mathrm{Pr}_{2}\right)_{2} \mathrm{~N}\right]\right\}_{\mathrm{n}}(\mathrm{E}=\mathrm{Te}, \mathrm{Se}, \mathrm{S})$ : Synthesis, NMR Spectra and a Structural Comparison. Dalton Trans. 2010, 39, 1745-1750.

(173) Ritch, J. S.; Chivers, T. A Square-Planar Tellurium(II) Complex with Te,Te'Chelating Ligands, Acta Crystallogr. Sect.C 2015, C71, 407-409. 
(174) Copsey, M. C.; Panneerselvam, A.; Afzaal, M.; Chivers, T.; O’Brien, P. Synthesis, X-ray Structures and AACVD Studies of Group 11 Ditelluroimidodiphosphinate Complexes. Dalton Trans. 2007, 1528-1538.

(175) Copsey, M. C.; Chivers, T. Formation of $\mathrm{Ga}_{2} \mathrm{Te}_{2}$ and $\mathrm{M}_{3} \mathrm{Te}_{3}(\mathrm{M}=\mathrm{Ga}$, In) Rings from Reactions of Sodium Ditelluroimidodiphosphinate with Group 13 Halides. Chem. Commun. 2005, 4938-4940.

(176) Eisler, D. J.; Robertson, S. D.; Chivers, T. Gold Complexes of Ditelluroimidodiphosphinate Ligands - Reversible Oxidation of $\mathrm{Au}(\mathrm{I})$ to $\mathrm{Au}(\mathrm{III})$ via Insertion of Gold into a Phosphorus-Tellurium Bond. Can. J. Chem. 2009, 87, 39-46.

(177) Robertson, S. D.; Chivers, T; Akhtar, J.; Afzaal, M.; O’Brien, P. Nickel(II) Complexes of Heterodichalcogenido and Monochalcogenido Imidodiphosphinate Ligands; AACVD Synthesis of Nickel Ditelluride. Dalton Trans. 2008, 7004-7011.

(178) Panneerselvam, A.; Malik, M. A.; Afzaal, M.; O’Brien, P. O.; Helliwell. M. The Chemical Vapor Deposition of Nickel Phosphide or Selenide Thin Films from a Single Precursor. J. Am. Chem. Soc. 2008, 130, 2420-2421.

(179) Ritch, J. S.; Chivers, T. Group 11 Complexes of the $P, T e$-centered Ligand $\left[\mathrm{TeP}^{\mathrm{i}} \mathrm{Pr}_{2} \mathrm{NP}^{\mathrm{i}} \mathrm{Pr}_{2}\right]^{-}:$Synthesis, Structures, and Insertion Reactions of the Copper(I) Complexes with Chalcogens. Inorg. Chem. 2009, 48, 3857-3865.

(180) Lusser, M.; Peringer, P. [Hg(EPPh $\left.\left.\mathrm{CHPPh}_{2}\right)_{2}\right](\mathrm{E}=\mathrm{S}, \mathrm{Se}, \mathrm{Te})$ : Organomercury Compounds without Mercury-Carbon Bonds. Inorg. Chim. Acta 1987, 127, 151-152.

(181) Konu, J.; Tuononen, H. M.; Chivers, T. Structural and Spectroscopic Studies of the PCP-Bridged Heavy Chalcogen-Centered Monoanions $\left[\mathrm{HC}\left(\mathrm{PPh}_{2} \mathrm{E}\right)\left(\mathrm{PPh}_{2}\right)\right]^{-}(\mathrm{E}=\mathrm{Se}, \mathrm{Te})$ and $\left[\mathrm{HC}\left(\mathrm{PR}_{2} \mathrm{E}\right)_{2}\right]^{-}\left(\mathrm{E}=\mathrm{Se}, \mathrm{Te}, \mathrm{R}=\mathrm{Ph} ; \mathrm{E}=\mathrm{Se}, \mathrm{R}={ }^{\mathrm{i}} \mathrm{Pr}\right)$ : Homoleptic Group 12 Complexes and One-electron Oxidation of $\left[\mathrm{HC}\left(\mathrm{PR}_{2} \mathrm{Se}\right)_{2}\right]^{-}$. Inorg. Chem. 2009, 48, 11788-11798. 
(182) Uhl, W.; Wegener, P.; Layh, M.; Hepp, A.; Würthwein, E-H. Chalcogen Capture by an Al/P-Based Frustrated Lewis Pair: Formation of Al-E-P Bridges and Intermolecular Tellurium-Tellurium Interactions. Organometallics. 2015, 34. 2455-2462.

(183) Nordheider, A.; Chivers, T.; Thirumoorthi, R.; Athukorala Arachchige, K. S.; Slawin, A. M. Z.; Woollins, J. D.; Vargas-Baca, I. A Planar Dianionic Ditelluride and a Cyclic Tritelluride Supported by $\mathrm{P}_{2} \mathrm{~N}_{2}$ Rings. Dalton Trans. 2013, 42, 3291-3294.

(184) Chivers, T.; Krahn, M.; Parvez, M. An Extended Network of Twenty-Membered $\mathrm{K}_{6} \mathrm{Se}_{6} \mathrm{P}_{4} \mathrm{~N}_{4} \quad$ Rings: $\quad \mathrm{X}$-ray $\quad$ Structure $\quad$ of $\quad\left\{\left[(\mathrm{THF}) \mathrm{K}\left[{ }^{\mathrm{t}} \mathrm{BuN}(\mathrm{Se})(\mu-\right.\right.\right.$ $\left.\left.\left.\left.\mathrm{N}^{\mathrm{t}} \mathrm{Bu}\right)_{2} \mathrm{P}(\mathrm{Se}) \mathrm{N}^{\mathrm{t}} \mathrm{Bu}\right] \mathrm{K}(\mathrm{THF})_{2}\right]_{2}\right\}_{\infty}$. Chem. Commun. 2000, 463-464.

(185) Chivers, T.; Krahn, M.; Parvez, M.; Schatte, G. Preparation and X-ray Structures of Alkali-Metal Derivatives of the Ambidentate Anions $\left[{ }^{t} \mathrm{BuN}(\mathrm{E}) \mathrm{P}\left(\mu-\mathrm{N}^{\mathrm{t} B u}\right)_{2} \mathrm{P}(\mathrm{E}) \mathrm{N}^{\mathrm{t}} \mathrm{Bu}\right]^{2-}(\mathrm{E}=$ $\mathrm{S}, \mathrm{Se})$ and $\left[{ }^{\mathrm{t}} \mathrm{BuN}(\mathrm{Se}) \mathrm{P}\left(\mu-\mathrm{N}^{\mathrm{t}} \mathrm{Bu}\right)_{2} \mathrm{PN}(\mathrm{H})^{\mathrm{t}} \mathrm{Bu}\right]^{-}$. Inorg. Chem. 2001, 40, 2547-2553.

(186) Nordheider, A.; Chivers, T.; Thirumoorthi, R.; Vargas-Baca, I.; Woollins, J. D. Planar $\mathrm{P}_{6} \mathrm{E}_{6}(\mathrm{E}=\mathrm{S}, \mathrm{Se})$ Macrocycles Incorporating $\mathrm{P}_{2} \mathrm{~N}_{2}$ Scaffolds. Chem. Commun. 2012, $48,6346-6348$.

(187) Nordheider, A.; Athukorala Arachchige, K. S.; Slawin, A. M. Z.; Woollins, J. D.; Chivers, T. Sodium and Rhodium Complexes of a Spirocyclic $\mathrm{Te}_{5}$ Dianion Supported by $\mathrm{P}_{2} \mathrm{~N}_{2}$ Rings. Dalton Trans. 2015, 44, 8781-8783.

(188) Nordheider, A.; Hüll, K.; Prentis, J. K. D.; Athukorala Arachchige, K. S.; Slawin, A. M. Z.; Woollins, J. D.; Chivers, T. Main Group Tellurium Heterocycles Anchored by a $\mathrm{P}_{2} \mathrm{~N}_{2}$ Scaffold and Their Sulfur/Selenium Analogues. Inorg. Chem. 2015, 54, 3043-3054.

(189) Bochmann, M. Metal Chalcogenide Materials: Chalcogenolato Complexes as SingleSource Precursors. Chem. Vap. Deposition 1996, 2, 85-96. 
(190) Bwembya, G. C.; Song, X.; Bochmann, M. Phosphinochalcogenoic Amidato Complexes of Zinc and Cadmium as Novel Single-Source Precursors for the Deposition of Metal Selenide and Telluride Films. Chem. Vap. Deposition 1995, 1, 78-80.

(191) Garje, S.S.; Ritch, J. S.; Eisler, D. J.; Afzaal, M.; O’Brien, P.; Chivers, T. Chemical Vapour Deposition of II-VI Semiconductor Thin Films using $\mathrm{M}\left[\left(\mathrm{TeP}^{\mathrm{i}} \mathrm{Pr}_{2}\right)_{2} \mathrm{~N}\right]_{2}(\mathrm{M}=\mathrm{Cd}, \mathrm{Hg})$ as Single-Source Precursors. J. Mater. Chem. 2006, 16, 966-969.

(192) Ahmad, K.; Afzaal, M.; Ritch, J. S.; Chivers, T.; O’Brien, P. Epitaxial CdTe Rods on Au/Si Islands from a Molecular Compound. J. Am. Chem. Soc. 2010, 132, 5964-5965.

(193) Garje, S.S.; Eisler, D. J.; Ritch, J. S.; Afzaal, M.; O’Brien, P.; Chivers, T. A New Route to Antimony Telluride Nanoplates from a Single-Source Precursor. J. Am. Chem. Soc. 2006, $128,3120-3121$.

(194) Garje, S.S.; Copsey, M. C.; Afzaal, M.; O’Brien, P.; Chivers, T. Aerosol-Assisted Chemical Vapour Deposition of Indium Telluride Thin Films from $\{\operatorname{In}(\mu-$ $\left.\mathrm{Te})\left[\mathrm{N}\left({ }^{\mathrm{i}} \mathrm{Pr}_{2} \mathrm{PTe}\right)_{2}\right]\right\}_{3}$. J. Mater. Chem. 2006, 16, 4542-4547.

(195) Feldman, K-O.; Wiegand, T.; Ren, J.; Eckert, H.; Breternitz, J.; Groh, M. F.; Müller, U.; Ruck, M.; Maryasin, B.; Ochsenfeld. C.; et al. $\left[\mathrm{P}_{3} \mathrm{Se}_{4}\right]^{+}$: A Binary Phosphorus-Selenium Cation, Chem.-Eur. J. 2015, 21, 9697-9712. 